\title{
DESIGN AND MANUFACTURE OF PNEUMATIC MOTOR TYRES.
}

By COLIN MACBETH.

\section{Functions of a Pneumatic Trre.}

IN discussing the design of pneumatic motor tyres, it is well to consider broadly their functions. This can be done under six main headings, which, in the order of their relative importance, are as follows:-

1. Comfort.-To allow of high speods on poor surfaces such as can only be obtained when using wheels having a yielding periphery.

2. Safety.-To provide a sure grip on all conditions of road surface when driving, but particularly when accelerating, braking and cornering.

3. Reliability.-To provide means of protecting the air container from penetration by road obstacles and consequent loss of pressure.

4. Durability.-To give long mileage and only to fail from fair wear and tear.

5. Handiness.-To be reasonably easy to fit and take off when required.

6. Efficiency.-To absorb the minimum amount of engine power.

Tyres must fulfil the above requirements in all climates and on all conditions of surface, and when subject to overloading and under-inflation.

The conditions under which tyres are used vary so widely, and the abuse to which they are subject is so very great, that a high factor of safety must be provided in order to ensure that they can withstand very rough usage, and it is not possible to treat the question of tyre design on the same basis as metal parts can 
be dealt with in machine design, namely, by merely specifying the "strength" to be incorporated in the various parts of the tyre.

\section{Features limiting Scope of Designer.}

The tyre designer has not a free hand to-day when instructed to design a certain size of tyre or line of tyres, for while he is unhampered in quite a number of directions, the limiting features can be well summarised as follows:-

(a) Type and size of rims on to which the tyre is to fit.

(b) Competition to be met.

(c) Loads to be carried.

(d) Clearance to be maintained.


- Scrionséstraicht sigk qun

Figs. 1, 1 a.

(a) Type and size of rims on to which the tyre is to fit.

To-day the shapes of common rim sections have been reduced to two-the beaded edge, or B.E., type, Fig. 1, and the wired-on, or W.O., now generally called straight sided, or S.S., type, Fig. 1a. The tyre designer must be sure that his tyres fit standard rims without trouble.

(b) Competition to be met.

Car manufacturers and users all wish to get the best tyre at the lowest price, and for this reason a given size of tyre made up from first-class materials to be manufactured on a competitive basis must conform closely to the general dimensions adopted 
by tyre manufacturers to-day. This fact in itself means that the tyre designer must work closely to established sizes.

\section{(c) Loads to be carried.}

These are well established for the various sizes of tyres, and a certain size of tyre therefore is sold to carry a given load; the necessity for meeting competition prevents oversizing of tyres. In this respect the tyre manufacturer is largely in the hands of the chassis makers, namely, he sells a tyre to suit the particular size of rim standardised by the chassis makemr his car.

\section{(d) Clearance to be maintained.}

The design of a given size of tyre cannot vary materially from oommon practice as regards outside dimensions without trouble arising due to the reduction of clearance or over-gearing.

As an example showing how the designer is hampered, take the case of one who wishes to make a tyre which would compete. with other makers as regards:-

Quantity of materials in tyre;

Rim to be fitted;

but wishing to provide for:-

Larger sectional width than usual;

Reduced number of plies;

Reduced air pressure;

Better cushioning effect.

Such a tyre would require unusual clearances and reduced backaxle gear-ratios.

\section{Details allowing Scope to the Designer.}

While it is necessary for the tyre designer to conform to a specification within fairly narrow limits, yet there are certain details in reference to which he has a free hand. These can be. summarised as follows:-

\section{A.-Contour and construction of bead portions within the limitations of rim on which tyre will fit.}

With a given type of rim the actual shape of the tyre at the. point of attachment can vary considerably according to the ideas of the tyre designer and still ensure a good fit. 
B.-Constructional design of casing walls.

These may be composed of any suitable material, although cotton is now almost universally used.

The usual construction is to make up the body of the casing of a number of superimposed plies of rubbered cotton material, each pty being suitably insulated from adjacent plies, and the outer part of the casing being suitably protected from the weather.

Fig. 2 shows a $3 \frac{1}{2}$ in. tyre with a casing having four plies of square woven canvas, the thickness of each ply in the finished



Fig. 2.

casing being approximately $1 \mathrm{~mm}$. The load coming on this casing, dealing with it as a pressure-containing vessel, with an inflation pressure of $50 \mathrm{lb}$. per sq. in., equals $64 \mathrm{lb}$. per sq. in. of section measured along the bead circumference. This gives a load on each ply of $16 \mathrm{lb}$. per in. width. It is actually possible for such a casing to withstand an internal pressure of $400 \mathrm{lb}$. per sq. in., so that we have a pressure-containing vessel with a factor of safety of eight to one, reckoning on tensile strength. of the plies as the basis on which strength against bursting is calculated. 
An essential point necessary to ensure a good casing is, not that it shall be very strong merely as a pressure-containing vessel, but that it shall remain a sound casing, without separation of the plies or fracture of the threads in the plies due to failure of the insulation between the plies or between the threads, after many thousands of miles usage. It is also essential that the casing shall be flexible and thus able to efficiently abșorb blows from obstacles on the road and to withstand the continual flexing action due to ordinary running conditions. These requirements can only be fulfilled with a properly designed canvas which has been property treated and assembled in proper condition as regards equality of stretch and disposition of threads in conjunction with suitably proportioned mixings.

\section{C.-Pattern and general proportions of tread surface and its foundation on casing.}

There are, perhaps, wider variations between the practice of different manufacturers at the tread portion than at any other point, both as regards the design of the tread surface and the type of foundation for the tread in order to ensure proper adhesion to the casing. On these two points the tyre designer has a pretty free hand so long as the tyre gives good results on the road and has a pleasing appearance.

D.-Textiles used-their quality, disposition and type of weave.

Tyre manufacturers have an absolutely free hand as to the quality of cotton used, the method of incorporating it in the casing, and the method of uniting the threads, whether by weaving in the ordinary way into square fabric or the use of what is commonly known as "cord fabric," or any other method of ply formation which may be found suitable.

\section{E.-Rubber mixings used-their characteristics.}

The manufacturer is not hampered in any way as to the mixings he chooses to use in his tyre providing they give satisfactory results: the main lines on which variations occur are summarised as follows:-

E1. Hardness.

E2. Degree of vulcanisation.

E3. Disposition.

E4. Volumetric and area costs. 
These points can be dealt with separately as follows:-

$$
\text { E1.-Degree of hardness. }
$$

This is varied according to the particular part of the tyre in which the mixings are incorporated-thus, bead cores, which require to be of a more or less inflexible nature according to the type of tyre used, are generally of a vulcanite or semi-vulcanite type, being fairly hard and unyielding, so that friction or movement between the core and adjacent parts of the tyre cannot take place.

Casing rubbers must be very elastic and yielding, and are required to insulate one ply from another and to insulate even one thread from adjacent threads. They must also protect the casing from damp or dirt, whether from the outside inwards or from the inside outwards.

The mixings used in the casing for insulation purposes are, perhaps, the most vitally important, as they affect very materially the life of the tyre as a pressure-containing vessel.

Tread rubber.-These rubbers must:-

(a) Be yielding and still tough.

(b) Resist cuts.

(c) Resist abrasion.

(d) Resist the action of high temperature from exposure to direct rays of the sun and of low temperature from frost.

(e) Resist decomposition by oil and other injurious substances.

Cushion rubbers.-Another important place for which special mixings are required is at the point of attachment of the tread toi the casing. On the efficiency of the mixings at this point depends largely the question of maintaining a proper junction between the tread and the casing. If once the junction of tread and cushion rubbers, or of cushion rubber to the casing, fails, there is a probability of early failure due to an extension of the separated portions eventually causing a failure of the casing itself.

\section{E2.-Vulcanisation.}

The life of the tyre depends on correct vulcanisation at all points. Thus, if any portions are over-vulcanised they are liable to deterioration due to cracking if exposed to the atmosphere, and to internal breakdown due to excessive hardness. If under- 
vulcanised, the portions affected are liable to excessive distortion and early breakdown due to separation of adjacent parts.

\section{E3.-Disposition.}

An insufficiency of rubber at one point, such, for instance, as poor insulation due to too little rubber between adjacent plies, will lead to breakdown due to lack of adhesion, causing loose plies and internal friction and heating. Failures due to this cause should not be confused with separation troubles due to tyres run for long distances under-inflated, for such a practice causes ply separation at the tyre shoulders although the tyre itself may, be sound in every way. On the other hand, too great a quantity. of rubber at one point, for instance, an excessive thickness of rubber at the side walls of a tyre, will tend to cracking of the surface, and will also reduce resiliency.

If cushion rubbers and the tread portions are wrongly proportioned, they will be liable to cause separation due to too great or too little thickness, as the case may be. The best proportions of tyres at this point depend very largely on the design of tread adopted and the load carried, and no fixed proportions can be laid down to suit all cases.

\section{E4.-Volumetric and area costing.}

In taking out the cost of a tyre, it is necessary to reckon on the cost of materials to fill a given space and to cover a given area.,

Purchasers of tyres often think that a certain tyre must be better because they are getting more weight for their money, whereas in actual practice the best qualities of mixings generally weigh less per cu. in. than poorer qualities, which make use of possibly cheap but heavy mineral matters.

On a competitive basis, therefore, it is advisable to reckon on the basis of cost per ou. in. for mixings, though as regards textiles cost should be reckoned per superficial foot of materials used.

\section{F.-Metal parts-their quality and disposition.}

In the case of tyres making use of metal parts, such as steel studs or wire insertion in the beads, it is very necessary to use materials of suitable nature. For instance, steel studs in non-skid tyres require to be very hard on their surfaces but soft on the portions which are riveted to the washers, while the wire used 
in beads of S.S. tyres requires to be very ductile, and yet to have sufficient temper to retain its shape without permanent set when subjected to rough usage.

Detail Design is dependent on Manufacturing Systems.

There are many different ways in which a tyre can be made while still having the same general construction in the finished

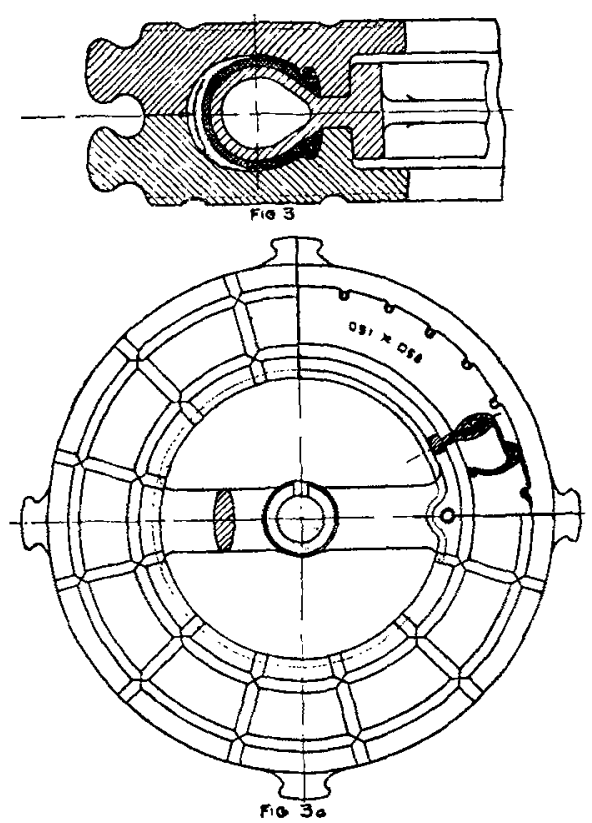

Frgs. 3, 3a.

article, and while still having the same shape of tread, casing, bead, ete.

Although motor pneumatic tyres have been made for upwards of a quarter of a century, there are, perhaps, more good ways of making tyres to-day than at any previous date in the history of tyre manufacture, and no one way can be stated to be the best or to have become accepted as the best.

Before dealing with the design of a new tyre or line of tyres, it is necessary that the designer should know the broad methods 
of manufacture to be employed, particularly those appertaining to:-

(1) The moulding system to be used.

(2) The curing system to be used.

Although a tyre is a combination of assembled units, such as bead, casing and tread, which do not vary materially in the raw state, yet methods of uniting them into a complete tyre are many and varied; the broad divisions of the more usual methods of moulding and vulcanising may therefore be outlined as follows:-



Fias. 4, 4a.

\section{Movlding Systems.}

1. External pressure system, using shaped casings.

2. Internal pressure system, ditto.

3. Drum system using flat casings.

\section{1.-External pressure system.}

The casing is vulcanised approximately to its final shape on a metal core, and moulds are clamped on to the casing by external $25(2)$ 
pressure during vulcanisation. Figs. 3 and $3 a$ show an assembly of the core with the tyre on it enclosed in the two halves of a mould. Figs. 4 and $4 a_{\text {a }}$ show details of the core. This system requires great accuracy in tyre building and moulds, but provided a proper system is adopted the method is very good.

\section{2.-Internal pressure system.}

Here the shaped casing is vulcanised approximately to its final shape and is pressed outwardly against a mould by means of an



Fros. 5, 5a.

expanding tube or other pressure-containing means within the casing. This does not entail a close working to gauge and volumes, but care is required to prevent overstretch of the casings and to prevent undue cost of the air-containers used, see Figs. 5 and 5a.

\section{3.-Drum system.}

In this system the casing is moulded flat-wise on a drum by means of internal or external mechanical pressure, its final shape 
being obtained at a later stage. This system is not regularly used except for very small sizes of tyres. Figs. $6,6 \mathrm{a}$, and $6 \mathrm{~b}$ show the well known wire and canvas "lapping" system, and Figs. 7, $7 \mathrm{a}$, and $7 \mathrm{~b}$ show a special expanding flat sectional press.

\section{VulCanising Systems.}

The vularnising system employed may vary considerably, irrespective of the method of moulding adopted. Broadly, the vulcanisation systems are those which:-

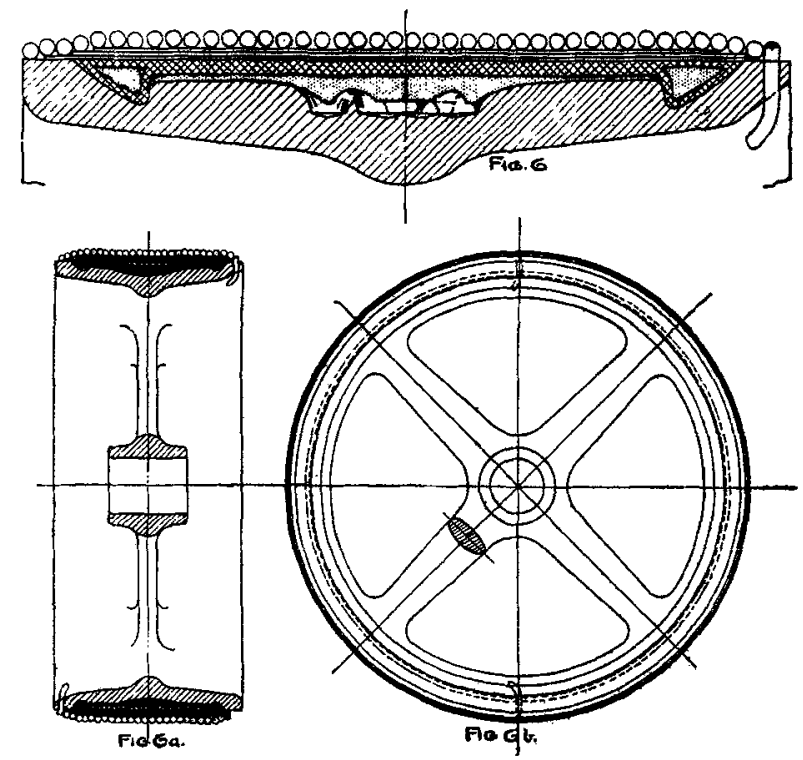

Figs. 6, 6a, 6b.

Either vulcanise the casing unit and cread unit apart one from the other and later vulcanise them together, or

Vulcanise these units at one time as a whole. These can be summarised as follows:-

1. Two-cure two-piece system.

2. Two-cure one-piece system.

3. One-cure one-piece system. 

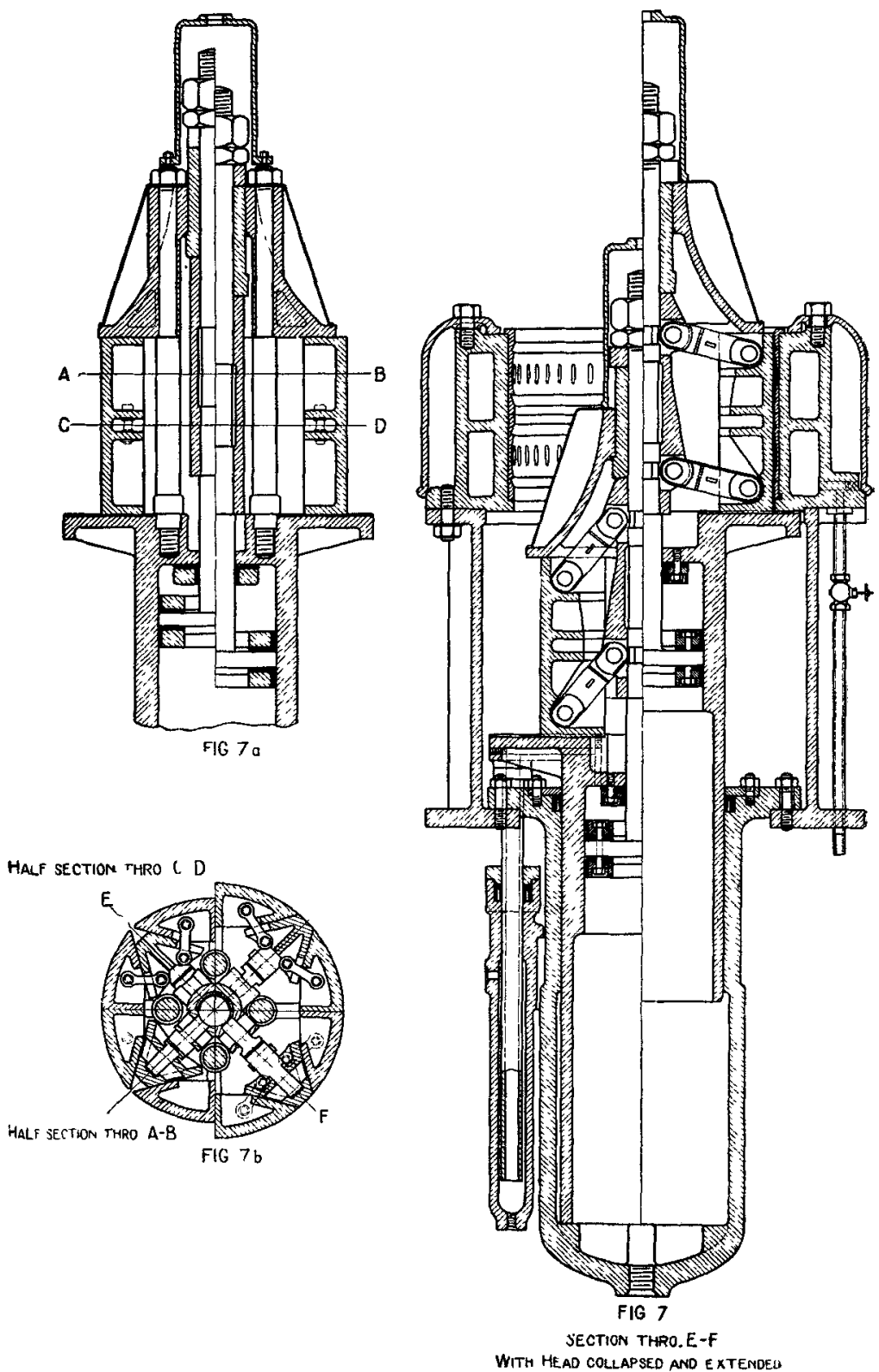

Frgs. 7, 7a, 7b. 
DESIGN AND MANUFAGTURE OF PNEUMATIC MOTOR 'IYRES. 391

\section{1.-Two-cure two-piece system.}

A. Giving a tyre which is not vulcanised completely at one moulding operation but may be-

A1. Moulded without the tread to the final shape by external pressure, buffed and solutioned, raw or semi-cured tread then fitted

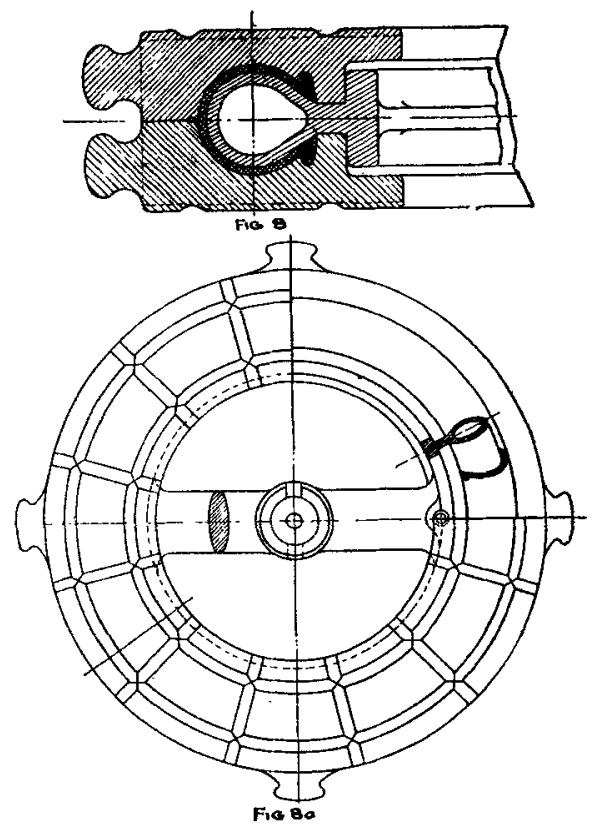

Figs, 8, 8 a.

and finally the whole tyre cured with canvas wrapping round it, seo Figs. 8, 8a, 9, and 9a.

A2. Moulded without the tread to the final shape but by internal pressure, see Figs. 11 and 11a.

A3. Moulded without the tread in flat shape by external pressure, to be later finished in final shape with added tread, see Figs. 10, 10a, and 10b. This method is commonly used for small tyres having rubber and steel studded treads-usually called "combination" treads. 


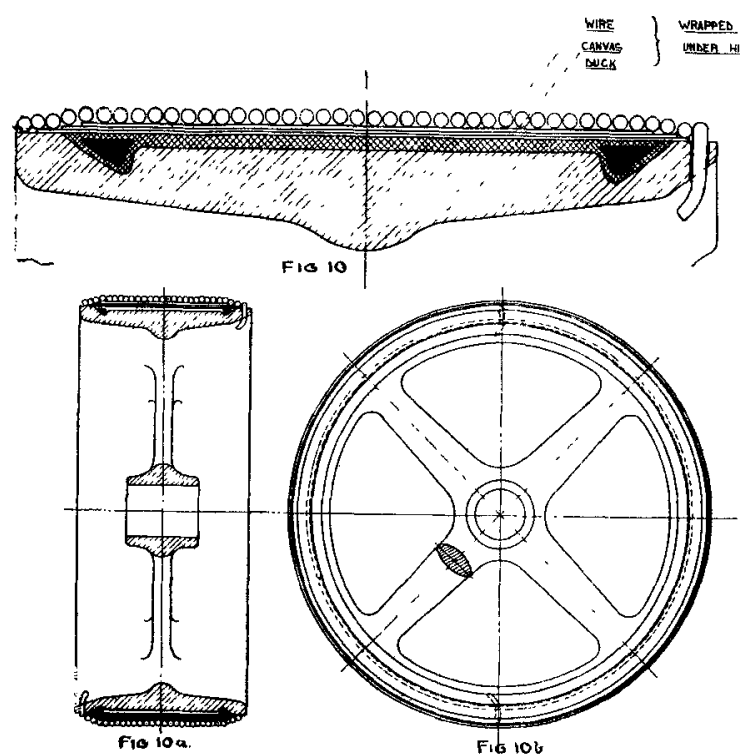

IIGS, $10,10 \mathrm{a}, 10 \mathrm{~b}$
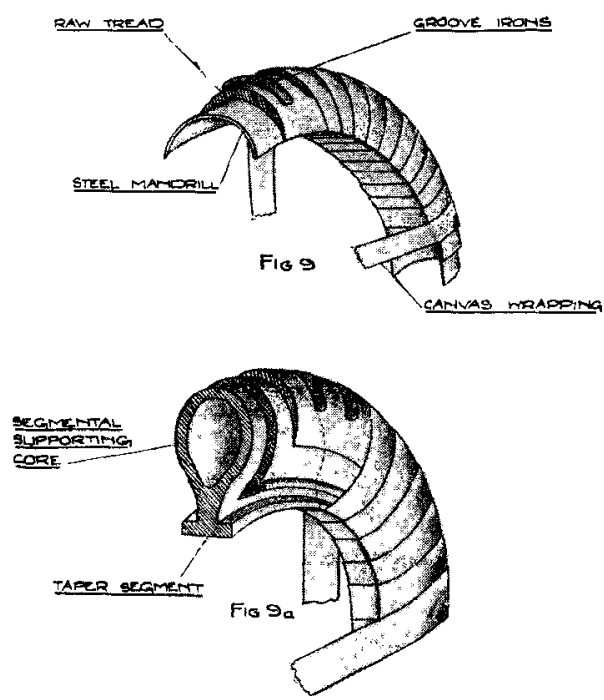

焉是 Figs. $9,9 e$ 


\section{2.-Two-cure one-piece system.}

B. Giving a two-piece moulded tyre with a one-piece appearance.

B1. Casing moulded without the tread to final shape by external pressure, buffed and solutioned, raw tread then fitted, the whole finally cured in a pattern mould, see Figs. 8 and $8 a, 3$ and $3 a$.

B2. Where the case is semi-cured on a flat drum by external or internal means with the tread, and then shaped for final oureonly used for small size tyres. Figs. $6,6 a$, and $6 \mathrm{~b}$, or Figs. 7 , $7 \mathrm{a}$, and $7 \mathrm{~b}$.



Fias. 11, 11a.

3.-One-cure one-piece system.

Where the complete uncured tyre is moulded and cured in a "patterned" mould.

C1. To final shape by external pressure, see Figs. 3, 3a, 4, and $4 \mathrm{a}$.

C2. To final shape by internal pressure, Figs. 5 and 5 a. 


\section{Types of Rim.}

These having now been standardised under two broad types, namely, the Beaded Edge (B.E.) and the Straight Side (S.S.) types, it is as well to outline the broad features of each and their relative advantages, as the design of tyres and the results obtained from each depend to a very considerable extent on the type of rim to which they are attached.

\section{Beaded Edge Rims.}

The one-piece type, Fig. 12, Plate VII,

Is the best known;

Has been longest in use;

Is the simplest rim known;

Is the lightest rim known;

Requires an extensible bead tyre to fit on it;

Gives very good protection against wet getting into tyre;

Is likely to survive for small car use to the exclusion of other types.

The two-piece loose flange type, Fig. 12a, Plate VII,

Reduces muscular effort when fitting large tyres;

Is not excessively heavy;

Makes it possible to use inextensible bead tyres which do not require stretching over the flange on to the rim seat;

Is liable to rusting effect on beads;

Gives trouble due to rusting in place, and is liable to blow off in use.

This rim is seldom used on European cars and on very few American modern cars.

The collapsible type, Figs. 13 and 13a,

Requires to be detachable from the wheel felloe;

Entails considerable weight of the combination;

Requires little muscular effort in fitting;

Involves considerable complication due to having to provide detachable and collapsible features.

Generally, B.E. rims are most satisfactory when of the one-piece type. 
DESIGN AND MANUFACICLE OF PNEL MATIC MOTOR TYRES. 395

\section{Straight Side Rims.}

Two-piece type, Fig. 14, Plate VIII.

This type, though comparatively unknown in Europe, is almost universal in U.S.A. for cars larger than Fords.

It is a development of the standard English wired-on cycle tyre and rim on a larger scale.

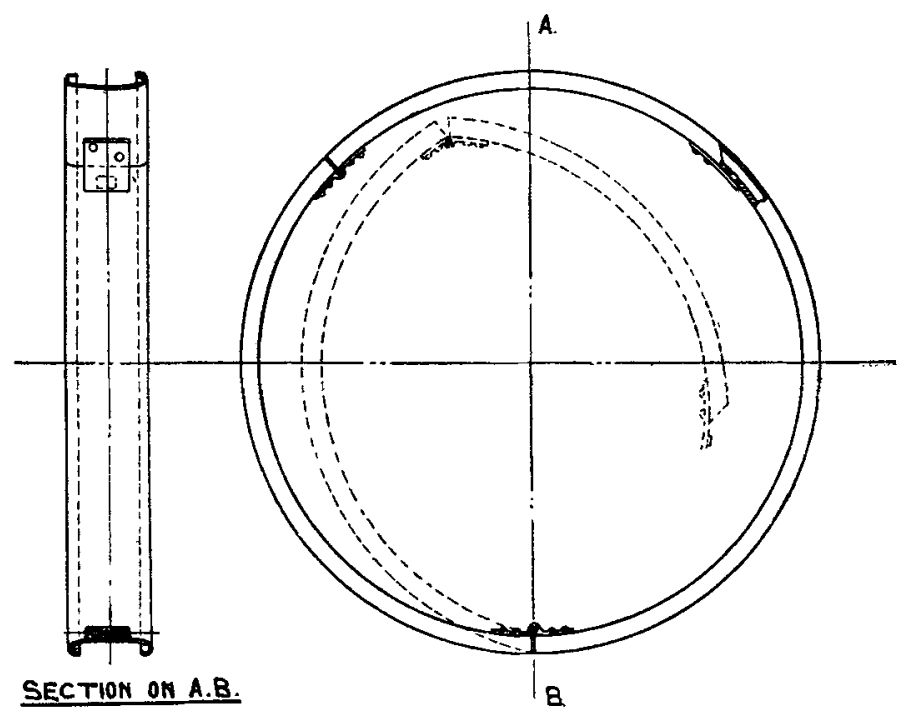

FIG.130.

FIG. 13.

\section{BeAded EDGE Collapsible RIM.}

Fras. 13, 13a.

The merits of this combination are very great, and can be summarised as follows:-

Little effort needed to fit and take off tyres;

Good support given to tyres at point of attachment;

Widc base given to section helps to prevent rolling;

Simplified construction of tyre bead facilitates manufacture. 
One-piece detachable, Figs. 15 and 15a, Plate VIII.

The smaller sections of S.S. rims are sufficiently shallow and flexible to enable them to be contracted, thus allowing of a onepiece section of rim having great lateral strength.

The following are its main features:-

Detachability necessary;

Considerable weight entailed;

Easy fitting, though several tools are required;

Great lateral strength and accuracy of rim section;

Freedom from rust damage.

S.S. rims bid fair to be generally adopted for all but light ears and Fords, as the care and effort needed in handling by the user is less than with large B.E. tyres. Also. S.S. tyres are more durable than B.E. tyres in the larger sections, due to the better support given to the tyres against rolling action, and such tyres suffer much less than B.E. tyres from rim cutting caused by running deflated.

Tyres on B.E. rims are subject to great loal pressure at the rim clinch, and many tyre makers have found great difficulty in obtaining freedom from failure at this point. This difficulty does not arise with well designed and constructed tyres, provided that the rims are well finished at this vital point.

\section{Destgn.}

Explanatory Note.

It must be understood that the methods of design dealt with in this paper do not deal with tyre design as it might be if the necessity for suiting existing standard sizes and for meeting keen competition were not taken into account. The author will not deal with the theory of the action of a pneumatic tyre, but will endeavour to show clearly how a tyre of well known type is designed and manufactured.

Having summarised the well known systems of moulding and vulcanising and the two common methods of attachment to the wheels, we will assume that the tyre designer is given a specification of requirements for a line of tyres. We will then follow: out the preparation of a design complying with this specification, and then describe manufacturing methods to suit such tyres. 
DESIGN AND MANCFACTURE OF PNEUMATIC MOTOR TYRES, 397

\section{Specification of tyre under consideration as regards design and manufacturing methods.}

$30 \times 3 \frac{1}{2}$ Rubber Non-skid.

(a) Rims. B.E. type "British standard" section.

(b) Casing. Canvas, 4 plies.

(c) Tread. All rubber non-skid type.

(d) Moulding. By external pressure system.

(e) Curing. By one-cure, one-piece system.

Fig 2 shows the assembled cross section of a rim, cover and tube in inflated condition complying with the above specification.

We will now deal with the various points which arise in working out the required design, taking them successively from the point of application of the tyre on the rim to the actual pattern of tread adopted.

Beads, and how Tolerances allowed IN Rims afrect the Design of Beads.

Fig. 2 shows a $30 \times 3 \frac{1}{2}$ "British standard" rim with a tyre fitted. It will be noted that the tyre beads bed at the clinch or rounded lip of the rim and for a slight distance underneath this clinch towands the corner of the rim. This portion is known to designers as "point A." The beads also bed on the base of the rim from the toe and along a portion of the under surface of the. bead. The design of tyres would be much simplified at the bead portion if rims were made more accurately to size. The limits of variation allowed in the sectional shape of the rims, which are very considerable, are illustrated as follows:-

Fig. 16 shows a $3 \frac{1}{2}$ in. "British standard" rim with the maximum, mean and minimum sections which will pass the gauges, and demonstrates the wide tolerances allowed.

Figs. $16 \mathrm{a}, 16 \mathrm{~b}$ and $16 \mathrm{c}$ show respectively $3 \frac{1}{2}$ in. rim sections of mean, maximum and minimum dimensions, each with a correctly shaped bead of the same design in place. The tolerances allowed by the American Tyre and Rim Association are considerably closer than British tolerances, as is evident from Figs. $16 \mathrm{~d}, 16 \mathrm{e}, 16 \mathrm{f}$ and $16 \mathrm{~g}$, showing the S.A.E. $3 \frac{1}{2}$ in. rim. 
The consequences of the more serious defects due to incorrect rims can be summarised as follows:-
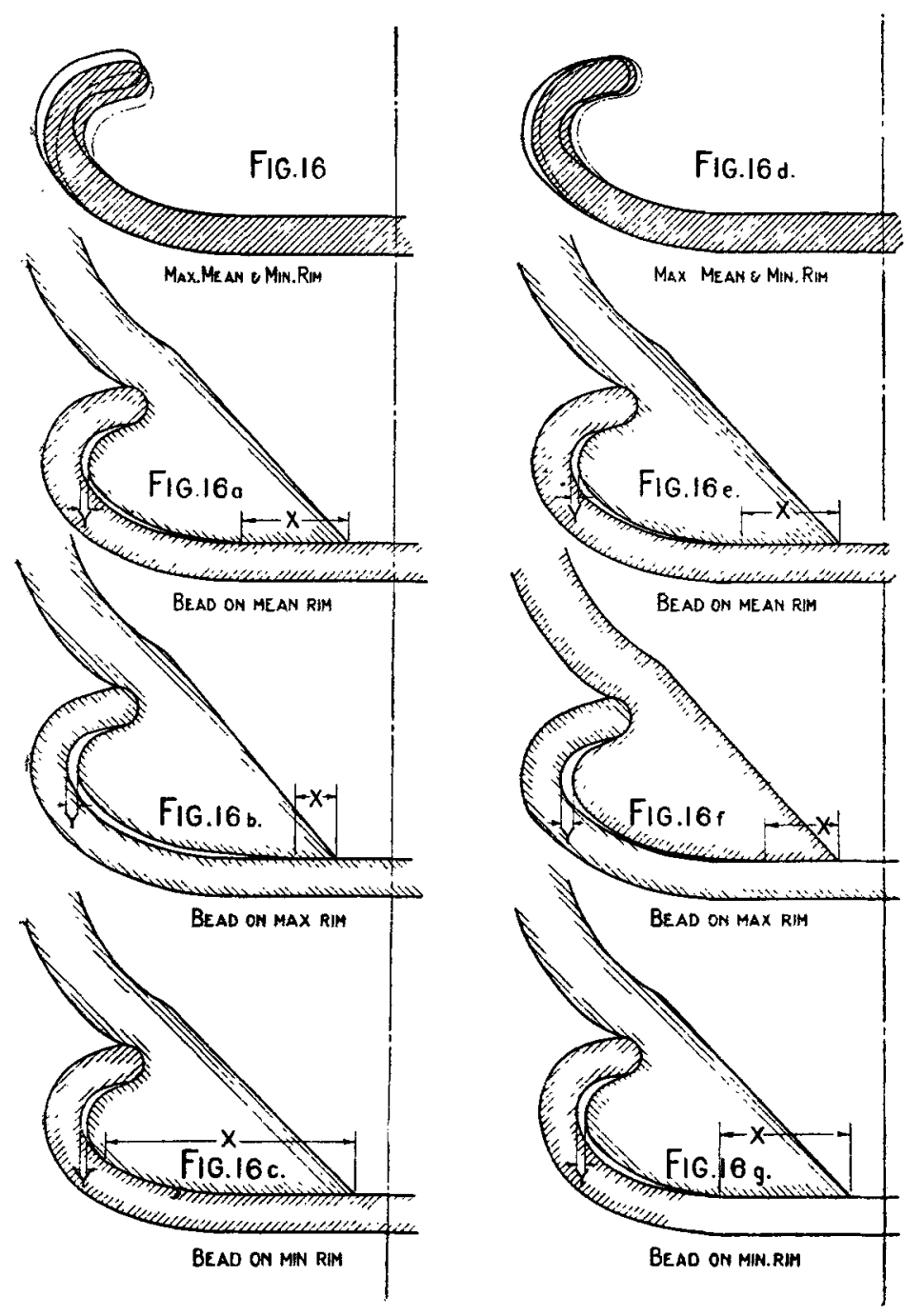

Figs. 16, 16a, 16b, 16c, 16d, 16e, 16f, $16 \mathrm{~g}$.

Narrow rims.-Fig. 17 shows a rim which is too narrow from the clinch edge to the corner of the rim. This prevents the tyre 
from bedding into the clinch point properly, and puts an undue pull on the junction of the case plies to the bead core, cansing an eventual failure as shown in Fig. 17a.

Sharp edges of rim at clinch.- This is shown in Fig. 17b, and

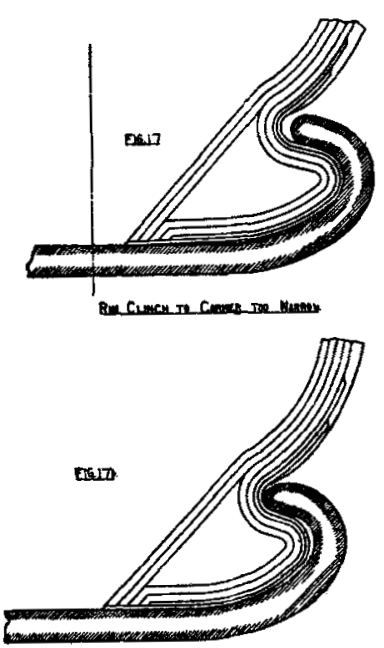



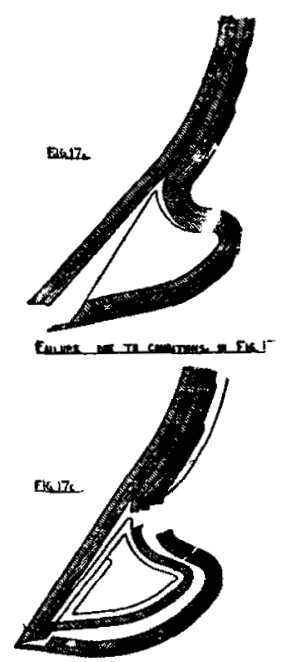



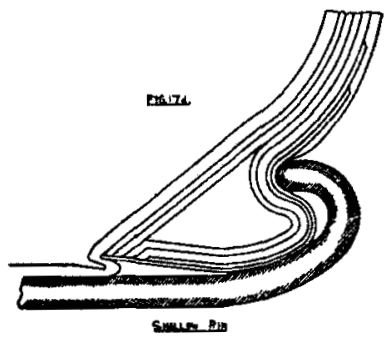

Figs. 17 to $17 d$.

the effect in Fig. 170. The consequence of this defect is that the outer plies are cut right through and the bead core is peeled ont of the tyre, causing early failure.

Shallow rims.- The effect of these is that the toe of the bead 
is not easily able to lie down on the base of the rim, as shown in Fig. 17d, and tends to pinching of the tube due to the air pressure forcing it below the bead toes.

Reinforcement of Bead portion of Tyre by Chafing Strips.

Fig. 18 shows how chafing strips are added to prevent damage to the vital plies of the casing by sharp or rusty rims or any undue



ElG.18.

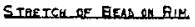



FIG.18.

USE Qf CHAENG STRUP

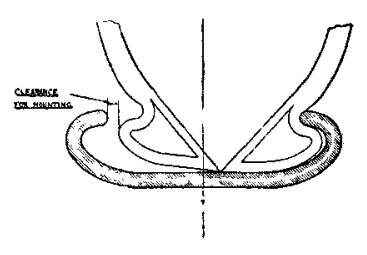

FIG. 18 b.

LUMITITIN OF BEAQ TOE LENGTH CLEGRAMCE OF. MOVHTING

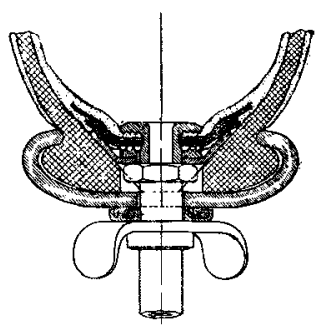

LMIITATION of BEAQ TOC LEMGTH L.B.

Figs. 18 to $18 \mathrm{c}$.

frictional action which takes place when the tyre is overloaded or under-inflated.

These chafing strips are continued down to the toe of the bead and take care of any rusting effect on the tyre surface caused by water getting into the rims. again protecting the vital casing. 
plies. They are also useful in the case of tyres running at any. time in a punctured condition, as they then prevent an immediate failure due to the great load coming on the casing plies, which would otherwise be pressed directly on to the upper surfaces of the rim edges.

Chafing strips provide protection at the point of great compression, and are very essential on the large sections of tyres; for instance, the pressure per inch of bead length at this point is $217 \mathrm{lb}$. for $150 \mathrm{~mm}$. tyres, and may reach a pressure of $723 \mathrm{lb}$. per sq. in. of contact surface at the clinch, whereas on a smaller tyre such as the $3 \frac{1}{2}$ in. the pressure may reach $81 \frac{3}{4} \mathrm{lb}$. per inch of bead length or $355 \mathrm{lb}$. per sq. in. of contact surface. These figures are based on rims of correct thickness at the clinch point; thin rims increase the intensity of pressure on the clinch surfaces.

It should be noted that a tyre to fit a given size of rim need: not vary as regards the shape of its bead, although the body of the casing and the tread dimensions might vary considerably; thus a bead for a rubber-studded tyre would be the same as that for a steel-studded tyre of similar dimensions.

\section{Bead Core.}

It is obvious that on a B.E. tyre the core of the bead is necessary to ensure that the outer plies retain their proper shape to give a permanently good grip on the rim. The tendency when in operation is to separate the bead core from the inner plies, so that the adhesion of the core to the inner plies and also to the outer plies must be ensured by proper mixings and vulcanisation. On this point it is well to emphasise the necessity for the proper consolidation of the casing to do away with any sponginess in the plies between the bead core and the edge of the rim. If this is not allowed for, a failure of the tyre will take place at this vital point.

It is very necessary that the bead core shall (while being sufficiently hard to prevent distortion or movement when in use) be capable of being stretched without undue effort over the outer diameter of the rim and sprung into place on the bed of the rim. The stretching quality must be combined with the necessary elasticity, so that repreated fitting and demounting can be carried out without the tyre becoming loose on the rim. The moulded bead for B.E. tyres is usually composed of a semi-vulcanite centre with a wrapping of rubbered canvas round it, the combination being MACBETH. 
moulded and semi-vulcanised before incorporation in the casing. The correct design of the bead core in this type of tyre is of vital importance to insure freedom from defects in making the box-moulded type of tyre.

\section{Limitation of toe length.}

This is necessary to allow easy fitting and to enable the valves and "security" or "spreader" plates to b'e properly fitted, see Fig. 18a. It is also necessary to limit the too lengths so that when fitting or taking out the second side of the bead it shall miss the first side, as shown in Fig. 18b.

\section{Percentage of stretch on rims.}

Fig. 18c shows in dotted lines the position in which the beads of a tyre are moulded, and the amount of radial stretch to which they are subject when actually fitted on the rim. The stretch is generally 1 to 4 per cent when fitted on the rim, according to the ideas of the manufacturer, and according to the amount of bead stiffness and the size of the tyre concerned. The correct determination of stretch has an important bearing on ease of fitting and freedom from blowing off and "nipping" troubles.

\section{Casing dimensions.}

Assuming that the "square footage" and quality of canvas incorporated in the tyre is such as to enable the manufacturer to compete ;with other makers, it is necessary to decide upon the number of plies incorporated in the casing. Having done this, the "square footage" allowed limits within very small variations the main dimensions of the tyre itself, namely, the diameter of the tyre and its outside sectional width when inflated on the rim.

\section{"Toe to toe" size-or sectional periphery.}

This dimension gives a very good basis of comparison between one maker's tyre and another, provided an equal number of plies and an equal quality of canvas are used. Given a certain "toe to toe "dimension, we can then very closely estimate the dimensions of the tyre mould to give the required section.

All well known tyres are built up of textile material having. bias running threads incorporated in the body of the casing, and it is obvious that any appreciable variation in the angles of the 
threads forming the casing itself will have a bearing on the width and diameter of the finished tyre produced from a given: size of mould. The reason for this is, of course, that on inflation there is more or less displacement of the cotton fibres (which are subject to load due to the contained air pressure) in their efforts to arrange themselves throughout their length under equal loading conditions. There is, therefore, a certain amount of "cut and try" method in getting out the first sample moulds of a new type of tyre, though with experience sizes an be very closely worked to.

The tyre should be moulded and vulcanised as nearly to its: inflated shape as possible, so that in use it will approximate to the shape and condition in which it was when it was vuleanised. If much distortion in the inflated condition does take place it makes the tyre liable to disintegration at the distorted points.

For the $30 \times 3 \frac{1}{2}$ tyre under review, we will adopt 4-ply casing, which has proved well equal to the average conditions under which this size of tyre works, and since it conforms to the practice of other manufacturers, puts the design on a competitive basis.

The method of treatment of the canvas and of incorporating it in the casing will be dealt with under the heading of "Manufacture."

\section{Non-skid tread design.}

The tread adopted for the tyre dealt with and shown in Fig. 19, Plate IX, was designed to give high efficiency as regards the six main points as set forth in the first paragraph of the paper.

For comfort.-A sufficient depth of pattern has been provided to give a proper cushion between the casing and the road.

It will be observed that the studs are well radiused at their base, so that each one can be likened to a supporting stool, distributing the load over the maximum possible area on the casing.

For safety.-A tread must have a good "fore and aft" and "lateral" grip on all conditions of road surfaces. The design in question is a bold pattern, which is equally effective whether "driving" or "braking," and it should be pointed out that so long as "fore and aft" grip is maintained, a car is under brake control.

Just as soon as the "fore and aft" grip fails, the wheels become loeked and the car depends for safety entirely on the "lateral gripping" powers of the pattern. 
Fig. 20, which illustrates a section of the tyre on the road when the car is under the tendency to slide into the curb, shows that not only do we have a scraping edge $\mathrm{E}$ directly exposed to the surface of the road, but we have a second scraping edge E2: between that and the centre of the tread, and finally a bold centre rib E3, and that all these three points are presented like saw. toeth to resist the lateral sliding action. In addition, the centre studs under lateral sliding conditions bring into effect their well buttresser sides $\mathrm{E} 4$ which are provided with square edges $\mathrm{E} 5$.



FIG. 20.

Fig. 21, Plate IX, shows that though the tread is in a half-worn condition, the scraping edges are still sharp and the large studs still have their buttress edges intact. Thus, although this tyre has lost a considerable amount of "fore and aft" grip, yet the "lateral "gripping points still retain about two-thirds of their original efficiency.

Reliability.-For reliability, the tread should be impervious to blows from all road obstacles, and should protect the casing from 
damage due to blows or bruises. Given a good design of tread, the most important thing is to have a thoroughly good quality of mixing, able to resist cuts though still providing a good cushion. This point does not particularly come under the control of the tyre designer, though he must know that, given certain properties in tread mixings, he has to provide sufficient thickness to give the tread a chance of acting as an efficient protector.

In the case of a large tyre it is not sufficient merely to put an tread on to a case, but on account of the very high load which comes upon the tread surfaces in contact with the road, it is necessary to provide a specially soft high-quality "cushion" between the tread and the case in order to prevent separation under the loading conditions or when running over rough stony roads.

In the case of the larger section tyres, it is necessary in some cases to fit what is termed a "breaker strip," and sometimes two or more are used. This practice, however, is to a considerable extent dependent on the design of tread adopted and the quality. of mixings used and on the ability of the tread to protect the casing without requiring further reinforcement. In the case under consideration, a soft rubber pad has been used between the tread and the casing.

Tread proportions.--It cannot be laid down as a law that a heavy and bold pattern tread will in itself be an effective nonskid and protector for a definite mileage, but the quality of mixings and the thickness of tread used will also affect the results.

The design under consideration is an example of an endeavour to so balance the pattern that the great bulk of the tread is disposed where the greatest wear comes, while yet providing suffcient material at the borders of the tread to ensure proper stability: and good protection from glancing blows from road obstacles.

The result of such bulk distribution is to extend the mileage for which the non-skid qualities are retained, and to provide at all times a "lateral" emergency grip.

\section{The rolling factor of a tyre section and its effect on the stability of pneumatic tyres.}

All motorists know that when tyres are under-inflated a "roll" takes place, and this is undoubtedly due to the lateral displacement of the tread contact point, as compared with the true running plane of the rim. 
The "stability" of a given size of section is demonstrated on Fig. 24, where wo have the base $\mathrm{P}$ of an inverted loaded triangle as compared with the height $\mathrm{R}$ of such triangle. The apex angle $\mathrm{X}$ will be reduced when an oversize tyre is fitted to the rim, and the rolling factor will vary according to the angle $\mathrm{X}$.

\section{TABle I.}

Rolling Factors for Canvas Beaded Edge Tyres.

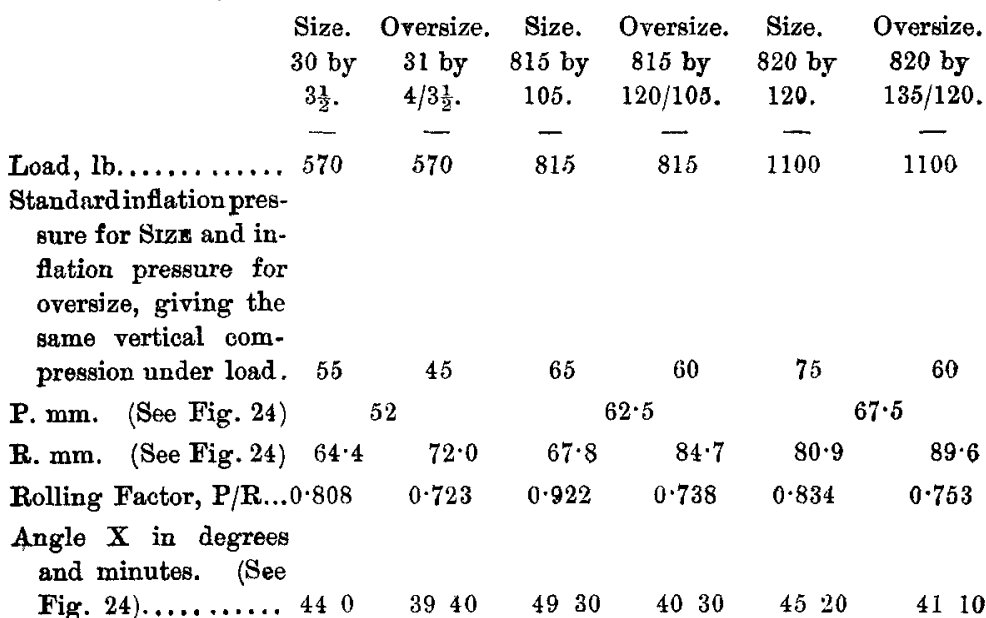

Table I. shows average figures of the angle $\mathrm{X}$ and the rolling factor $P / R$, and is interesting as showing samples of current practice as regards these properties adopted to-day for B.E. canvas tyres; thus, on standard sizes the angle $X$ varies between 44 and 49 degrees, and in oversizes on the same rims, between 39 and 41 degrees, the oversize figures being taken with tyres run at a proportionately reduced pressure compared with that of the standard size tyres.

It is obvious that with a well inflated tyre the rolling factor will depend very largely on the "grip" of the tyre on the road; for instance, a plain tyre would not "roll" but would skid, whereas a non-skid pattern would "roll" somewhat but would not skid. It is obvious also that non-skid patterns will tend to roll more than plain patterns on dry surfaces, due to their better gripping qualities. 


\section{Resistance of tread and casing to road obstacles.}

Figs. 22 and 22 a show what takes place in the tyre section. when going over a considerable road obstacle, such as a stone of conical shape. It is obvious that a reverse bending action takes place at the centre of the casing right above the obstacle, and

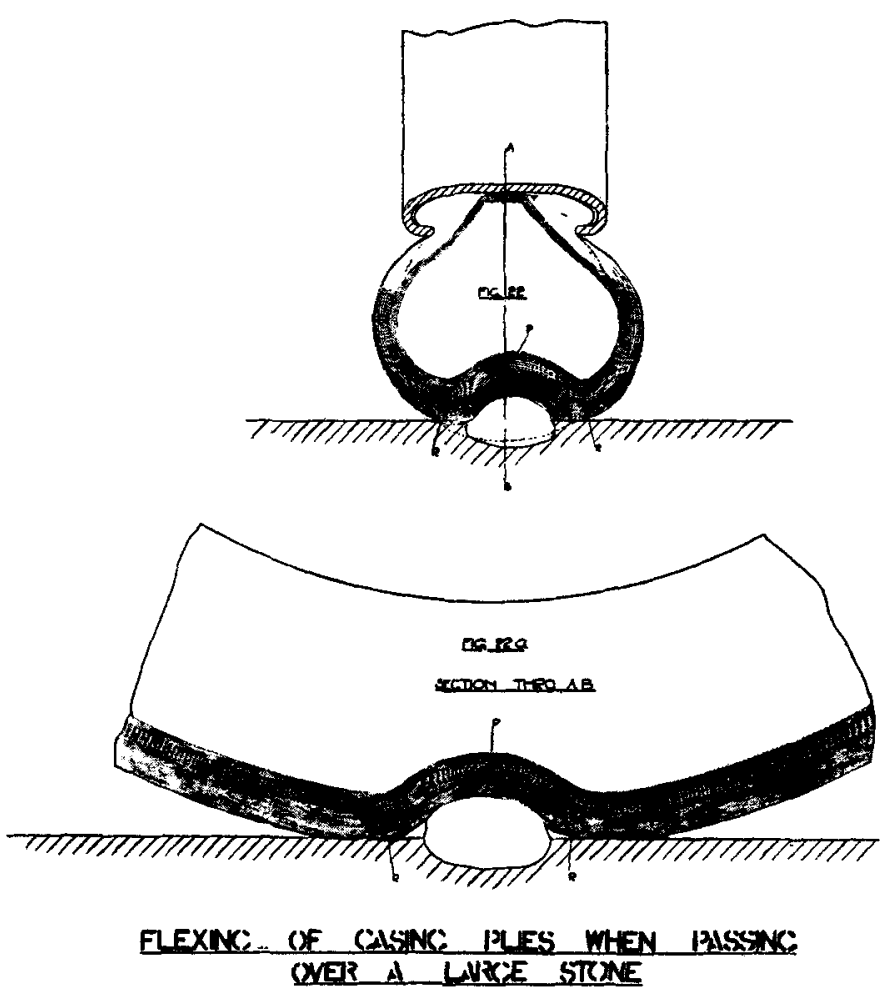

Fias. 22, 22a.

that the inner plies at the point $\mathbf{P}$ are very considerably stretched, as are also the outer plies at $R$ on each side of the obstacle. The load which comes on the fibres of the casing under such conditions depends on the contained air pressure, and on the amount of distortion of the casing from its natural curvature when under load. It is obvious also that if a large section is adopted, the 
resistance to absorbing or swallowing the road obstacle would be reduced, as local displacement of the casing would be less.

Effect of inflation on the surface in contact with the road.

Fig. 23 is an impression from a tyre fully inflated, and indicates the surface in contact with the road, whereas Fig. 23a shows the'

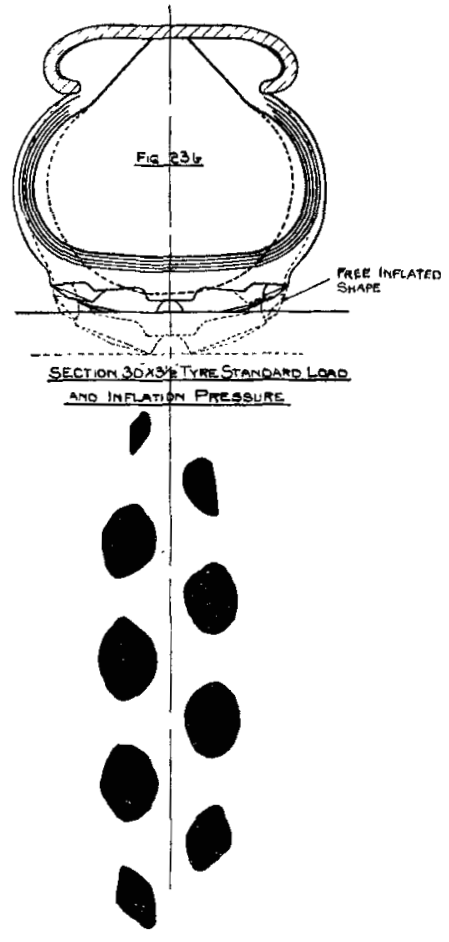

Fic 23



ZOLE. PER SQ. IN UNOER INFLATED

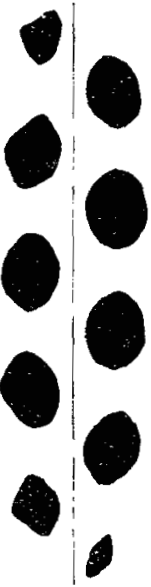

Fi6230

Figs. 23 to $23 \mathrm{c}$.

increased surface in contact with the road with the same tyre with the same load but with $20 \mathrm{lb}$. less pressure.

Figs. $23 \mathrm{~b}$ and $23 \mathrm{e}$ show cross sections taken through the loaded portions of the same tyres, and give an accurate representation of the increased flexing to which the casing plies are subject under such conditions. It is obvious that the tyre which is inflated to 
DESIGN AND MANUFACTURE OF PNEUMATIO MOTOR TYRES. 409

a lower figure will not have the $\operatorname{sam} \theta$ life as a properly inflated tyre.

\section{Trre Manufacture.}

The pneumatic tyre is an assembly of prepared "rubbered" parts vulcanised together to form a complete tyre; the parts are



Fis 24

FOR BOTH TYRES

INFLATION PRESSURE S5LS. PEA SQIN.

LOAD 570 LD.

\section{ROLLING OF TYRES.}

Fig. 24.

built up from semi-finished materials coming under two headings, as:-

1. Prepared canvas.

2. Prepared mixings. 


\section{1.-Preparation of Canvas.}

The casing is the most important unit in the tyre, and the usual methods of dealing with the textile material forming it before delivery to the tyre building department are as follows:-

Textile.-Plain square woven "duck" from high quality Egyption cotton, having the required number of threads per inch

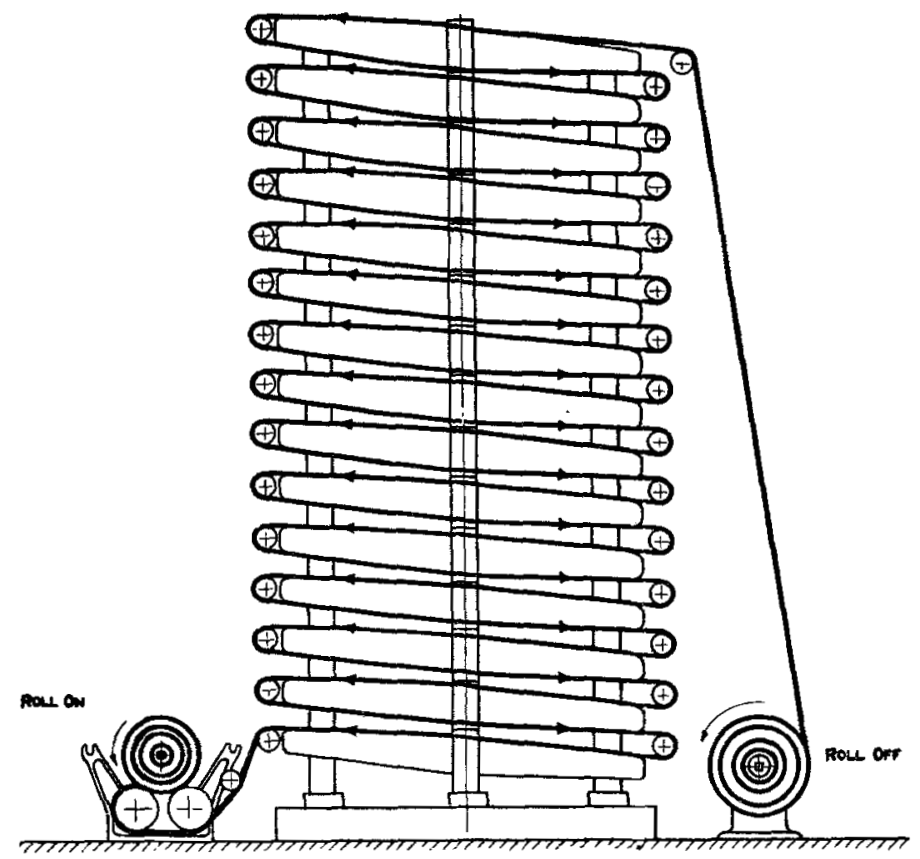

Fic.26.

Fit. 26.

and the twist in it being such as to absorb the rubber insulating material. The duck is shown in its various stages of rubbering in Plate X:-

Fig. 25, unrubbered or raw.

Fig. 25a, soaked.

Fig. 25b, 1st frictioned coat.

Fig. 25c, 2nd frictioned coat.

Fig. 25d, topped coat. 
DESIGN AND MANUFACTURE OF PNEUMATIC MOTOR TYRES. 411

It is necessary that both warp and weft threads in the completed tyne shall be equally tensioned and of equal strength, and steps

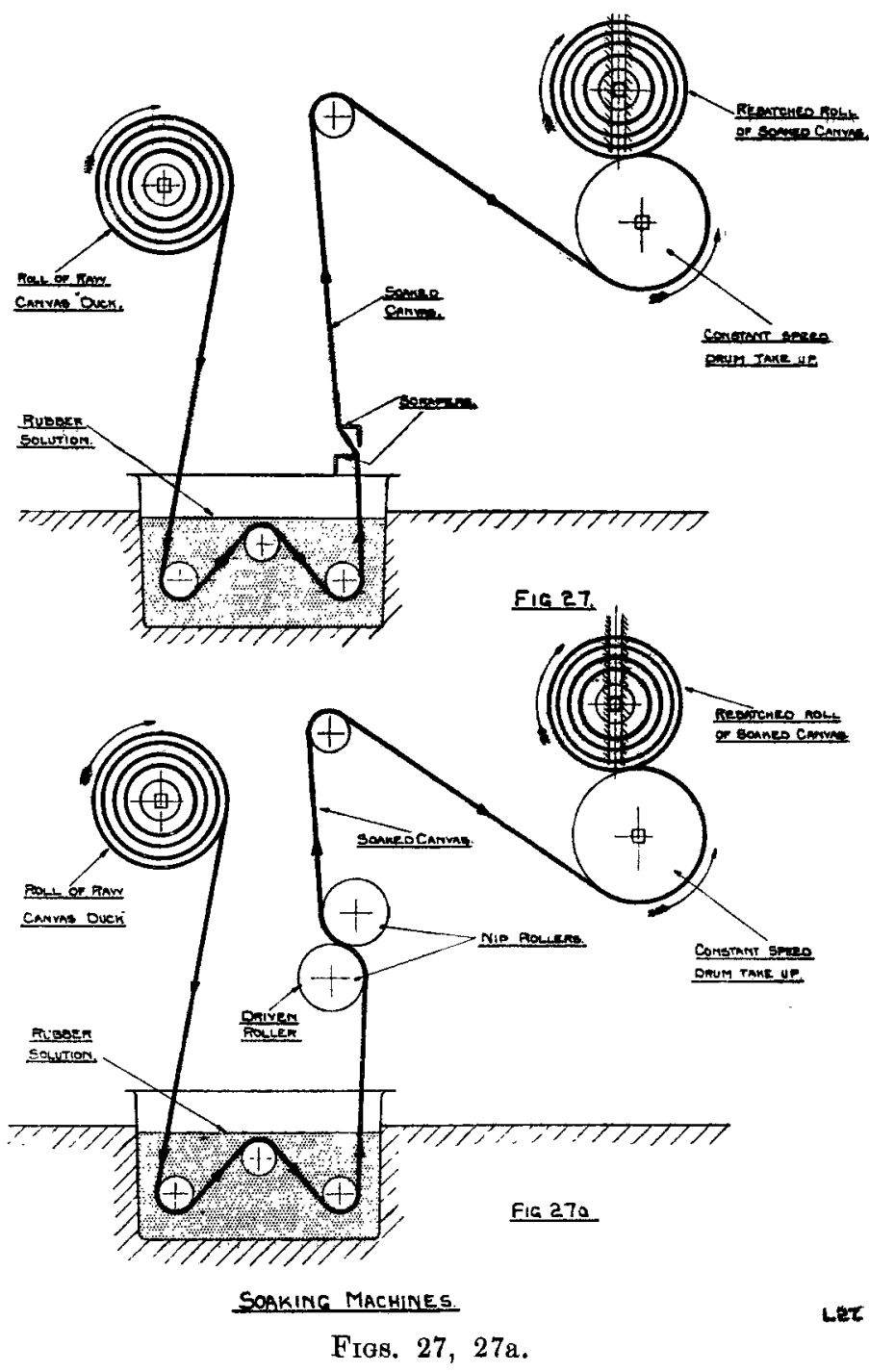

are taken throughout manufacture at the cotton mills, and subsequently in the tyre factory, to see that such conditions obtain. 
Drying.--Before rubbering it is necessary to thoroughly dry the rolls of "duck." This is generally done on either a cylinder drier or a "cell" drier. Fig. 26, this shows diagrammatically the path of the cotton through the drier.

The "cells" are steam chests with curved surfaces top and bottom, and the guide rollers are each positively driven to prevent tension on the canvas, and the machine embodies a constant-speed take-up gear.
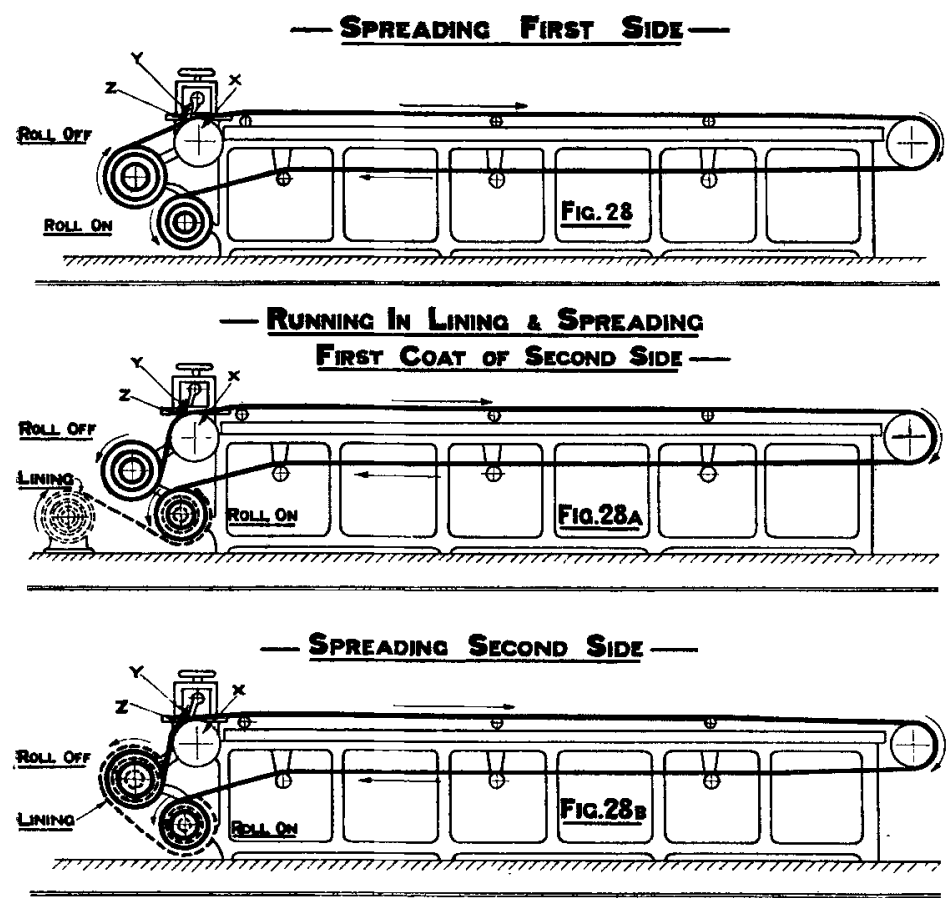

FIGs. 28, 28a, 2lb.

Soaking.-The first rubbering operation is to soak the canvas in a very dilute solution of rubber and solvent. A common form of soaker is shown in Figs. 27 and 27a, where the path of the canvas can be followed, and it will be observed that the surplus solution is scraped off, or as an alternative to scrapers a pair of "nip" rollers is sometimes used. It is obvious that this simple machine embodies a constant-speed take-up gear. 
Drying after soaking.-There are many ways of doing this, the simplest being to pass the rubbered duak over steam-heated chests, merely evaporating the naphtha, which on such a machine is not recovered.

There are a number of satisfactory machines which recover from 70 per cent up to sometimes over 90 per cent of the solvent

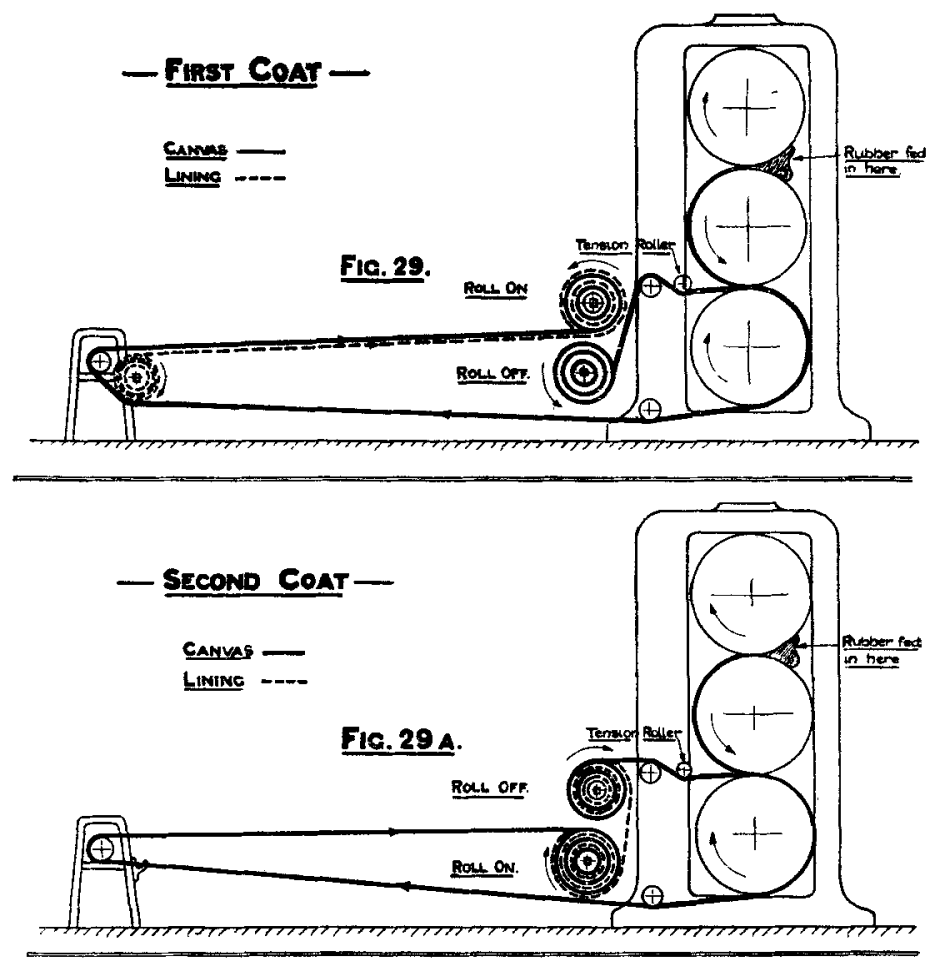

\section{Thiprading Diacram \\ Calenipes (Frictioning)}

Figs. 29, 29a

while drying the soaked material, making a very substantial saving in the cost of manufacture, as the recovered solvent is re-used.

Spreading.-The spreading method is shown in Figs. 28, 28a and $28 \mathrm{~b}$. This is a very good method but very difficult to arrange in conjunction with a solvent recovery plant, for though the 
quantity of solvent used is not so great as in soaking, yet it is considerable. The principle involved in the spreading machine is that of laying successive thin layers of mixed rubber on to the canvas in a state aptly expressed as "dough." The canvas passes over a rubber-covered driven roll $X$, the "dough" $Z$ being laid on a "doctor knife" $\mathrm{Y}$, which is adjusted to lay a film of dough against the canvas surface and "spread" it properly.

Between each layer the canvas is dried as it passes over the machine. This method is expensive but very good, as it reduces the danger of damaging the canvas during treatment.

Calendering canvas.-A method practised by some manufacturers is to entirely eliminate the soaking operation and in many! cases the spreading operation also, and to rely on the action of "friction" calenders for forcing the rubber into the canvas. A 3 -roll friction calender is shown in Figs. 29 and 29a. The canvas is run through the calender twice so that both sides are frictioned. The "frictioning" action is due to the different speeds at which the rolls revolve. The middle roll runs faster than the bottom roll, and the canvas runs at the same speed as the bottom roll; consequently, a rubbing or "frictioning" action occurs which forces the soft rubber into the threads of the canvas.

"Topping" of canvas on calender.-Though the "frictioning" method is satisfactory for "impregnating" the threads of the canvas, thus ensuring the insulation of adjacent threads in one ply from each other, it does not in itself provide sufficient insulation between plies as built up into a casing. It is usual, therefore, to follow the "frictioning" operation by a "topping" or "skimming" operation which coats one or both sides of the canvas, as shown in Fig. 30. "Topping" calenders also generally have three rolls, but the relative speeds of the rolls are arranged differently from those on "friction" calenders. The top roll runs slightly faster than the middle roll in order to properly sheet out the rubber fed to the top "nip," thus ensuring that an even thickness of film comes round the middle roll. The middle and bottom rolls run at equal surface speeds, and at the bottom nip the function of the rolls is merely that of "transferring" the "film" of rubber to the surface of the canvas.

The rolls are suitably controlled as to their distance apart and as to the temperature of the roll surfaces.

These notes on canvas treatment apply to drying, soaking, 
spreading or calendering methods employed for all textiles used in the tyre, not only for the casing plies.

\section{Rubber Preparation.}

Compounding.-Each of the rubber parts requires to be com. pounded from suitably proportioned rubbers, "fillers" and "curing agents" so that it may be well able to carry out its functions in the complete tyre.

Influence of Hrat Transmission Differences on Mixings.

Before mixings can be proved suitable for use in tyre construction in actual manufacture, it is necessary to determine that the



Threadinc Diagram

Fra. 30.

proportions are such as to ensure correct vulcanisation. No calculation can determine the time and temperature of cures, as it is necessary to allow for the "lag" due to heating the vulcanising vessel and the moulds or wrappings round the tyre and transmitting heat through the metal moulds to the various parts of the tyre contained in the moulds.

Thus it is necessary to ascertain by actually cutting up sample tyres that the interior is properly vulcanised. By suitably varying the amount of curing agents in the mixings, all parts of the tyre can be brought to a satisfactory state in a given time when subjected during such time to a given temperature or range of temperatures. It is of vital importance in tyre manufacture to 
make sure of the "cures," and the production methods and manufacturing programme must conform to good "curing" requirements. When once definitely decided upon, cures can be "standardised" for given mixings when dealt with under standard conditions.

\section{Mixing.}

The mixing of the rubber with various powders is usually performed on 2-roller mixing mills, the rubber and powders having previously been carefully weighed in batches having the required proportions. The rubber is first masticated on the mill until it is sufficiently plastic for the powders to be absorbed. These are gradually put in, and afterwards the rubber is cut and turned over on the mill so that the whole mass becomes homogeneous. The finished batch is known as "mixed rubber" and as such' is delivered in sheet form to the pneumatic tyre manufacturing section.

Having outlined the methods of preparing the canvas and the mixings, we now come to

\section{Pneumatic Tyre Manufacture proper.}

Pneumatio tyre factories generally have two preparatory sections:-

$$
\text { A.-The Rubber and Strip Assembling Section. }
$$

In this department the rubber is calendered and cut to correct gauge and width for such sub-units as side rubber, eushions, etc., and tread rubber and bead cores are prepared. In addition, all rubber and canvas sub-units are conveniently assembled together before being sent to the "Rubbering Section" for attachment to the completed casing.

\section{B.-Canvas Cutting and Batching Section.}

Here, the various strips of canvas, such as casing plies, bead wrappers, chafing strips, ete., are eut from the prepared canvas rolls into strips and batched for assembling as required into the component parts of the tyre.

Naming of parts and system of assembling from units.

Fig. 31 shows the names of the parts of the $30 \times 3 \frac{1}{2}$ tyre section in finished form, the parts from which the complete tyre is made up being shown in units in Fig. 31a. 


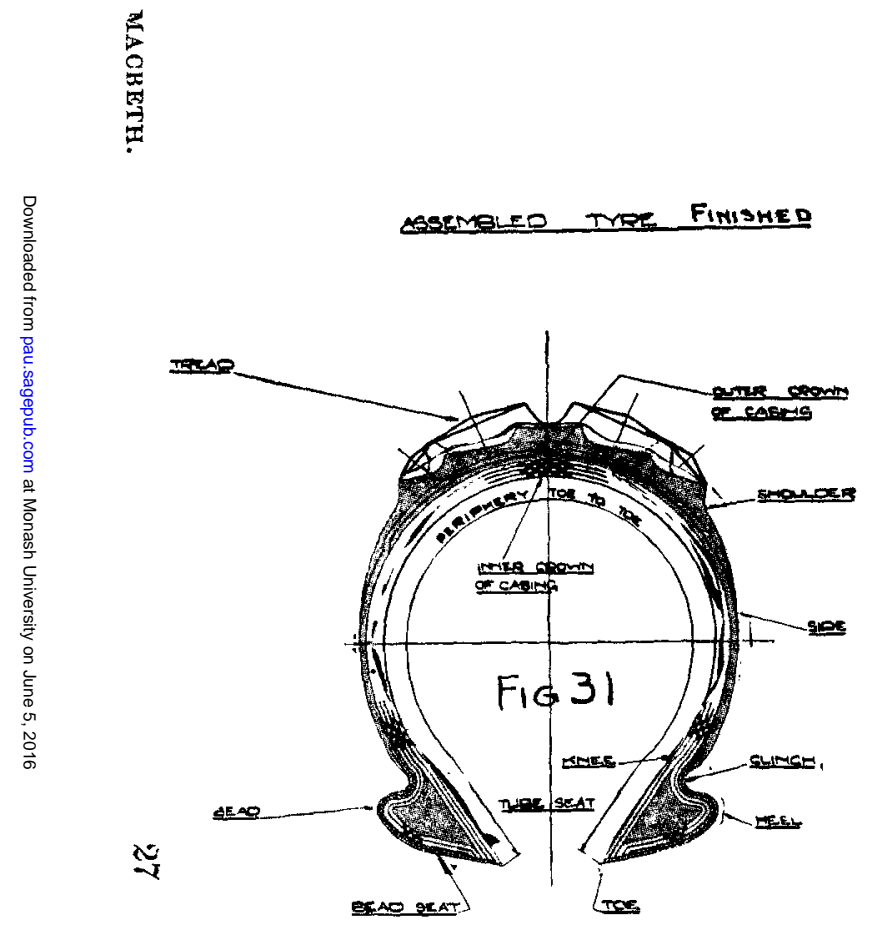

Fir. 31.



Fia. 31 a. 
The units are composed of a number of sub-units, which are grouped together under two headings.

RUBBer (sub-units).

A. Tread rubber, the tread portion proper, which is in the form of long strips, of suitably shaped profile, made from preriously mixed rubber.

B. Cushion rubber, suitably calendered strips made from previously mixed rubber.

C. Side rubber, Ditto.

D. Bead core. (Incorporated in complete bead, G.)

Canvas (sub-units).

E. Chafers, strips of prepared canvas cut from rolls.

F. Breaker strips, prepared canvas cut from rolls.

G. Beads, having wrapper strips of prepared canvas cut from rolls and having cores which are of tough vulcanite mixing.

H. Case plies, strips of prepared canvas cut from rolls.

\section{UNITS.}

The rubber unit is composed of sub-units $\mathrm{A}, \mathrm{B}, \mathrm{C}$ and $\mathrm{F}$. The casing unit is composed of sub-units D, E, G and $\dot{H}$.

A diagram of the successive steps in manufacture is shown in Fig. 32, on which each of the sub-units can be traced in its progress from the mixed rubber or prepared canvas until the main units are assembled as a complete uncured tyre on a core, to be then vulcanised and finally finished, examined and passed to stock. The diagram shows how sub-units flow along and are assembled into units, and how the main stream becomes finally the uncured tyre.

\section{A.-Tread rubber.}

The mixed rubber used to make a tread is taken from the mixed rubber stores in a cold and tough state, and it is first necessary to make it plastic so that it can be brought to the desired shape in the tyre. The "box-moulded system" of manufacture requires great accuracy in measurements, and at no point is this 
IESIGN AND MANUFACTURE OF PNEUMATIC MOTOR TYRES. 419

more essential than in regard to the proper thickness and disposition of tread rubber.

Furthermore, non-skid pattern treads call for very careful cal-

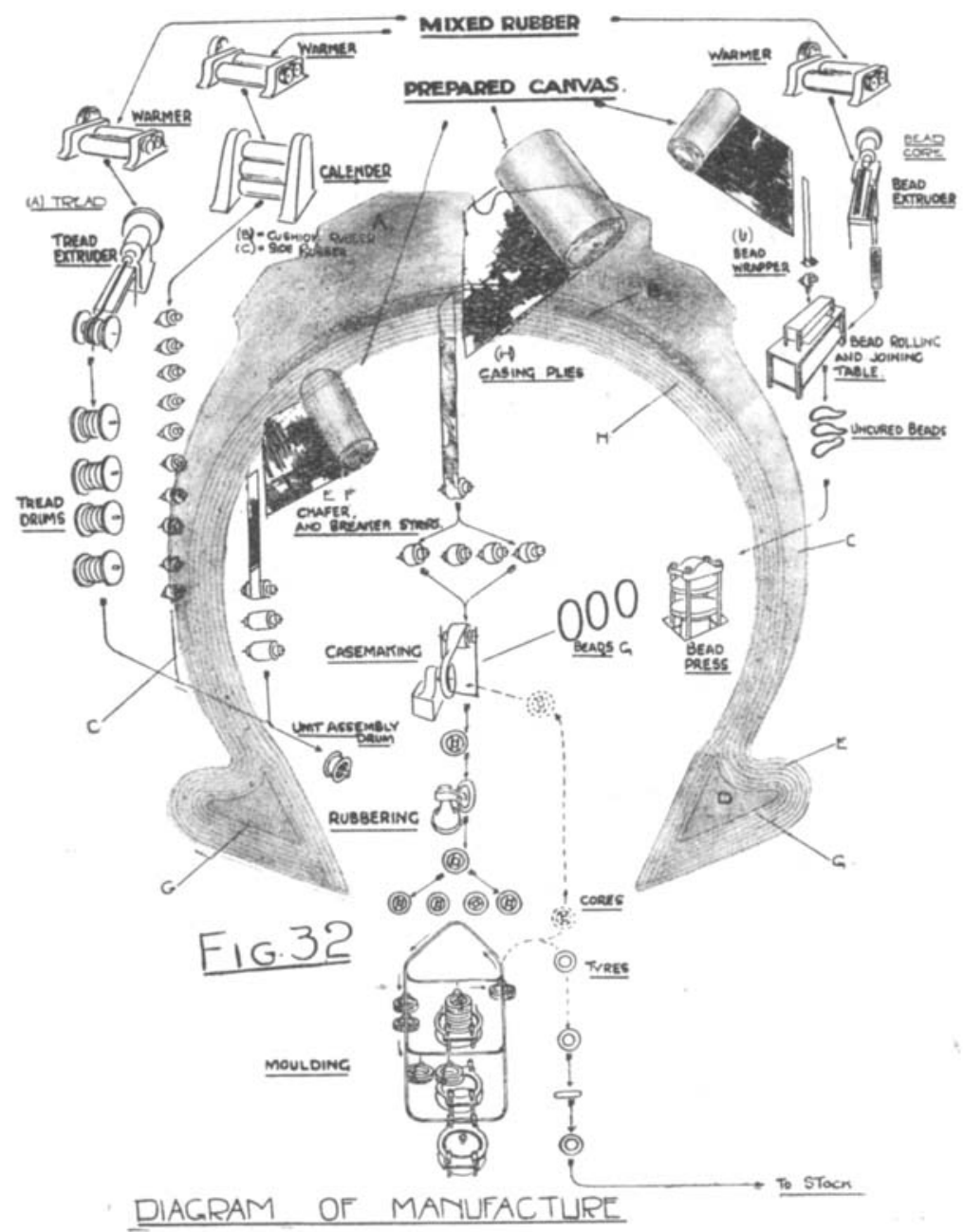

FIG. 32.

culations to obtain the correct amount of rubber to ensure perfect moulding. For this reason it is generally the practice to shape raw treads on either profile calenders or "spewing machines," $27(2)$ 
these latter being sometimes termed "extruding" or "forcing" machines.

The method of tread manufacture desaribed is that of "spewing."

The rubber is first put on a breaking-down mill and next on to a "warming-up" mill, the processes being shown in perspective in Fig. 33, Plate XI.

The rubber, after being sufficiently worked on the "warmer," is cut off by an attachment in the form of a strip, which is fent in lengths to the spewer. The rubber strip on entering the machine is forced forwards by a water cooled serew through a die which gives it the desired shape.

The tread on emerging from the die runs on to a conveyor belt and is eventually batched up on to a circular drum shown in the general perspective view. The drums on which the rubber is batched are carried on a suitable "stillage" at the end of the conveyor belt in pairs, the conveyor having a suitable tilting end so that it can feed either the top or the bottom drum as required. As the different coils on the drums are filled up, the drums are moved sideways so that they can be completely filled with raw treads.

As an example of the required accuracy in working to limits, it may be stated that a variation in weight of only $1 \frac{1}{2}$ oz. over or under is allowed in a tread weighing $3 \frac{1}{2} \mathrm{lb}$., or about 2.5 per cent over or under in a length of about 100 inches.

\section{B.-Cushion rub.ber. C.-Side rubber.}

These are made from mixed rubber which, after being broken down and suitably warmed as described above, is fed into a calender which sheets it out to the required thickness, and which is fitted with knives which cut it into strips of the required width. These strips are batched up on spools by the apparatus shown in Figs. 34 and 34 a, Plate XI. These spools with the strip rubber on are made to fit in centres on suitable tables on to which the rubber is drawn and cut to the required length. The spools are also arranged with projections at the end which fit on bars on a "stillage" base for convenience of transport.

It is very necessary to work to close limits of thickness of calendered sheet. This must not vary more than $0.05 \mathrm{~mm}$. or 0.002 in. from the required figure. 


\section{D.-Bead cores.}

Mixed rubber for the bead cores is broken down and warmed up as described above for the tread. It is then fed to an extruding machine which has a multiple die, a number of beads: being extruded simultaneously. This machine is similar in construction to the tread extruding machine. The bead cores, however, are not batched up in continuous lengths as are the treads, but are extruded on to a table and cut to lengths. A large number of the cores are put together in suitable trays, which' are arranged to load on to stillages for convenience of transport.

\section{E.-Chafing strips. F.-Breaker strips.}

These strips are cut from the previously prepared rolls of canvas to the required width. They are usually cut on the bias at an angle of 45 degrees on a special bias cutting machine, Fig. 35, Plate XII. Some breaker strips, however, are cut on the straight, this operation being performed on a special machine, Fig. 36. The width of the canvas roll is as far as possible such that no scrap is made, each strip being of the required length to subsequently fit the tyre. The strips out on the straight are continuous lengths, and are cut to the desired lengths as desired without scrap. The strips are batched up roughly on spools, these spools being of similar construction to those used in the calender and described above, so that they can subsequently be mounted on suitable centres on the assembly tables.

\section{G.-Bead wrappers.}

These are cut from previously prepared rolls of canvas on the, bias as described for the chafing strips and breakers, and are suitably batched up ready for assembly with the bead cores.

\section{Bead assembly and curing.}

The sub-units $D$ and $G$ described above are now assembled together to form the bead. This operation is performed on an bead rolling table, the bead wrapper being laid on the table with the core on it and the rapper rolled round the core by; means of a "rolling board." After "rolling," the bead is joined up to form an endless band. Figs. 38,38a, 38b, 38c and $38 d_{i}$ Plate XIV, show the various stages in manufacture of a bead built 
on the round core principle, and Figs. 39 and 39a, Plate XIV, show sections of an uncured and a cured bead.

The presses, as will be seen from Fig. 37, Plate XIII, consist of an upper fixed platen to which is attached a steam chest, the. lower platen being worked by a hydraulic ram and having attached
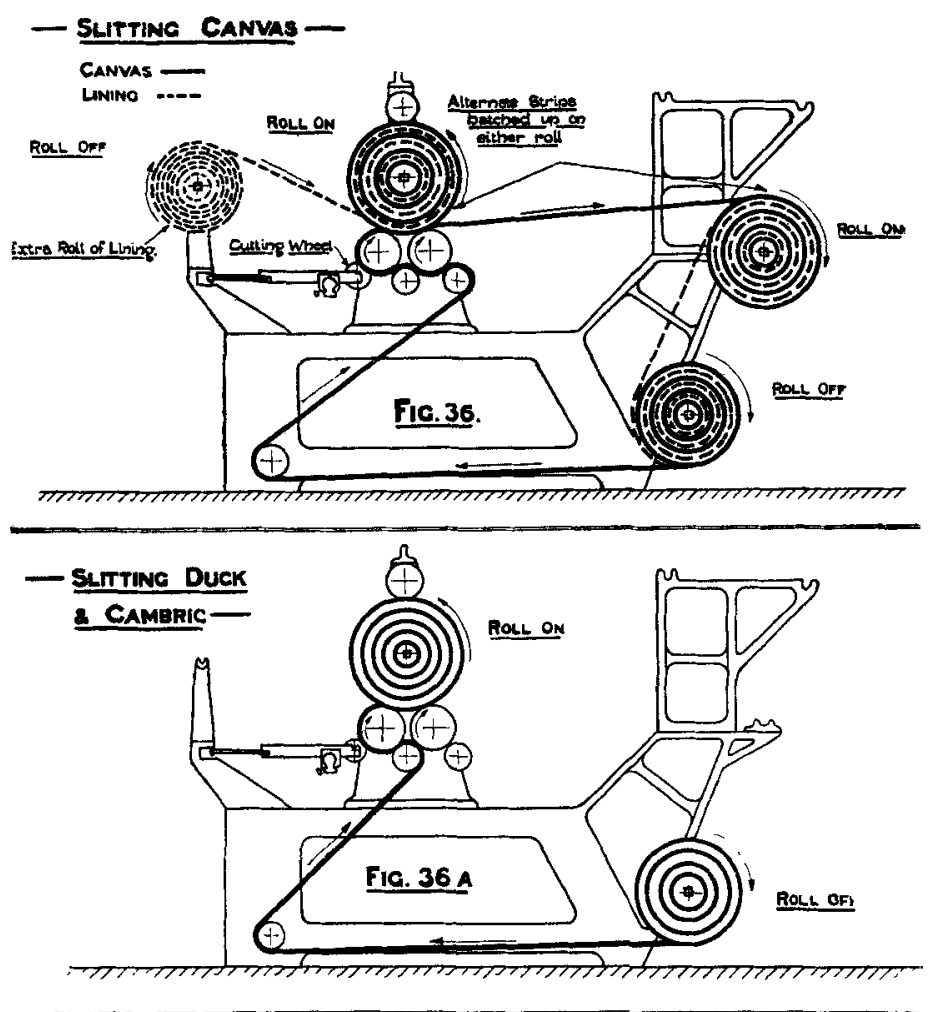

Fras. 36, 36a.

to it a second steam chest. In between these is a floating steam chest guided by the pillars of the press, the press thus forming two separate compartments into which moulds can be placed. Usually, two moulds are placed in each compartment, i.e., four beads are cured at ouce in each press. This cure is only of short duration to give the bead a permanent shape so that it can be 
applied to the casing as will be described later. The beads aften moulding are gauged for size and shape. The presses may have a multiple number of "daylights," or steam chests, and may do many more beads at one time, but the principle involved is the same. It is the practice of some manufacturers to make their: Leads in long lengths instead of in "ring" form, but the adoption of ruch a practice depends generally on the methods adopted for

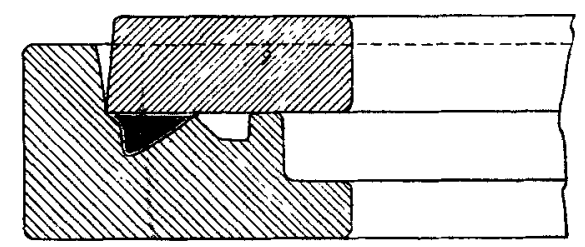

F.G.40.

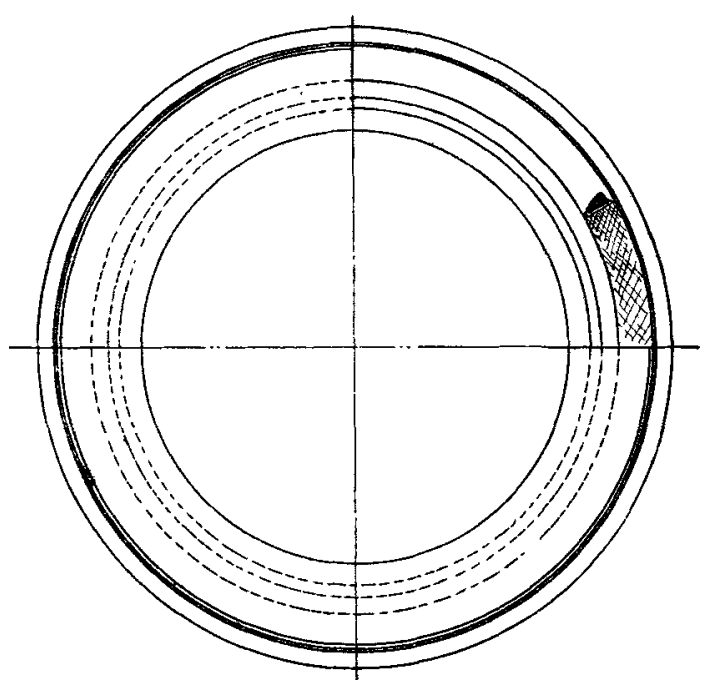

Fra. 40.

"setting" the beads on to the casing itself. There is no doubt that the "ring" type of bead is the best, though not the cheapest. Fig. 40 shows details of a bead mould.

$$
\text { H.-Case plies. }
$$

These are cut from previously prepared rolls of canvas on the bias cutting machinc. 
Bias cutting muchines may be broadly divided into two classes:-

1. Horizontal type, with shear blades. These may be described as a type of guillotine shears, with suitable automatio feeding gear, which feeds the canvas intermittently between each stroke of the shear blades by an amount equal to the width of strip required.

2. Vertical type. A machine of this type, using a conveyor and batching arrangement, is shown in Fig. 35 . On the left will be seen a framework on which are mounted stock rolls of prepared canvas, also "stripping rollers" over which the canvas is passed to separate it from the cloth lining, and a compensating roller which controls the "let-off" from the stock roll. It is essential that an efficient "stripping" arrangement be provided, as, if the canvas is very tacky and a thorough stripping action does not take place, accurate feeding to the knives would not be possible.

The canvas is finally passed over a second framework which contains the feeding and cutting gear. The roller on the top of this frame, from which the canvas hangs vertically, controls the amount of feed, i.e., the width of strips to be cut, and this can be varied as desired. The strip in its vertical descent passes under, and is held by, a clamp during the cutting stroke.. The knife is of the "draw cut" type, and reciprocates across the canvas in a carriage guided by the cross slide, which can be angularly adjusted to vary the bias angle of the strips as desired.

\section{Conveying and Eatching Arrangement.}

After the plies have been cut they are caused to fall by means of stripping gear on to a suitable conveyor, which carries them in succession past a number of batching turrets, on which they are roughly batched in suitable cloth lining.

As each tyre casing is built up of plies of two widths, i.e., narrow plies going inside the bead core and wider plies going. outside and below the beads, it is common practice to join these up on spools in lengths suitable for three to five complete casings per spool. Thus, as the plies cut on the bias eutting machine are programmed in quantities of "wides" and "narrows" as required to suit output, it is necessary to have a second operation in which the narrow and wide plies are correctly assembled and 
batched up on a ply batching table, suitable for casemaking machine operators. The arrangements in the batching section depend largely on the method of casemaking adopted.

\section{Ply. Batching.}

On the batching tables the plies are batched up, narrow and wide together, in the correct order, so that they form a continuous' strip, which is later wound on the casemaking machine. Figs. 41

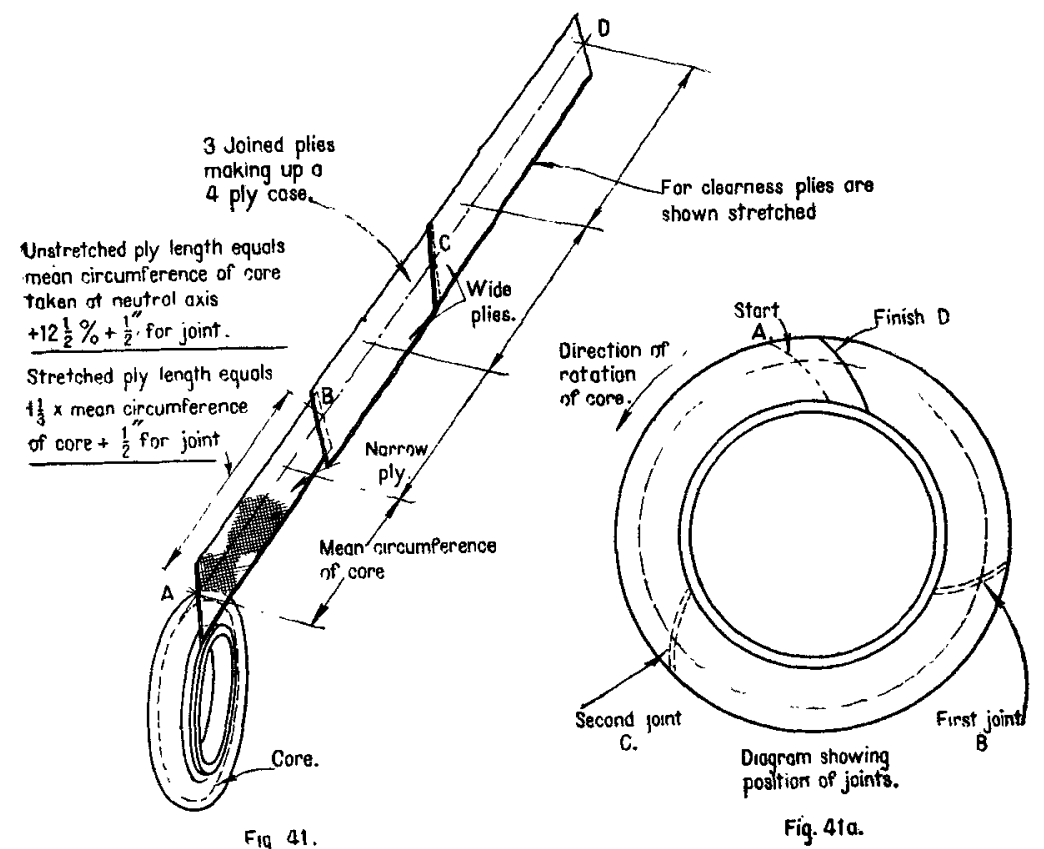

Figs. 41, 41a.

and 41a show diagrammatically how three plies are formed in one long length for a 4-ply case, and how their joints are arranged so that "overlapping" is obviated, and how the built-up casing: has its joints distributed.

\section{Casemaking.}

Given a suitably prepared material, the satisfactory performance of a pneumatic tyre depends more on the efficiency of casemaking 
methods than on any other mechanical operation in the construction of a tyre. The operation consists in converting bias-cut rubbered canvas strips into the form of a ring-like carcass, having a "horseshoe" shaped cross section composed of a number of plies, and in attaching a pair of bead cores to the carcass interlocked with the plies. In order to properly attach the plies, they must be arranged on the bias so that they can be "stretched."

Fig. 42 is a section through a ply laid on a core, and shows the action that takes place and that a bias-cut strip of canvas which has a circumference corresponding to that of the neutral axis line NA, has all portions "without" the neutral axis line



FIG. 42.

"stretched" circumferentially, and all portions "within" the neutral axis line "condensed" circumferentially but stretched radially inwards.

Figs. 43 and $43 \mathrm{a}$, Plate $\mathrm{XV}$, are photographs showing the lay of the canvas warp and weft threads at various points on the surface of the core. These threads in the unstretched canvas form squares and cross each other at 90 degrees. Owing to the stretching of the canvas, the warp and weft threads are angularly displaced, and the squares become diamond shaped at all points except on the neutral axis. Above this line, owing to the circumferential "stretch" and lateral "contraction," the threads form diamonds with their long diagonals lying in a circumferential 
direction, the one diagonal increasing and the other decreasing gradually from the neutral axis to the crown 0 . Below the neutral axis, the formation is the reverse of the above, the long diagonals of the diamonds being disposed radially and the variation from the square configuration increasing with the distance from the neutral axis.

The aim of the tyre manufacturer is to so lay the plies that:-

(a) all threads shall be equally loaded in resisting the bursting action due to inflation and other loads coming on the casing;

(b) all threads shall be equally flexible and yielding when withstanding blows from the road surface or obstacles. on the road;

(c) threads shall not be damaged by excessive local stretching or by "puckering" of plies in shaping them to the contour of the core. There are probably more patents taken out in connection with casemaking machines and methods than for any other tyre making operation, but as regards tyres built up from prepared strips on to cores in ring form and of horseshoe section, all well known machines come under one of two types:-

$$
\begin{aligned}
& \text { 1.-The "Continuous" Ply-Laying Machine; or } \\
& \text { 2.-The "Intermittent" Ply-Laying Machine. }
\end{aligned}
$$

1. The continuous method, Fig. 44, Plate XVI. In this case the plies are joined together to make a long strip and wound on to the core under tension, each successive ply being shaped and laid against the core progressively and simultaneously. The plies are arranged in such order that the batched length has its joints stepped round the circumference of the core at suitable intervals, as shown in Fig. 41a. With the continuous system it is easy to ensure an even tension throughout the casing, and very little attention is required from the operator to get uniform results.

2. The intermittent method, Figs. 44a, 44b and 44c, Plate XVI. The strips are prepared in such lengths that each wraps round the core once with suitable overlap for joint making. They are joined together to form a continuous strip; but after the first ply has been laid on the core the canvas is cut or torn in a bias direction, leaving the first ply in the form of a band round the core. 
This ply is now "spun" down at high speed by means of a pair of angularly controlled disks, which are fed inwards towards the centre of the core at a suitable rate in order to condense the canvas and attach it to the core or to the previously laid plies. This operation is repeated until all the plies have been attached. It is feasible by this system to lay down two plies at once and then to spin them down together.

The intermittent system is liable to cause considerable variations in tension at the commencement and finish of each ply, resulting in variations in the angles of the threads at such points.

Satisfactory results depend very largely on the skill of the operator when using this type of machine. By means of the spinning down disks it is, however, easier to lay the plies at a lower circumferential stretch than with the continuous system.

\section{Canvas Tension or Let-off.}

Constant stretch or tension on the canvas is most important. The following are three well known methods of controlling the tension or let-off:-

\section{Brake controlled Let-off.}

This type, shown diagrammatically in Fig. 45a, Plate XVII, has a serious defect in that it makes no allowance for varying "hardness" of the canvas or for temperature change effects; consequently, accurate stretching depends largely on the skill of the operator. It is better suited to the intermittent type of machine than to the continuous type.

\section{Positive controlled Let-off.}

This type, shown diagrammatically in Fig. 45, Plate XVII, is equally effective whether with hard or soft canvas, and temperature variations do not affect the results. The gear does not allow for the gradually increased diameter of the casing as successive plies are laid, and this gives a small increase in stretch on the outer ply. This type is better suited to the continuous type of machine than the "braked" let-off.

\section{Positively controlled compensating Let-off.}

This arrangement, shown diagrammatically in Fig. 45b, Plate XVII, lets off more canvas as the diameter of the case increases. 
It has, however, a tendency to slippage and to damage the surface of previously laid plies. It is obvious that the means of driving; the let-off is through contact of a roller with the surface of the tyre itself. This type is also better suited to the continuous type of machine than the "braked" let-off.

\section{Casemaking Machine Operation.}

We will now describe in detail the complete operation of making a casing on a machine of the continuous ply-laying type with a positive let-off. Fig. 46, Plate XVIII, shows a perspective view of a battery of machines each having a stock of raw materials as follows:-

Canvas strips.-On "boxes" from a "buffer stock" stores on suitable stillages; a reasonable number of spare filled boxes are mounted on the casemaking machine as shown, thus the operator never has to wait.

Beads.-A supply of beads ready solutioned and handy on the core turret.

Cores.-A stock of these, both bare and with casings on, is carried on a suitable turret situated in front of each machine, which has two horizontal bars supported by a vertical pivot and capable of being connected up as desired to the casemaking: machine, either to put on a new core or take off a finished case and core. This system prevents delays, and the operator of the casemaking machine is able to load and unload the machine without assistance. No lifting is required, only sliding horizontally. The cores, both empty and full, are transported to and from the core turret on suitable stillages by means of elevating: trucks.

\section{Sequence of Operations.}

These can be broadly stated as follows:-

1. Simultaneous laying of prepared strips from stock rolls.

2. Guiding strip as fed on to stretching or shaping means and re-batching the lining.

3. Stretching or shaping the plies before application tot casing. 
4. Eliminating any wrinkles or puckers which may have formed in the stretching operation.

5. Attaching the stretched and formed ply to the surface of the core or to previously laid plies.

6. Laying on plies to the core in proper form, particularly the portions of the plies that lie within the neutral axis line.

It is understood that these operations on the continuous laying type of machine are all carried out at one and the same time intil the length of batehed up strip necessary to make up the tyre has all been "run on."

Machine controls.-Figs. $46 \mathrm{a}$ and $46 \mathrm{~b}$, Plate XIX, show the type of machine concerned, and the main features of it which require movement or adjustment on the part of the operator.

\section{OPERATION 1}

is to set the suitably prepared inside bead upon a setting ring or spider, which is centred by the spindle on the casemaking machine, so that at the proper time this bead can be attached to the casing and be perfectly concentric with other parts of the casing.

\section{Operatron 2.}

The core from the previously loaded turret, as shown in Fig. 46, is made to slide aoross and secured to the spindle of the machine by a suitable " $\mathrm{C}$ " shaped washer which does not require the nut to be taken of the machine and thus can be quickly withdrawn.

\section{Operatron 3}

The core has been suitably solutioned so that the starting end of the canvas can be properly attached to it and will adhere. Suitable shaping and feeding arrangements ensure proper stretching of the canvas on to the core.

The first end of the canvas is run on-initial tension being taken care of by means of a canvas leader or short piece of canvas attached to the first ply, which is torn off when sufficient length 
is laid on the core. The purpose of the canvas leadi: is solely to ensure correct tension at the start of the first ply.

The operator now brings into action a ply-laying head having reciprocating fingers which move radially in wards, stroking down the plies and attaching them to the previously solutioned core surface. This operation is continued until the whole of the inside plies are laid on, when the machine is stopped and a slit is made at each side of the casing allowing the canvas to be pushed upwards so that the beads can be set outside the inner plies.

\section{Operatron 4.}

Bead setting now takes place, the outside bead having been suitably placed in another setting ring, this outer ring being sentralised by contact with suitable portions of the tyre core, and by means of two screws with handles the two beads are brouglit, hard together and attached to the core.

Outer ply laying.-This is done by means of a cradle which is provided with quite a number of small rollers each laying down a portion of the plies round the bead, so that the plies are gradually folded over and properly attached to the bead. This cradle can be lowered away from the tyre casing when required.

\section{Operation 5.}

After all the plies have been laid on, the canvas is torn off on the bias whilst still under tension in such a way: that the finish of the plies just overlaps the commencement of the tyre.

The surplus canvas is now cut away or trimmed at the bead edges by means of a swinging attachment having a downwardly. pressed lever which presses two cutting out knives against the ply edges below the bead.

These knives are compensated to allow for rocking action and very accurately trim out the edges. It is very necessary to reduce the amount of trimming as far as possible, but in practice some slight trimming is necessary to ensure close working to volumes at the bead toes.

Tho making of a tyre on such a machine takes from four to twelve minutes, according to the number of plies incorporated in the casing. It is apparent, however, that with the progressive 
system of working incorporated in this type of machine the action is continuous excepting only for the stop necessary to attach the bead rings. It is obvious, too, that with this type of installation the operator has all his plies brought to him, and does not require any help from other workers. It is a fair example of the application of "buffer" stock methods with a view to getting high efficiency from operators and eliminating stoppages due to irregular supplies or to the temporary absence of workers on whom operators depend for their supplies.

\section{Transport of Tyre Casings on Cores.}

The tyre casings, together with the cores on which they have been built, are taken from the casemaking machine turret and loaded on to a stillage for transportation to the rubbering section.

\section{Rubbering, Strip and Tread fitting, etc.}

Fig 47 , Plate XX, is a photograph of the rubbering section taken from the centre and looking towards the casemaking machines.

Fig. 48, Plate XXI, is taken from the centre, looking in the opposite direction.

In the first view will be seen a turret examining post A with a group of stillages B containing finished cores. At this point the cases are carefully inspected and gauged before being passed for subsequent operations.

The box-moulding system, i.e., moulding of a tyre (built on a rigid core) in a definite confined space between two rigid bodies, makes it necessary to work to very fine limits, both for shape and volume.

The rubbered thickness or "gauge" of prepared casing plies varies in practice in spite of the great care taken at all steps in the preparation of the canvas. It is therefore necessary to carefully gauge the cases and to make due allowance for this variation by varying the thickness of calendered rubber fitted to the casings. This is done by means of a C-shaped gauge, shown in Fig. 49, Plate XXII, which indicates on a dial the thickness of rubber which has to be applied to each side of the case in order to give the correct overall dimensions necessary for moulding.

After the case has been passed by the inspector and gauged, it is lifted off the examining post by the hook $\mathrm{C}$, which is sus- 
pended from the overhead runway $D$. This runway passes over a battery of rubbering stands $\mathrm{E}$, on each of which is mounted a vertical pivot carrying two swinging arms, each of these arms in turn being provided with a centre suitable for mounting a core. Each of these centres is arranged with a pair of collapsible leaves to form a safety device, which effectively prevents the core falling off the centre and injuring the operator. The leaves are arranged with heads of part spherical shape, so that on the core being presented to them they collapse inwards, allowing it to pass, and when the core is in position expand again under! spring action and lock it securely. The arms can be swung through the complete circle in a horizontal plane, in addition to which each is separately pivoted on a horizontal axis so that the tyre can be held in any desired position for the convenience of the operator.

A runway is situated orer the extreme outer position of the circle of swing of the arms for loading and unloading.

When rubbering the arm is swung back to the side remote from' the runway.

As previously mentioned, all the sub-units necessary to complete a raw tyre have been previously assembled as a rubbering! unit in a suitable multiple spool. Several of these spools will be seen lying under the tables in Fig. 47, Plate XX.

On the top portion of the table the operator unrolls as required each of the strips which have to be applied to the tyre casing. A strip of rubber with its spool and lining unwound is shown at $\mathrm{G}$.

The bead strips which have been previously assembled together are first applied to the casing, where they are carefully rolled down by means of a hand rolling tool shown in Fig. 50, Plate. XXIII. Care is taken that they are well rolled down and that no. air is trapped between them and the casing. The next step is to: put on the pad rubber. This is rolled down against the casing by means of the flat roller shown in Fig. 50a, Plate XXIII.

The breaker strip (if used) is next applied and rolled down in a similar manner, after which the undertread and tread are applied.

When the case has been completely assembled, it is again gauged by means of a similar gauge to that previously described, and

MACR ETH。 28 
if passed by the examiner is again loaded on the runway $\mathrm{D}$ and passed into stock as an uncured case, this stock being carried on stillages with horizontal arms, as used in the casemaking department. Fig. 48, Plate XXI, shows this stock at the far end of the lines of rubbering stands.

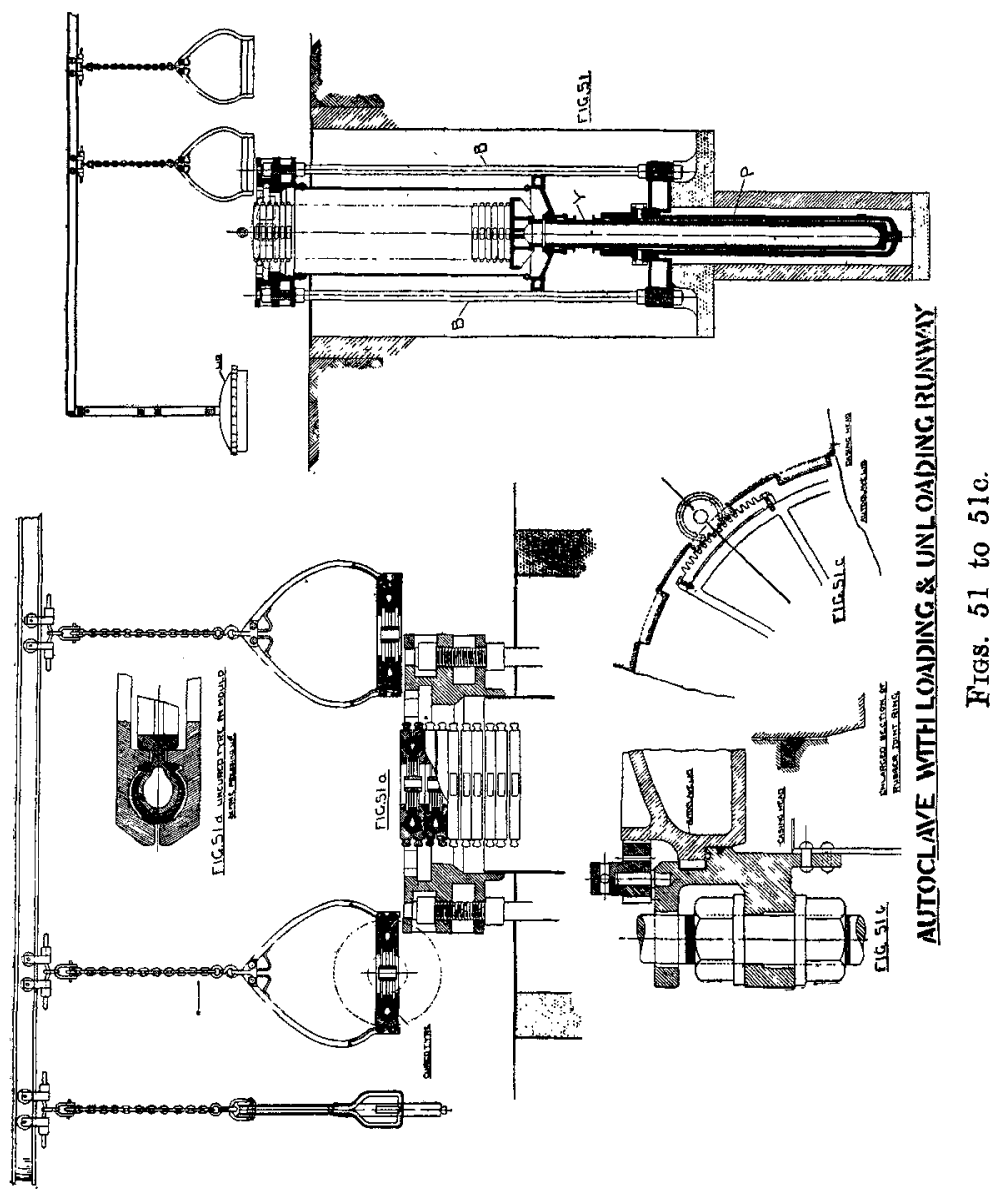

Moulding and Curing. Autoclaves.

The modern tyre curing vessel has been evolved from a simple horizontal "pan" into which bolted moulds were placed and stacked together in piles by hand mothods. 
French engineers developed the "autoclave," Fig. 51, as a vertical curing vessel in conjunction with a vertically moveable hydraulic ram $Y$ operated from a cylinder $P$ connected by bolts $\mathrm{B}$ to the steam vessel. This devioe is almost universally used for large tyre manufacture and is a great labour saver. There are many different designs in use, but most of the well knewn tyres are cured in machines which are in principle similar to Fig. 51.

The section shows the cylinder and hydraulic ram, ram table with a pile of moulds on it, and overhead conveyor with suitable. lifters by means of which the moulds are loaderd into and unloaded from the autoclave.

Fig. 51a is an enlarged section through the head of the autoclave.

Figs. $51 \mathrm{~b}$ and $51 \mathrm{c}$ show details of the bayonet type joint for the lid of the steam pan.

Fig. 51d is a section through an assembled mould with an uncured tyre in it before being "pressed up."

\section{Mould Handling System used for supplying "Autoclave" Presses.}

There are many systems in use for the filling and emptying of moulds, and for handling them into and out of the presses, the simplest and most laborious being that of lifting the moulds by. the operators with gloved hands. The most complete systems employ a complete installation of conveyors, both on the tables and overhead.

The system to be described is one designed to handle one tyre every forty seconds on each line of five presses of $12 \mathrm{ft}$. capacity each, and the aim has been to avoid using complicated conveyors with their liability, to serious hold-ups in output due to brealkdown at any one point, and to be able to change the sequence of operations without having to change expensive plant items.

Fig. 52, Plate XXIV, shows at the far end a row of presses in which the tyres are to be cured. Each one is charged with anything up to thirty-three tyres per cure, according to the tyre section.

The organisation is such that a press "blows" every twentyone minutes, so that each twenty-one minutes a "heat" of tyres must be dealt with. 
At the point " $A$ " there are stillages " $B$," each having about five tyres on it arranged according to the programme of sizes to suit the moulds to be filled. The endless triangular runway $\mathrm{C}$, with suitable trolleys $D$ and pendant hooks $E$, enables tyres on their. cores to be unloaded from the stillages.

When the bottom half of a mould arrives at the point $F$, the moulder runs a tyre above this and elevates the table $G$ by the hydraulic ram $\mathrm{H}$, at the same time unhooking $\mathrm{E}$. The tyre and bottom half slide on rollers to the table $\mathrm{J}$, which is elevated $\mathrm{by}$ another ram, thus enabling the top half of the mould $K$ to be placed on the tyre.

The operator then puts the hooks $L$ on to a pair of lugs on the top and bottom mould halves, depresses the table $J$ and away goes the filled mould with a push down towards the press to be filled. Fig. 51 shows a section of the press with moulds being put in. A mould suspended from its hooks is placed above the previously piled moulds, the "ram" is raised by depressing a valve lever and up comes the previously piled mould, letting the operator release the hooks of the new mould; the hooks then swing away to let the next mould be dealt with. The ram, of course, gradually descends as the moulds are loaded.

Figs. 3 and 3a show the section of a tyre complete in the mould, pressed up. These moulds are clamped together thoroughly, seeing that the hydraulic pressure on the ram equals 120 tons and upwards, according to the size of tyre dealt with.

The type of valve used for ram operation is one in which' high pressure water cannot be admitted until such time as the press is filled up and closed, thus preventing the operators from wasting expensive hydraulic power. The low pressure system works at $400 \mathrm{lb}$. per sq. in., and the high pressure system at $1,500 \mathrm{lb}$. per sq. in.

After curing, the moulds are discharged and transported again on the runway to the mould-opening point $M$, where again a ram-operated table rises and allows the mould to be unhooked. Levers applied by hand open the mould top from the tyre, and the top is taken along on the runway as at $\mathrm{N} \mathrm{N}$, where it is cleaned' for use again at the point $J$. The tyre and the bottom half of the mould slide on to another rising table $P$, at which point the hook $\mathrm{R}$ is inserted, the table depressed and the tyre on the core slides on the transverse runway $S$ to strippers. The bottom of 
the mould is raised by $\mathrm{P}$ again and slid off down the cleaning table $T$ for use again at the point $\mathrm{F}$.

Stripping off the tyre from the core is done by sliding the core on to a turret $\mathrm{U}$, at which point "strippers" loosen the tyre on the core and "soap" the inside of the tyre so that it can be "stripped" from the core. The cores run on another runway, when stripped, to eleaning and solutioning turrets $V$, from whioh they are again transferred by a runway to stillages $W$ ready for return to the casemaking department. The tyre, after stripping, is thoroughly, washed with warm water and very carefully examined. Valve notches are then cut, the inside surface is painted, and it is then passed to stock as the finished artiole.

\section{Transporting Methods.}

Tyre manufacture is essentially "mass production," but unfortunately many sizes are required, so that the factory must be laid out to suit a programme covering numerous sizes and a number of patterns.

It is seldom possible to arrange the flow of work in such a way that conveyors can be used. The transportation methods covered in these notes are based on the principle of moving "units" or bunches of units.

So far as possible the container used during transport is useid as the container or "support means" between, and even during, operations, and also at such periods as the units in question are considered as "buffer stock."

In compiling thiese notes, there has been no reference to previously published matter, as there is little or none on record; thus, it appeared advisable to deal with the matter as an example, demonstrating the broad principles on which tyre manufacture is carried on.

\section{S.S. ANd B.E. Tyres.}

The advantages of other types of tyres, such as the modern cord type of construction, and the Straight Side method of attachment, might well form the basis of further matter in reference to their. design, production and usage. 
The Effect of Unsprung Weight on the Tyre.

It appears likely that very greatly improved service will be obtained from tyres which do not have to withstand the "pounding" due to heavy unsprung weights. Improvement could be looked for in the direction of:-

1. Increased casing life due to reduced flexing.

2. Increased tread wear due to reduced "spinning" and consequent abrasion which takes place owing to tyres bouncing on rough roads.

A test such as the following suggests itself to prove the advantage of low unsprung weights:-

1. Compare results on two identical cars having the same total loads per wheel, one car having a lighter body than the other but with weights bolted to its axles near the wheel seats, the tyres being identical.

2. One car with the same load on each back wheel, but one end of the axle having extra load near the wheel seat, the other end having extra unsprung load above the wheel seat.

An analysis showing the unsprung weights on different cars would probably at once explain why some makes of car use up their tyres much more quickly than other cars having approximately the same engine power, back-axle load and body type. 


\section{THE DISCUSSION.}

Dr. W. R. Ormandy, in opening the discussion, said : This is the first paper that has been read before the Institution on this important subject, and I think that the things which the author has not told us are quite as interesting as those which he has told us. The question of the tolerance in rims appeals to me very much. It does seem an iniquitous thing that if the owner of a motor car happens to have a rim the tolerance of which is on the extreme limits, serious damage may be done to the tyre and its life reduced 2,000 or 3,000 out of a possible total of 8,000 or 10,000 miles just on that account. If the Americans can produce rims in which the variation is so much smaller, it seems to me that this Institution, together with the S.M.M.T., ought to take steps to ask the manufacturers of rims to make something which is less likely to cause trouble than the existing ones. The author told us that some tyre makers allow a possible extension in the bead of 1 per cent and others allow 4 per aent. When the tyre happens to have the limit of 1 per cent, and the rim happens to be to the limit in the other direction, the situation becomes impossible. The author has not dealt with cord tyres, but has kept severely to the ordinary canvas built-up. type, and when we realise the large number of operations in its manufacture, and the amount of hand work that there is in it, is not it rather a marvel that the tyres last as long as they do? Possibly the lange amount of hand labour accounts for the fact that, in spite of the price of rubber getting lower and cotton coming idown to one-third, tyres still remain very dear.

The author dealt with the subject of the canvas employed, but he skimmed over this delicate subject with a great deal of skill. He stated that tyres are generally made of Egyptian cotton, and that they are woven with equal tension on the warp and weft. That is desirable, of course, because the threads are to be used at an angle of 45 degrees approximately to the direction in which the wheel runs. He said very, little about the subject of twist on the thread. Now, the strength of a cotton thread is to a very large extent a function of the amount of twist-the number of turns per inch of the thread-and it is easy to get a thread of American cotton which has a shorter fibre at about two-thirds the price of 
(Dr. W. R. Ormandy.)

Egyptian cotton which is very much stronger if there is a bigger twist in the American thread and less twist in the Egyptian. Yet the tyre manufacturer has to use Egyptian cotton; he does not really want to do so, but he must if he wishes to get the best results, and it is rather an important matter. I should like to know why the tyre maker prefers a very low twist on his thread when he can get vastly greater strength, not 1 or 2 per cent, but 200 or 300 per cent more, if he puts more twist into the thread. Perhaps it has a bearing on the point raised further on in the paper, that the canvas is so prepared by the cotton spinner and weaver that when it comes from the soaking machine it is penetrated by the rubber. All I can say is, that if any firm can really get the rubber into the thread, they have done something that I have never been able to do. I have dissolved rubber in all sorts of solvents, $\frac{1}{2}$ per cent, 1 per cent, and 10 per cent solutions, boiled it in vacuum, put it under pressure, and even then, when the rubber is idried and the thread is untwisted, every fibre is perfectly free from rubber. Either the colloidal particles of the rubber are so big that the cotton threads act as a filter, or, when the drying operation takes place, the rubber particles are pulled out. I should like to point out that obviously there are a tremendous lot of difficulties in making a tyre, and there are many more than those which have been brought to our notice. The length of time a piece of rubber is in the mixing machine, and the length of time taken in getting the mineral matter into it affects the period of its vulcanisation, that is to say, the amount of work done on the rubber affects the time that is taken in vulcanising. That the tyre manufacturer can get a bead which is half vulcanised to start with, so that, when it is joined up with various plies of canvas and put into the mould and the final vulcanisation takes place, not only is the bead just cured to the right extent and to. the required degree of elasticity, but the rubber between the various layers of canvas is just cured and not over-cured, as well as the outer thickness at the top, means a marvellous co-ordination of work, and it cannot be done by any theory. Every single step has to be arrived at by the ordinary process of trial and error. I would like to ask the author a question with regard to the time of curing. Various chemicals can be mixed into the rubber so that it will cure quickly or slowly, and if the cure is arranged to be completed in, say, ten minutes, several different periods are involved. The first period is occupied in getting the mould hot: 
then there is the time before the outer surface of the stuff gets hot enough to begin vulcanising, the time required to pass through the thinnest portion, then there is a certain period of time when everything is in equilibrium and the whole thing hot, and then the steam supply is shut off and the mould cools down again, reversing the series of events. The thickest part cools most slowly, and the thinnest part most rapidly. If the total time of vulcanisation is ten minutes, then an error of a minute or two is a serious error. The Japanese, when they made a specification for a rubber cable, realised the fact that errors are introduced by this heating up and cooling down, and they stipulated that the vulcanising time should be six hours, no more and no less. Moreover, they! were not satisfied to specify six hours, but they sent a man down to sit through that period and watch it. The Japanese are the only people I have ever heard of who got exactly what they paid for in a rubber specification. I would like to know what is the length of time that is taken in the cure. In tyre manufacture the moulds are the most expensive part, and there is a great temptation on the part of the maker when he is using a one-piece cure to get the moulds out again as rapidly as possible, but the more rapidly the moulds are turned round the greater the effect of slight errors in the mixing or in the time the tyre is under the cure. The quality of the rubber and the durability is enormously altered by slight under- or over-vulcanising. I must be allowed to pay a very hearty tribute of thanks to the author for his paper, which gives a really able explanation on broad lines of how a tyre is made from beginning to end.

Col. A. E. Davioson: My remarks are made solely from the point of view of the user. On page 395 the author states that Straight Side tyres are comparatively unknown in Europe in spite of their great advantages, and I should like to know why it is that we do not get them in Europe. Is it that the manufacturer of the tyre cannot produce them because he has not got the necessary plant, or is it the car designer who is not providing the proper sort of rims? As users I think we are falling between two stools, because I am quite sure that the Straight Side tyre is the better one. From experience of the two types on a certain make of car, the average mileage with the Beaded Edge tyre was about 2,000, and with a Straight Side tyre about 7,000. We all know the difficulties that are met with in tyres with beads. To start with, they are so tight that they cannot be got on, and 
(Col. A. E. Davidson.)

when they are nice and easy to go on, they come off without warning. In France we had a lot of trouble with tyres caused by the beads coming away from the rims. On page 437 mention is made of the cord tyre. The figures given above for the extra life of the Straight Side tyres may possibly not be due entirely to the use of these as against the Beaded Edge, but partly to the fact that the Straight Side tyre was made on the cord system. Many cord tyres with beaded edge that have been tried have failed after a short mileage at the junction of the bead and the wall, and if that point of weakness had been eliminated, then the cord tyres, would have given very much better service than those with eanvas fabric. In this connection, errors in rim dimensions ;would appear to militate more severely. against the Beaded Edge tyres. On page 438 is mentioned the effect of unsprung weight on tyres and their life. I have no comparative results with pneumatic tyres, but with solid tyres $I$ was able to make some observations, and could not trace that tyres on light, i.e., chain-driven axles, ran any greater mileage than those on much heavier live axles. In fact, the figures rather indicate the opposite, namely, that the live axle gives a better mileage than the chain-driven axle, and this leads me to suggest that unsprung weight is only one factor, and not the most important, in tyre wear. I should like to suggest that the suitability of the spring in conjunction with the unsprung axle weight is really a more deciding factor. Watch some vehicle unsuitably sprung-say, a heavily sprung 5 -ton lorry running empty. Notice what blows are transmitted through the tyre to the road, and how the whole vehicle jumps about on a rough road. The shocks on the tyre cannot be attributed to the unsprung weight of axle, but to the unsuitability of the springs to the load. The same vehicle fully loaded will jump about much less. In short, it is held that if chassis makers could introduce on their vehicles a spring variable according to load, tyre shocks and road shocks would be reduced. It seems to be only reasonable to assume that other conditions, such as clutch, engine, driver, etc. being equal, tyres will last longer on a vehicle which holds the road well-that is to say, of which the springs are suitable for the weight of the axle and the weight on the chassis at the time--than on one which holds the road badly and of which the wheels are always leaving the ground, and consequently frequently spinning and then being pulled up.

Mr. O. D. Nonth: I must express my gratitude to the author 
for his wonderfully clear and thorough exposition of the art of tyre making. It is good to be made to realise the difficulties met with and the compromises necessary in other fields of labour than our own. The author points out the restriations of clearance imposed on the tyre designer who wishes to develop a tyre with thinner walls, larger section and lower air pressure than usual. Can he tell us the extent of the advantages that would acerue if he had a free hand in this matter? In other words, can he indicate the proportions of what he regards an ideal pneumatio tyre made at reasonable cost?

As II am just putting a new wheel on the market, I am naturally. concerned /with the probable trend of tyre design, and the author's powerful arguments in favour of the Straight Side tyre with inextensible bead are of great interest to me. The fact that this type is easy to manufacture will naturally be one of the biggest factors tending to its adoption; I can only express the hope that this fact will also be reflected in the selling price!

Does the author consider that the general proportions of the American S.S. rims and tyres make the fullest possible use of the anti-rolling feature? Could the tyre design be improved if the rims were modified? It would be a thousand pities if, right at the beginning of the manufacture of the Straight Side tyre in this country, the very best possible proportions were not standardised.

Particularly does this apply to the so-called "Giant" tyres, and I should regard it as a calamity if the American 24 in. rim were the only one standardised. Something smaller, say 18 or 20 inches, is badly needed if the advantages of pneumatic tyres of large section are not to be hampered in realisation by their preposterous overall diameter, which excludes them from many fields where they would be of great value.

I have been told, by parties not strictly disinterested, that with the "Giant" tyres there is sometimes a tendency for rolling strains to lift the toe of the bead from the rim and thus cause a tube nip, and a cursory inspection of the tyre sections would seem to support this. The walls of the tyre are very thick and the toe of the bead is very short, offering very little leverage for the air pressure to restrain its movements. Could the author tell us if there is any truth in this?

'The author's design appeals to me as a fairly easy job for the mould-maker, but it hardly looks circular enough to have a low 
(Mr. O. D. North.)

rolling resistance. Too much energy would seem to be dissipated in kneading the corners of the knobs for the tractive effort to be low. Probably the pedal cyclist, who has to supply the energy himself, is the best judge of a tread pattern from this standpoint.

I wonder if the author would care to take us into his confidence on the subject of tread mixtures and vulcanisation? I have noticed enormous variations in the tread life of tyres, and I certainly think some tyre makers have good and bad years, and I should like to know if-given an absolutely free hand and regardless of cost-it would be possible to compound a tread mixture that would give a longer life than those at present in use. If not, could the author say if he thinks a tyre should be designed to stand re-treading at least once?

The one thing that has opened my eyes more than anything else is the author's diagram on page 408 showing the dead-load distortion of a properly inflated tyre. It is much greater than $I$ hard realised, and I marvel that casings can be produced to stand this sort of thing for 10,000 miles. Quite apart from the local massage of the tread surface already referred to, we have in this continual deflection of the casing a very appreciable loss of energy, energy not merely lost but diverted to evil ends.

It is sometimes forgotten that the steel wheel on the steel rail is the most efficient combination, giving a rolling resistance of only $15 \mathrm{lb}$. per ton. Next to this comes the steel tyre on a smooth hard roadway, and then the solid rubber tyre under similar conditions. At high speed on rough surfaces the energy losses due to impact give the advantage to the more yielding tyre. And again on very soft road surfaces at slow speeds the pneumatic should give a lower rolling resistance than a rigid tyre, for the yielding pneumatic tyre distributes the load over a wider area, reducing the intensity to such an extent that the soft road bed is not displaced appreciably. The hard tyre, however, localises the pressure and displaces the material downwards and to each side, using energy which is not in any part given back on the receding side of the wheel, since the average road material is plastic but not resilient. Thus, the hard wheel on a soft road is, as it were, always running uphill, whereas the pneumatic may be pictured as running up a hill in front but also running down a lesser hill behind.

Given reasonably hard roads with a smooth surface, there is little doubt in my mind that at ordinary speeds solid tyres give a lower rolling resistance than pneumatics, unless the latter are 
over-inflated, and I can well believe that by stiffening up a pneumatic with internal filling pieces of rubber and using a smaller air tube, deflection under load, rise of temperature, fuel consumption and comfort would be reduced. The logical trend of that line of reasoning seems to be towards the solid or cushion tyre. The trouble is, however, that many of our roads are in such a condition that comfort of passengers and reduction of shock on axles compels the use of the yielding pneumatic tyre.

Major WHEELER: Without in any way disparaging the author's remarks on the purely technical side of the subject-I refer to the manufacture-I am sure I shall be echoing the views of several if I say I would rather have had him devote the second part of his paper to, say, "tyres, their ills and cures."

I should like to make a reference to the design of the internal section of the tyre. When air is pumped into a tyre we get a fluid in compression, and a compressed fluid always tends to make its containing cover or shell truly circular. Consequently, if the internal section of the tyre is designed oval, or, as we have seen from the diagrams, rather egg-shaped, a greater pressure is necessary to hold the cover to that shape than would be necessary to maintain true circularity. It seems to me, therefore, that the cover at certain parts has to be strengthened more than need be the case if a truly circular interior were designed. If my contention is correct, it is surely possible to make a saving in material with the usual accompanying advantages, and I should like to hear the author's opinion on that particular point.

$\mathrm{Mr}$ : MacBeth, in replying on the discussion, said: As the same questions were in some cases asked at more than one of the meetings, I have dealt with each point as one without special reference to the speaker.

B.E. rims.--Rim tolerances.--In reply to Dr. Ormandy, I would say that rims made by tyre manufacturers who are responsible for tyre performances are liable to be much more accurate than rims made by firms who do not make tyres also. Checking of rims is not organised in this country, thus it is possible for rims to be put on cars without proper supervision; only organised checking control can deal with this matter. Expert examination is required, as rims may pass the gauges and still have defects, as, for instance, sharp lips or square lips. It is also necessary to ensure that a rim which may have been right when made is not subse- 
(Mr. Macbeth.)

quently distorted in fitting to wood felloes or when spoking up into a wire wheel; it is in fact necessary to see that rims are correct when the wheel is finished.

Stretch percentage.-A tyre designed for 1 per oent stretch on a "mean" rim will still have 0.5 per cent stretch when fitted to a "minimum" rim, the variation in circumference of lips of rims being practically 0.5 per cent up and down from "mean" figures.

Mr. North asks if Américan size S.S. rims are satisfactory, and make the fullest use of the anti-rolling feature. I think they do, and that such rim standards are admirably designed to suit the sections fitted to them. I do not consider that S.S. tyres of standard sizes could be improved by altering standard sections of rim.

Unsprung weight.-In reply to Col. Davidson, I would say that satisfactory springing must be considered in conjunction with unsprung weight, and is certainly of at least equal importance. I do not agree that shocks on tyres cannot be attributed to unsprung load, as it is only necessary to observe a car or lorry running on a "pot-hole" road, when the chassis may be comparatively free from vertical vibrations, and yet a heavy axle will "pound " and bounce, whereas a light one will remain generally in contact with the road surface. Even if springs are in good condition, their design has a great bearing on the unsprung weight, as is obvious when comparing cantilever springs which reduce unsprung weight with semi-elliptical springs which increase it.

Col. Davidson instances a badly sprung 5 -ton lorry as imposing great shocks on tyres when empty. While it is true that with modified springing such a vehicle when running light would hold the road better, yet it is also a fact that if the unsprung weight had been reduced it would have very materially helped the unloaded vehiele to maintain the wheels in contact with the road.

Cotton.-Amount of twist.--It is a fact that excessively twisted yarns are not readily insulated; hard twisted yarns are also very liable to cause early failure due to frictioning action between warp and weft. The effect of impregnation and vulcanisation has a very important bearing on the strength of the yarns in the finished tyre, as it is obvious that a yarn which is very little twisted will be stronger when its fibres adhere together due to the presence of vulcanised rubber between them.

Impregnation.-In practice impregnation does satisfactorily insulate thread from thread when properly carried out. 
Vulcanisation.-Time of cures.-This varies for different types of tyres and different methods of moulding and vulcanising. Thus, a light cycle tyre cured on the Doughty Press can be perfectly cured in three minutes, whereas a solid tyre made in a heavy mould may take four hours or more. As I have already pointed out, the methods used in the factory, particularly the curing methods, must be so regulated as to ensure that quality has the first consideration.

S.S. rims.-Col. Davidson asks why S.S. tyres are not obtainable in Europe. They are obtainable from some British manufacturers. There are several reasons why the S.S. tyre was developed earlier in the U.S.A.; they are principally as follows:-

American manufacturers were not so successful in making a sound B.E. type, suffering as they did very seriously from rim cutting due to faulty bead design and construction.

Chauffeurs are scarce in the U.S.A., therefore easy fitting became more imperative.

The S.S. rim has only lately been adopted as a British standard, and war and post-war conditions have made it extremely difficult to equip British rim and tyre factories for the manufacture of wheels and tyres to suit the standard adopted.

The ideal design of tyre.-In reference to the making of a tyre when the designer does not require to conform to standard dimensions, I would define this as one allowing of increased vertical displacement under shock or when encountering road obstacles; such a tyre having larger section, thinner walls and lower air pressure requires a special rim to accommodate it in order still to retain a normal outside diameter.

Giant pneumatics.-There is already a call in the U.S.A. for a giant pneumatic tyre with about 20 in. rim diameter, and such a tyre would better suit omnibus requirements than the large diameters having $24 \mathrm{in}$. wheels. There is no trouble at all with giant tyres due to tube nipping, in fact all such tyres make use of a "flap" (as in Fig. 14) which effectually prevents such nipping on all sizes of S.S. tyres.

Giant tyres are not so liable to puncture as smaller and thinner tyres, in fact only the strongest and stiffest kind of spike would remain unbent when attempting to pierce a giant tyre with its reinforced tread.

In case of deflation giant tyres have not proved a source of 
(Mr. Macbeth.)

danger from overturning; the result being the same as when a solid tyre comes off the wheel, when in effect the vehicle drops some $4 \mathrm{in}$. to $6 \mathrm{in}$. at one side and rests on the brake-drum.

Tread design.-Non-skid patterns which have a good fore-andaft grip cannot well be as efficient against rolling resistance as plain or ribbed patterns and still retain their great "safety" features. The particular pattern illustrated has, under normal running conditions, a comparatively narrow track, and is designed to give little rolling resistance, but great gripping powers even under tho worst conditions combined with maximum life as a nonskid and as a casing protector.

Tread mixings.-As already pointed out, these can be varied at the discretion of the manufacturer, but it is well understood by tyre manufacturers that a tread having a high load as compared with the ruad contact surface must be well able to resist cutting and abrasions. Tyre makers generally use the best mixings they are able to make, and a steady improvement has been made in this respect. In fact often the tread is more durable than the casing.

Tyres.-Their ills and cures.-Major Wheeler raises a point of very great importance, and I would say that a volume of useful matter could with advantage be written on this subject. If the average user would carefully study the literature already published by the leading tyre makers on this subject and would then spend a little of his time examining into the condition of his tyres so that they get reasonable attention as given to other parts of the car, the increased service from the tyre would be very appreciable.

I suggest as a simple system the following:-

1. Use each of five tyres in turn as the spare.

2. Change the position of one tyre each week.

3. The tyre taken out of service to be taken off the rim, examined, repaired if necessary, thoroughly cleaned inside and outside, all rusty scale removed, and the inside thoroughly dried.

4. The rim examined, dents taken out, sharp edges filed, rust removed and the rim repainted.

5. The tube examined and repaired, the valve examined, and the tube refitted to the spare wheel.

6. It is obvious that in following out such a routine system it will be an advantage to have in the garage a sixth tyre and tube so that in making the routine changes the spare 
wheel can be refitted with a tyre already attended to, and thus the spare wheel will not be held up except when requiring attention to the wheel itself.

I would suggest that the user should consider his car tyres as he does his shoes. Thus clean and dry them as required and repair them soon enough so that the "uppers" remain sound.

Shape of section.--The circular section of tyre is very desirable, and tyres generally are designed as nearly as possible to, give a circular section when inflated. Square woven canvas makes some distortion inevitable by reason of the fact that the outer portion of the casing is stretched circumferentially and the inner portion radially inwards. Also, distortion of the bead portions due to stretch on the rim has a bearing on the resultant sectional shape.

Tyres on mud surfaces. - The value of pneumatic tyres (due to the small increase of area in contact with the road with increasing load as compared with solid tyres, as pointed out by Mr. E. B. Wood) is more marked still when it comes to the use of giant non-skid pneumatics which enable heavy loads to be carried and hauled over snow and soft ground where solid-tyred vehicles cannot be used.

Effect of exposure to heat and sunlight.-Tread and side rubber mixings when properly compounded can and do withstand such exposure well without hardening or cracking, and the ability to withstand such conditions is taken fully into account by reputable makers. Another point which must depend on the user's vigilance to some extent is the increase in internal pressures in tropical countries. It is obvious that, under hard driving conditions, tyres used in hot countries are subject to periodic over-inflation, and unless this point is watched mileage results will be very appreciably aflected.

The use of security bolts is not advisable with a properly designed tyre-in fact, their use is responsible for much nipping of tubes-and to-day the leading tyre makers do not advocate their use. The frictional grip of the beads of the inflated tyre against the rim is so much in excess of the grip of the tread on the road that creeping cannot take place unless the tyre is run absolutely deflated.

In conclusion, I think that if this paper makes the tyre people and the chassis people come closer together, it will do a lot of good to the tyre manufacturers. The tyre manufacturers are in very MACBETH. 
(Mr. Macbeth.)

close touch with one another, but they seldom talk about technical matters to each other. I think it is thought that the tyre man is a rule-of-thumb expert, but that is not the case at all. Tyre making is a very strenuous operation, and personally, as an engineer for about the last twenty-five years, I think there is more applied engineering in tyres than in anything else I have ever seen. 


\section{COMMUNICATION.}

Mr. E. B. Woon wrote: When in Mesopotamia in 1916 with a view to explaining to the military authorities the reason why a pneumatic tyred lorry was more suitable than a solid tyred lorry for use on the stoneless plains of alluvial mud of that country, I made some investigations as to tyre impressions. I found that the general characteristics of the pneumatic tyre are that, with increasing load, the length/breadth ratio of the impression remains approximately constant, and the pressure per sq. in. of area rises very, little, as is to be expected, the pressure on the ground at the centre of the impression probably differing little from that near the edges. In the case of the solid tyre, the greater part of the extension is transverse, i.e., parallel to the axle. With a 50 per cent increase of load, the length increases only 3 per cent and the breadth 23 per cent. The length/breadth ratio decreases and the mean pressure per sq. in. increases with the heavier loads. In this case, however, the pressure at the centre of the impression is probably some 50 per cent higher than the mean pressure, with a correspondingly greater destructive effect on roads made of dry mud.

I should like to ask the author if he could give us any information on (1) the action of high atmospherie temperatures, and (2) the action of sunlight, on tyres. Though I have no data, from a photographic point of view I did not find the actinic value of Mesopotamia sunlight quite as high as I expected. 
DESIGN AND MANUFACTURE OF PNEUMATIC MOTOR TYRES. 453

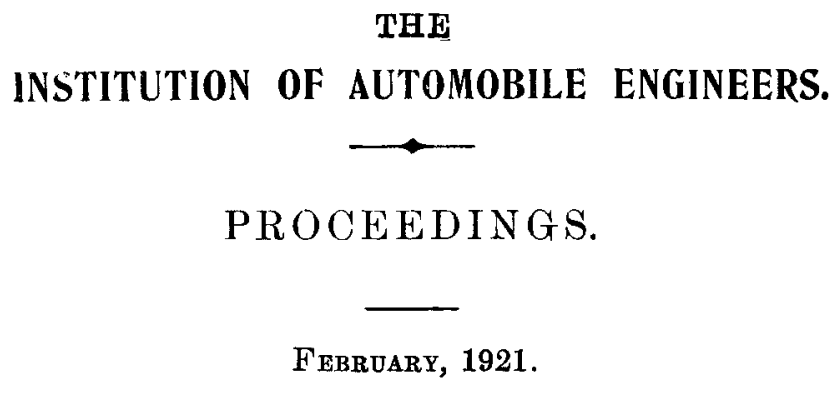

The Eighth Ordinary General Meeting of the Session was held at the Chamber of Commerce, New Street, Birmingham, on Thursday, February 24th, 1921, at 7 p.m., Sir Henry Fowler in the chair.

The Minutes of the previous Meeting were read, confirmed and signed.

The following paper* was then read and discussed:-

"The Design and Manufacture of Pneumatic Tyres," by Colin Macbeth.

There were present 120 Members and visitors.

* See p. 379, ante. 


\section{THE DISCUSSION.}

Mr. F. A. S. Acres, in opening the discussion, said: I have a strong impression that if a tyre is somewhat on the easy side, the rib tread will be more destructive to the casing than a tread of the ordinary round type, such as the grooved tread, owing to the flexing of the sides. One form of tyre made by a well-known French firm was moulded flat so that the tread was compressed when the tyre was blown out. This was supposed to give greater resistance to cutting, and I should like to know what the author has to say about that. The author quoted a rim of the type of the Warland as being easy of detachment. I agree with him that it saves a great deal of muscular effort, but I once timed several men fitting a new tyre on to a plain rim and on to one of these detachable rims, and the solid rim was actually quicker, because the loose rim is so difficult to hold steady. With regard to the effect of speed on tyres, I have seen a tyre mounted on the armature of an electric motor running at a peripheral speed equal to 130 miles an hour, and the tread stripped completely from the cover, and at Brooklands I have seen a cover with the tread absolutely disintegrated. It did not come off in strips but in little more than dust, and it was a first-class tyre. I shall be interested to hear what the author has to say on that. He also touched on the effect of under-inflation. Many drivers do under-inflate their tyres for the sake of comfort, but I have found that under-inflation causes the plies of the fabric to separate at each side of the tread, where the tread proper narrows down into the sides.

Mr. R. Selz: When I used to drive my own cars, I always took good care to select a brand of tyre which showed a cut, because with a compressed tread it is impossible to know what is going on inside the cover. If a tread which is in compression as some of the Continental tyres are gets cut, the compression sets up a suction which will take in the wet and the canvas will start rotting: before the damage is noticed. A tyre which will show a gash can be cemented up or re-vulcanised, and will then give a very good mileage. I have done some competition work and racing at Brooklands, but $I$ have never had a tyre fail. The mounting of tyres is a matter of skill more than anything else. I have 
(Mr. R. Selz.)

heard people talk about detachable rims, but personally I prefer to fit a tyre in the ordinary way, with beaded edge and keep the water out. There is more damage done to tyres by water than by rough usage, and I think the manufacturers of all tyres are to be congratulated on the fact that they are able to turn out tyres which do not require five or six holding-down bolts. With regard to the shape of the tread, there are certainly points about the rubber studded tyre which make it, perhaps, the best at the present time on the score of resiliency.

Major B. W. SHILson: I think that the progress that has been made in tyre design is at least as good as that which has been made in car design. The demands which a car makes on a tyre are very great indeed, as can be gathered when travelling behind a car and watching the way in which the back-axle is bumping about on the road. Therefore, I think it is all the more gratifying to get the tyre manufacturer with us and hear his views and his difficultiest. I would also like to thank the author for the very interesting diagrammatic way in which he shows what we might call his operation sheet, and I think that if applied to other branches of the industry it would enable a saving to be effected, at all events in handling.

Mr. P. J. Joyce: I should like to hear whether the Doughty process, which was used by the Dunlop Company some years ago, is used now.

Mr F. G. WoolLARD: I should like to ask whether any method has been devised for preventing punctures in the very large tyres that are now being used, more in the United States than here, on heavy vehicles, because it seems to me that a puncture on one of these giant tyres, which would probably let the vehicle down by anything from five to seven inches, might be rather disastrous, especially if the camber of the road should happen to be the wrong way and the vehicle were going at anything like speed. I should also be glad if the author would add a few words on the subject of unsprung weight.

Another point I should like to ask him about is whether we are tending to soft large tyres-or are we going to keep to the small relatively hard tyres? I mention this because I saw it suggested in a paper before the Society of Automotive Engineers, apparently in all seriousness, that we should do away with unsprung weight as we know it at present and spring the whole of the car on large 
soft tyres. I should like to know what the author's opinion on a process of that sort would be.

Mr D. V. RYan: My experience of re-treaded tyres has been that they invariably meet an untimely end through a blow-out, long before ordinary, wear and tear has made any impression on the tread. These blow-outs appear to be caused by the wall parting from the bead during the excessive internal pressure which obtains when the tyre strikes a large obstruction on the road. The point I would like cleared up is whether this fault is caused by the procedure adopted in re-treading a tyre, or whether the author is of the opinion that the strength of the walls did not warrant the operation. I might add that these repairs were carried out by a very reputable firm. I have noticed this occurrence on several of the leading makes of American tyres.

Mr. J. Dufry: I should like to ask the author his opinion of the Palmer process of building the casing. Is it the fact that they build the casing with a single strand of cord to provide a very flexible casing that will stand tyres being blown up comparatively soft? I believe that the Palmer Company claim that as one of the advantages of their tyres.

The President: I do feel, as the author has pointed out, that the closest co-operation is required between the tyre maker and the chassis maker, a good deal closer co-operation than has taken place in times past. We are, perhaps, too apt to look upon the tyre as the last thing we put on the car, and the last thing that need be thought about with regard to the car. I believe that is what the author is anxious to drive home to us, and I am certain that it could not have been done in a more effectual manner.

Mr. MacBetr, in replying on the discussion, said:-

Eliminating unsprung weight.-Mr. Woollard asks what the effect of doing away with springs would be. I think there is no doubt that such a practice would be a step backwards, as it would mean that the whole of the vehicle would represent unsprung weight. Given perfect roads there is no need for springs with good tyres, but we shall never be able to ensure all roads and tracks being such as will enable springs (or their equivalent) to be eliminated, as even a tyre of twice the ordinary sectional depth would not be able to allow for half the vertical displacement provided by ordinary springs.

Also, springs allow of very considerable canting of one axle in 
(Mr. Macbeth.)

relation to the other without serious body-racking or undue momentary loading on tyres. A well sprung lorry allows of suffcient "roll" to the body and ensures that the wheels can maintain contact with very irregular road surfaces, and allows for the swaying action taking place due to centrifugal forces when cornering.

Large soft tyres.-There is an undoubted tendency towards the use of a large soft tyre.

Reduction of unsprung weight.-I think there are many directions in which this end should be sought, thus:-

(a) Try and remove all brakes from the back-axle, confining them to sprung portions, as at the gear-box. The great saving in unsprung weight would allow of greatly increased strength of transmission details so that no failure should occur such as to make braking ineffective.

(b) Removing brake gear from the back-axle will facilitate the better connection of the springs to the back-axle in such a way that the point of load application on the axle more nearly coincides with the wheel position, thus reducing the bending moments on the axle and allowing of a lighter axle with safety.

(c) The successful application of the cantilever type of springs to lorries would greatly improve springing and reduce unsprung weight.

(d) The combination of rear wheels having brake-drums and internal annular gears arranged in one piece with the rims should all allow of reduced back-axle weight.

One-piece B.E. rims versus split or loose flange.-I agree with Mr. Acres that, provided that beaded edge tyres have a reasonable stretch when fitted to the rim, the one-piece rim is preferable to the loose flange or collapsible type.

Re-treading policy. - The perfect tyre is one which will gradually wear out without failure of any one portion prematurely. Thus, if under normal conditions such a result was obtained it is questionable if it is advisable to make a casing to outlast its tread -rather concentrate on increased tread life. If, however, a wellbalanced tyre has to stand abnormal punishment on stony roads and hard wear in hilly countries, it may be found that the tread surface is worn out while the casing is still good for many thousands of miles; such a tyre should be capable of being easily re-treaded if it has been properly cared for.

Causes of defective re-treading.-Mr. Ryan asks if re-treading 
failures are not sometimes attributable to lack of original strength in the tyre in question; I would say that quite a number of makes of tyres are not suitable for re-treading generally because a poor grade of cotton has been employed or unsuitable mixings or cures have been made use of.

Treads.-Treads run at high speeds on the track have a very high factor of safety against failure due to the centrifugal forces set up tending to separate the tread from the case. The instance mentioned was either due to initial defects or to the particular tyre used being unable to withstand the great heat set up in the tread at abnormally high prolonged speeds.

The tyre which broke up (as regards its tread) into little pieces was probably very considerably overcured in manufacture.

Compressed Treads. - The particular type refexred to by Mr. Acres and Mr. Selz as having a compressed tread was, I believe, designed in order that a cheap tread mixing could be used without a serious tendency to open gashes when cut.

I understand that the tyre referred to is no longer made with this feature, and am of the opinion that the compressed tread feature was obtained at the expense of undue strain and distortion in the casing itself.

Effect of tread design on casing life--Regarding Mr. Acres' remarks as to the destructive effect on the casing of a ribbed as compared with a grooved tread, I am of the opinion that the ribbed pattern, due to its greater flexibility at the tread. portion, is distinctly less destructive to the sides of the casing than a crossgrooved pattern.

A good non-skid pattern flexes more on stony roads than a plain pattern, which asks for more of the flexing to be done by the sides of the tyre.

The Doughty curing system, as mentioned by Mr. Joyce, was first used by the Dunlop Company for cycle tyres and motor-cycle tyres and is so used to-day. This process refers to the moulding and curing of tyres by machine and saves a very considerable amount of time and labour, where it can be applied, over more usual methods. The type of press shown on Fig. 7 for making B.E. small tyres works on the same principle, though it does not make the tyres to final shape.

Cord tyres, as referred to by Mr. Duffy, are, I believe, made by building up on a machine, laying strand after strand until twa complete plies form the casing. The particular make of tyre re- 
(Mr. Macbeth.)

ferred to is very efficient as regards power losses, as is exemplified by its use for track-racing purposes. I do not think that the makers claim any special suitability for their tyres for running with lower inflation pressures than usual.

The modern cord tyre is a development of the fabric cycle tyre -being assembled from multiple plies of warp threads (which have only an occasional light weft thread inserted to facilitate handling), which, as compared with woven canvas, can be made up into a tyre which is more efficient and resilient and less subject to disintegration in use. I have not dealt at any length with the cord tyre or the S.S. method of bead construction as I thought it advisable to deal with the type of tyre and attachment which is well known to all motorists in the British Isles.

In conclusion, I would like again to emphasise the desirability of combining the "technical forces" of the chassis maker and tyre manufacturer as regards all matters appertaining to the unsprung parts of automobiles.

Research work taking wheels and tyres fully into account would, I believe, lead to reduction in casts and improved road results--for instance, the following points would benefit and be standardised to a considerable degree:-

1. Rim sizes reduced.

2. Rim attachments standardised, enabling valve connections and tyre attachment tools to be simplified.

3. Hubs standardised.

4. Brake-drums and drum attachments standardised.

5. Mud-guard clearances standardised, enabling tyres and springs to be more definitely standardised.

6. Springs and springing improved.

7. Spring attachments improved.

8. Axles lightened and strengthened.

9. Axle attachments standardised.

10. Transmissions cheapened, due to being able to cater for attachment to uniform attachment points on the axles.

11. Jacking arrangements standardised, thus making standard jacks possible and cheapening them.

12. Incorporation of jacks with the chassis, due to ability to supply a standard accessory.

13. Improved tyres and wheels more easily commercialised, due to ability to cater for more defined requirements. 


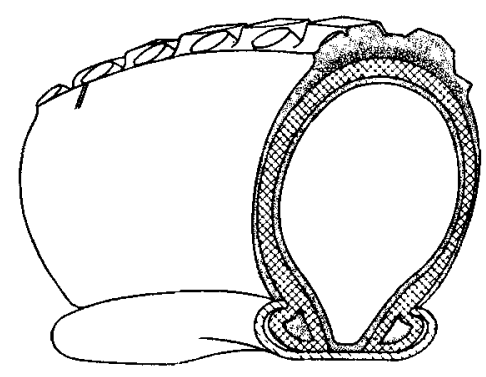

Fir, 12.

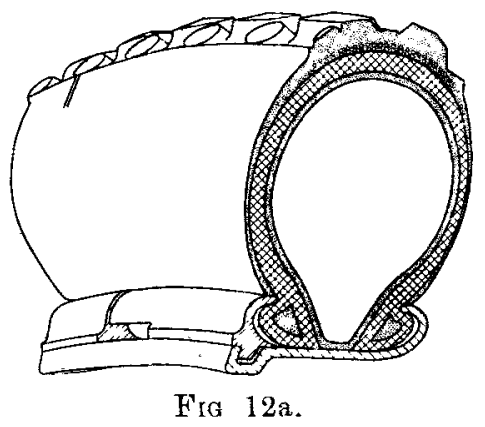




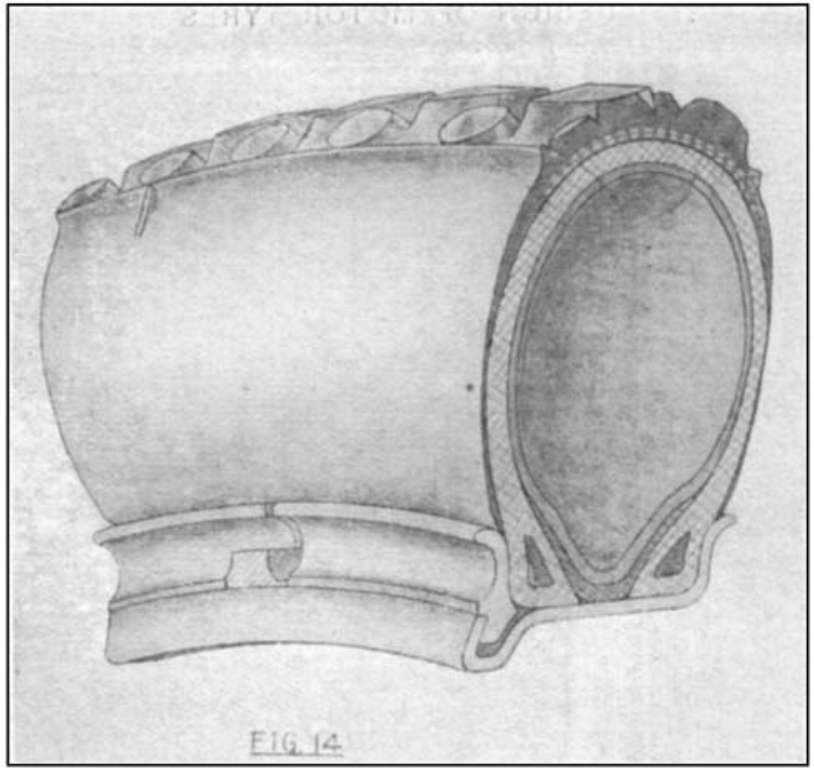

Fig. 14.

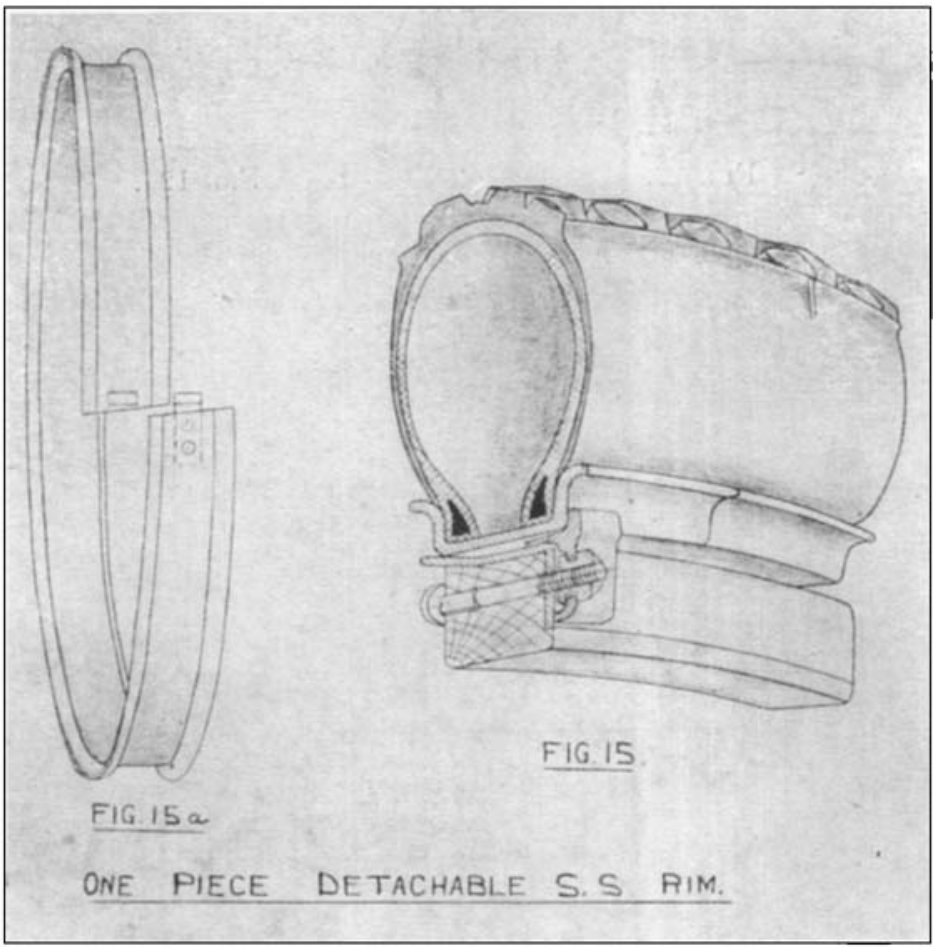

Downloaded from pau.sagepub.com at Monash University on June 5, 2016

Figs. 15 and 15a. 


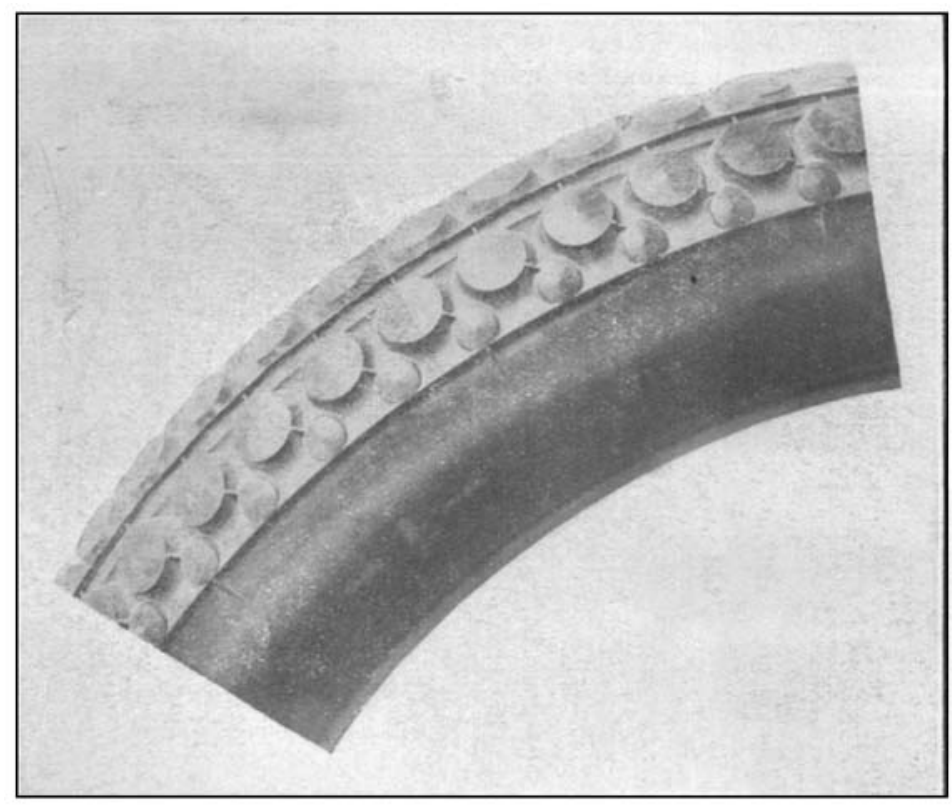

Fig. 19.



Fra. 21. 






Figs. 25 to $25 \mathrm{D}$. 


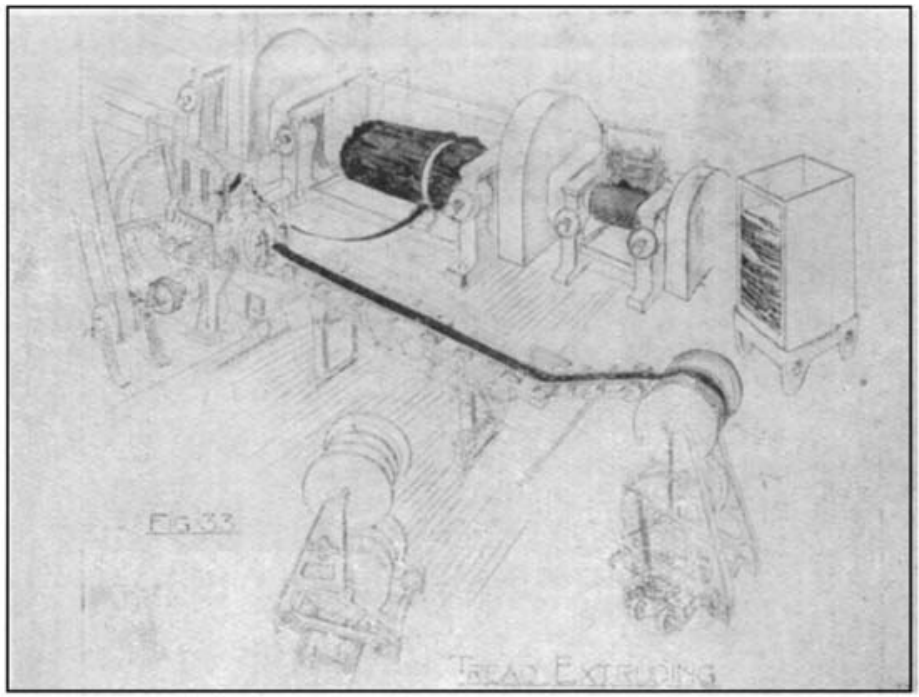

FIg. 33.

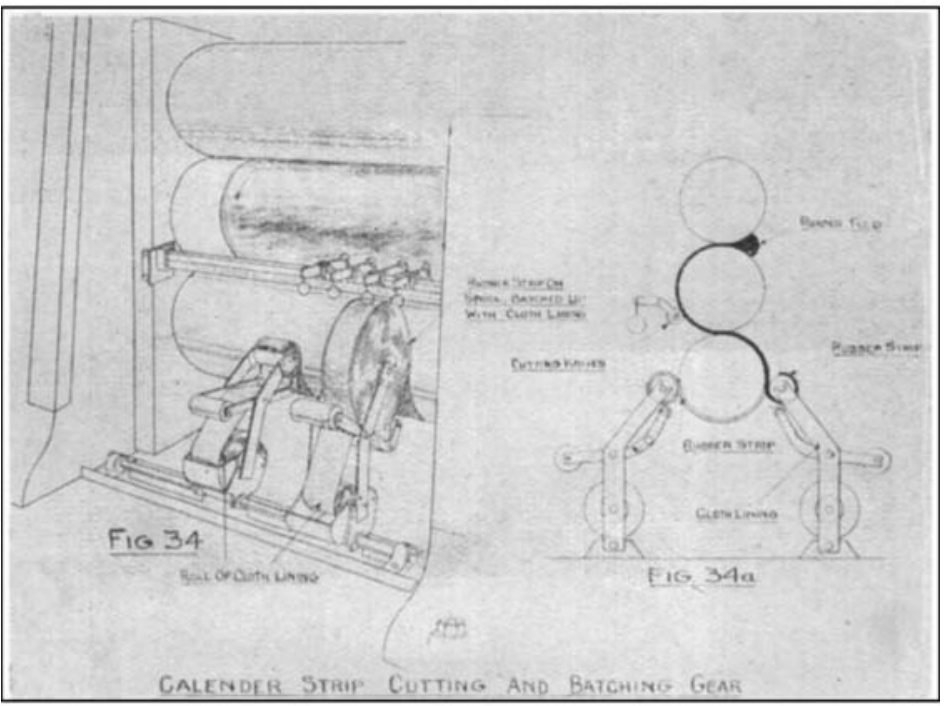

Fig. 34.

E 2 




FIg. 35.

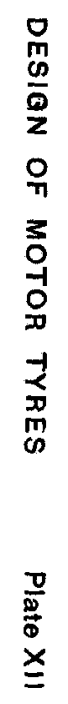




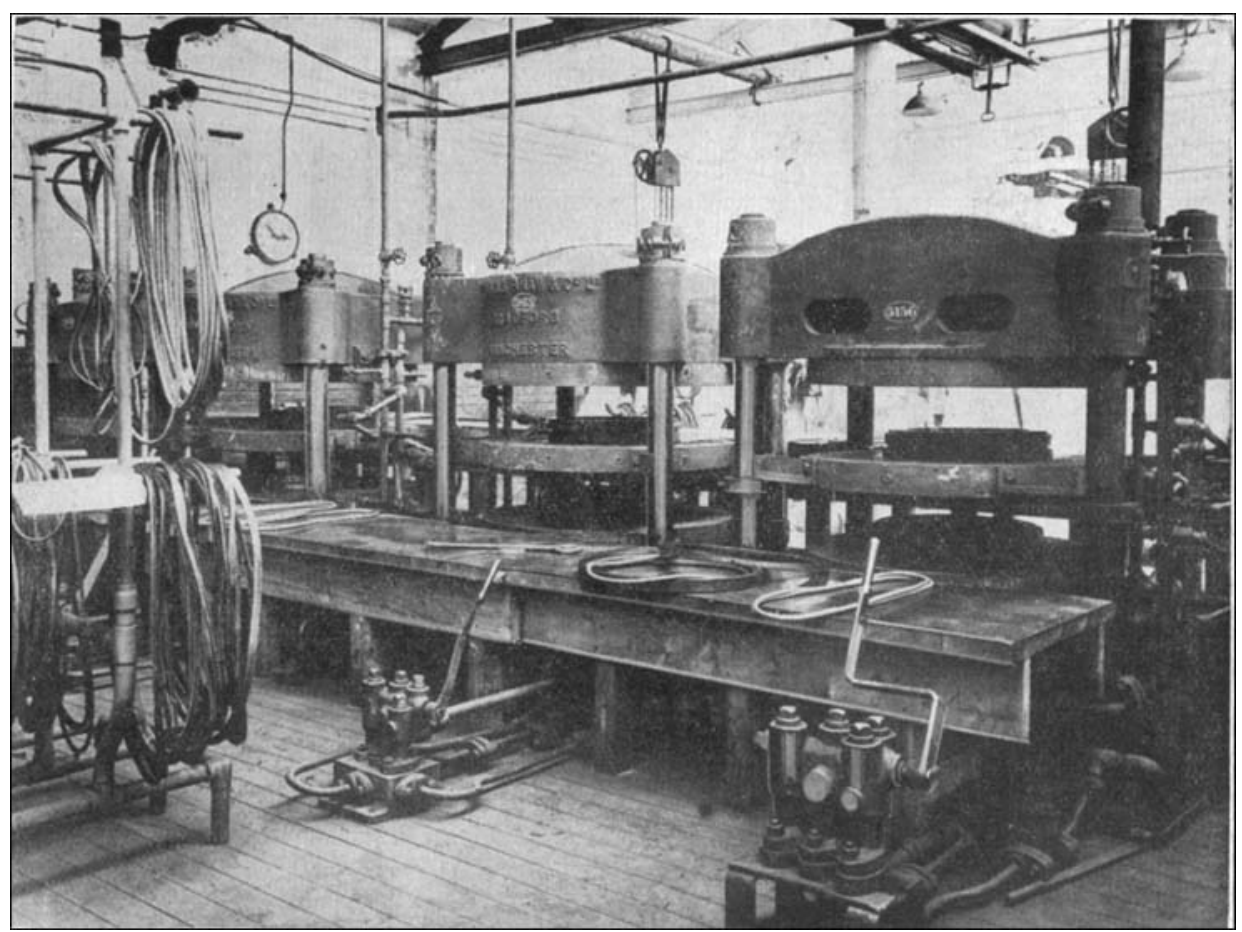

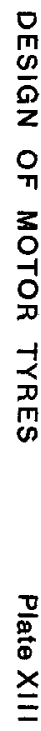

Frg. 37. 

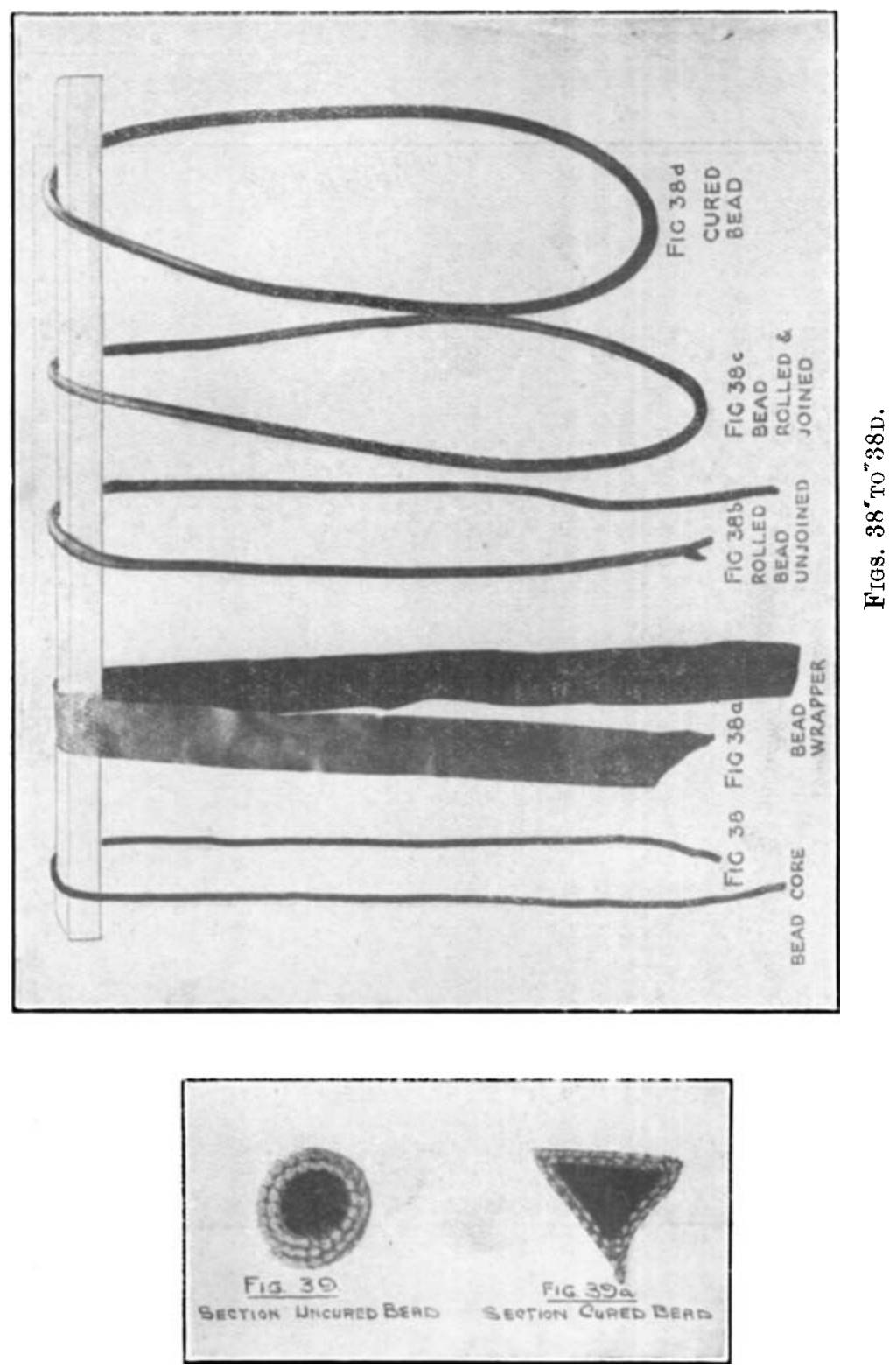

Figs. 39 aNd 39 A. 


\section{DESIGN OF MOTOR TYRES}

Plate XV

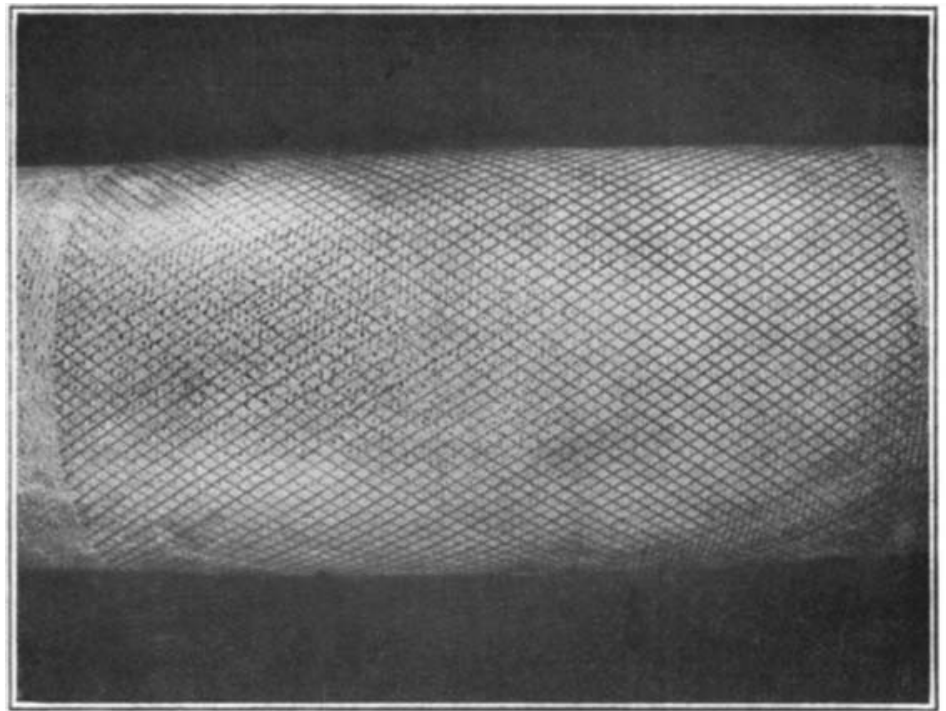

Fig. 43.

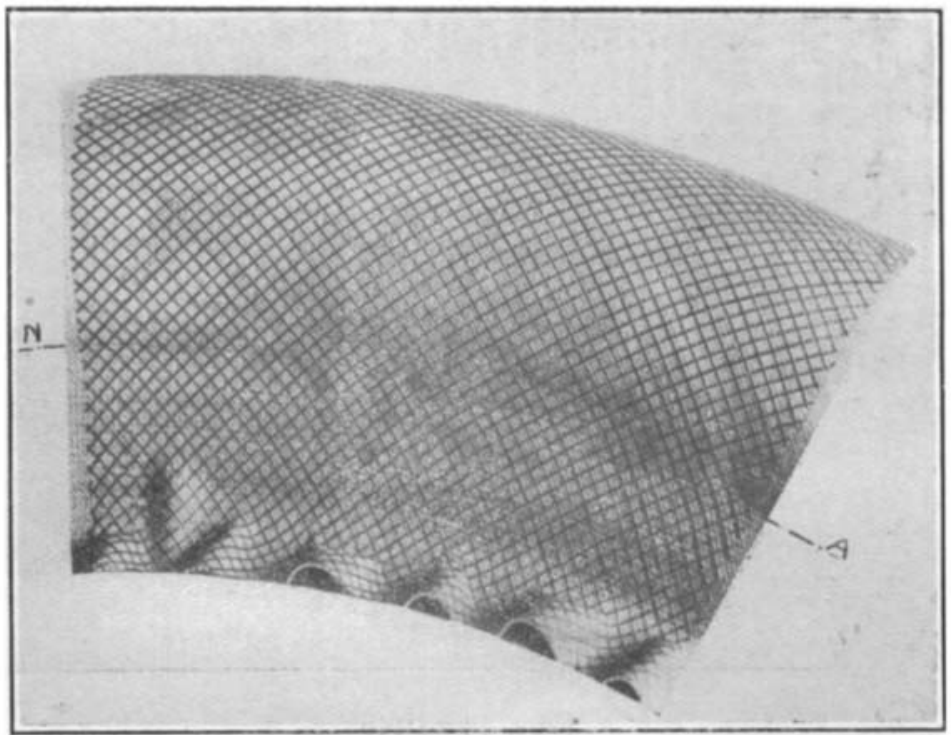

Fig. 43 A. 


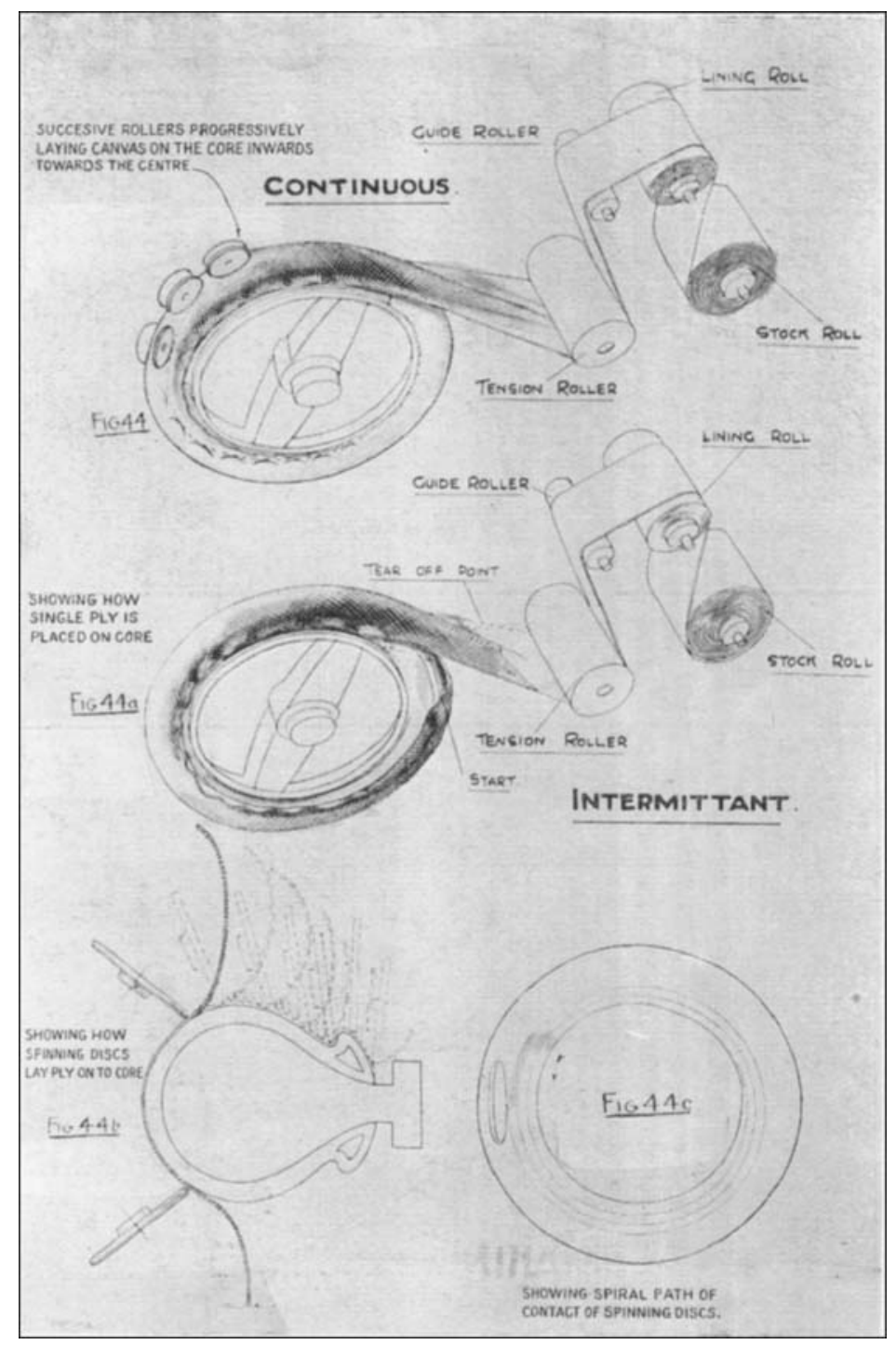

Frgs. 44 to $44 \mathrm{c}$. 


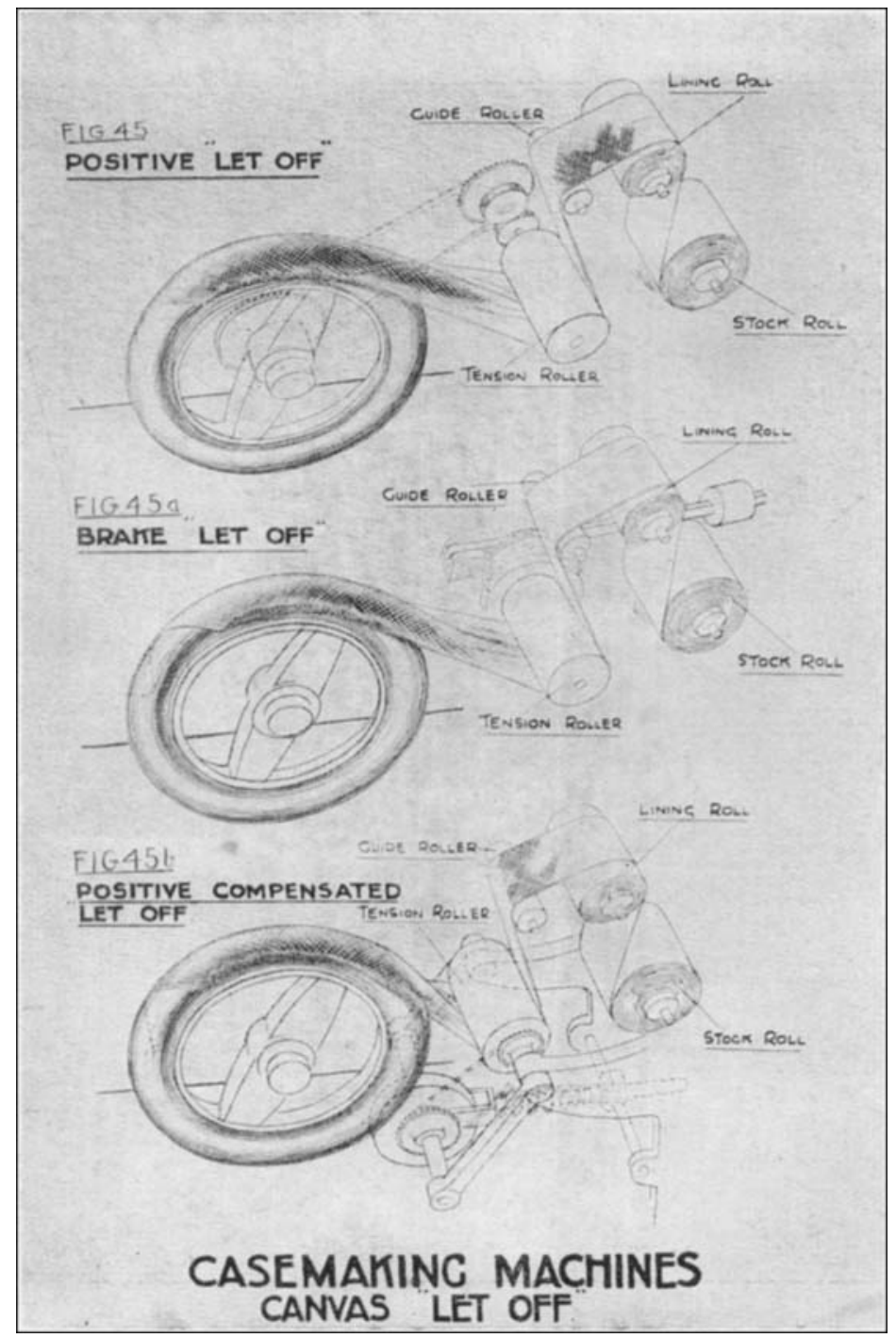

Figs. 45 то $45 \mathrm{~B}$. 


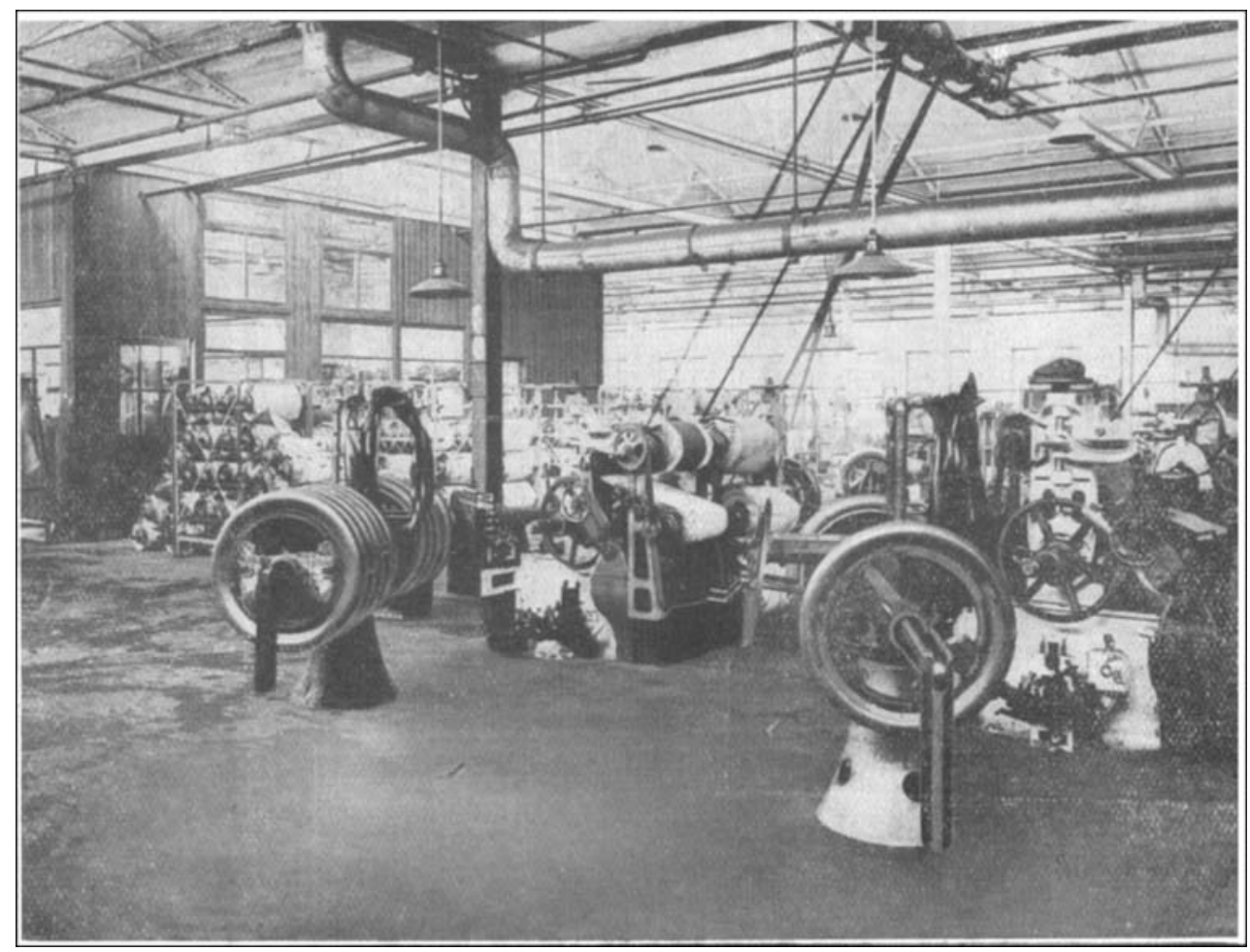

Fra. 46.

$\frac{0}{0}$
$\frac{0}{0}$
$\stackrel{\times}{\leq}$
$\equiv$ 


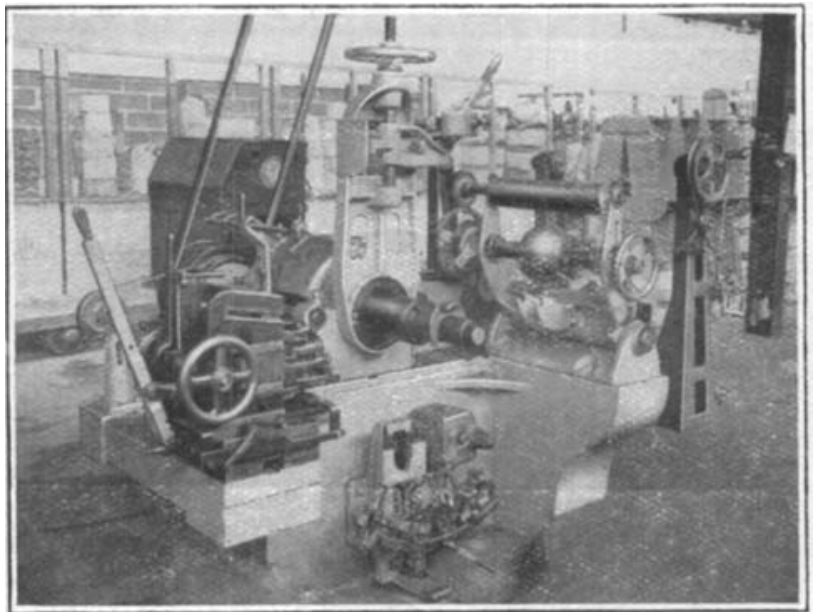

Fio. 46A.

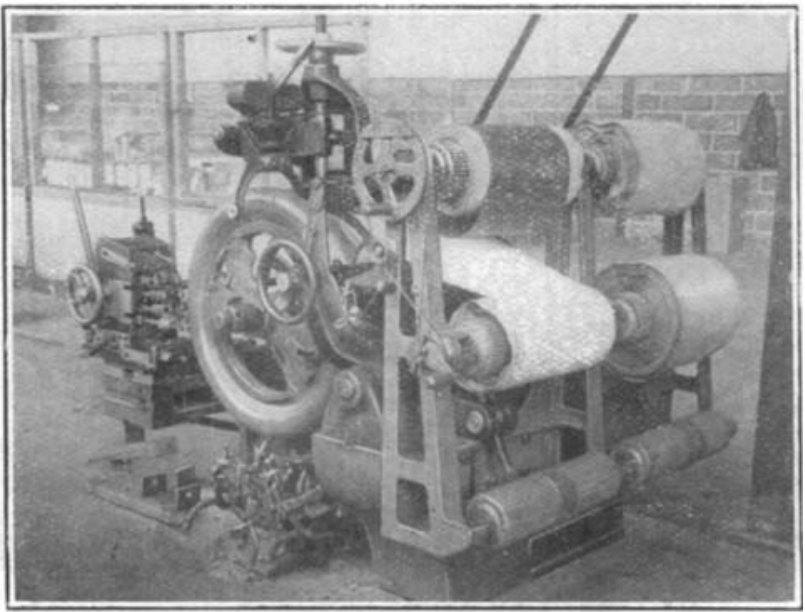

Fia. 46в. 


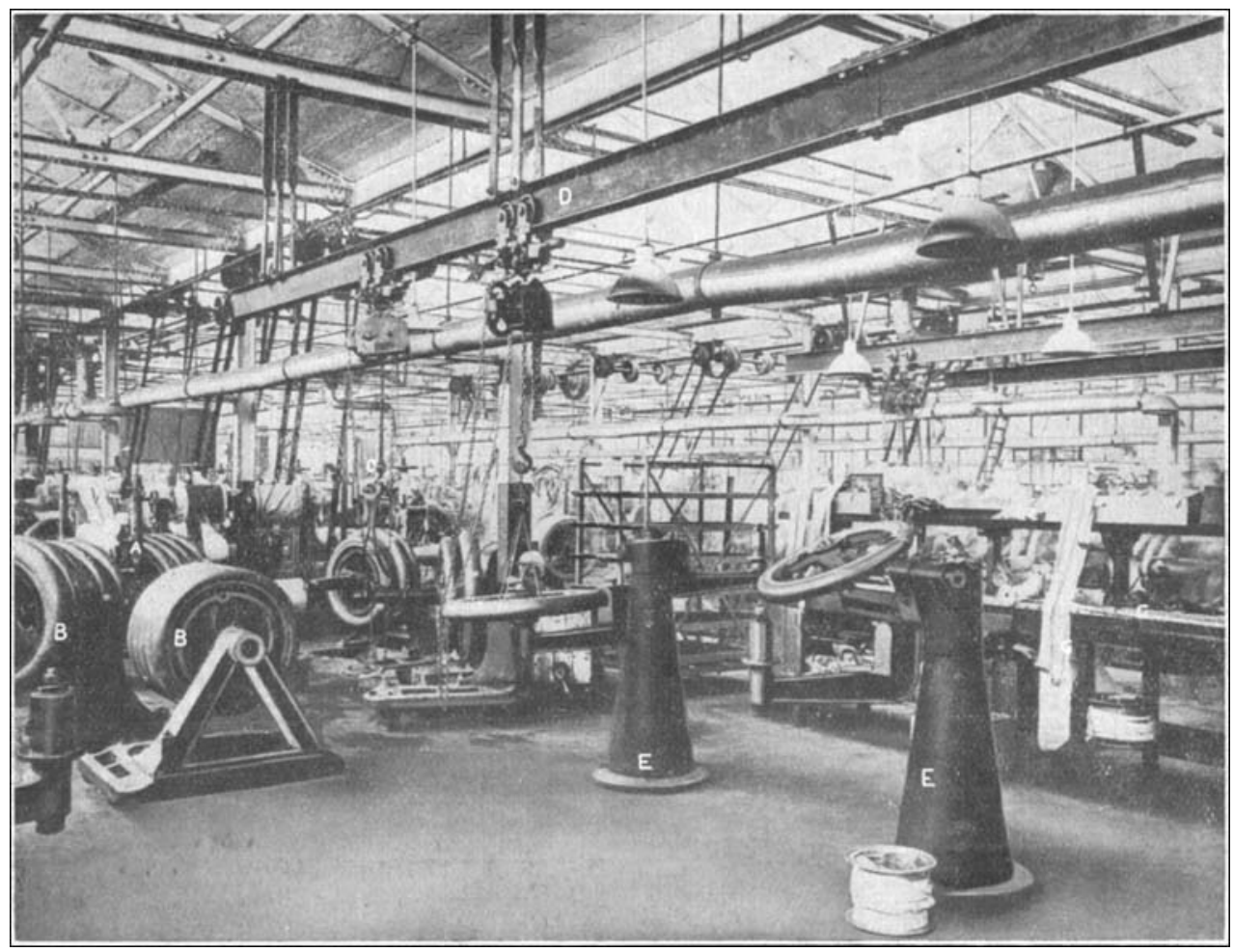

Fig. 47. 


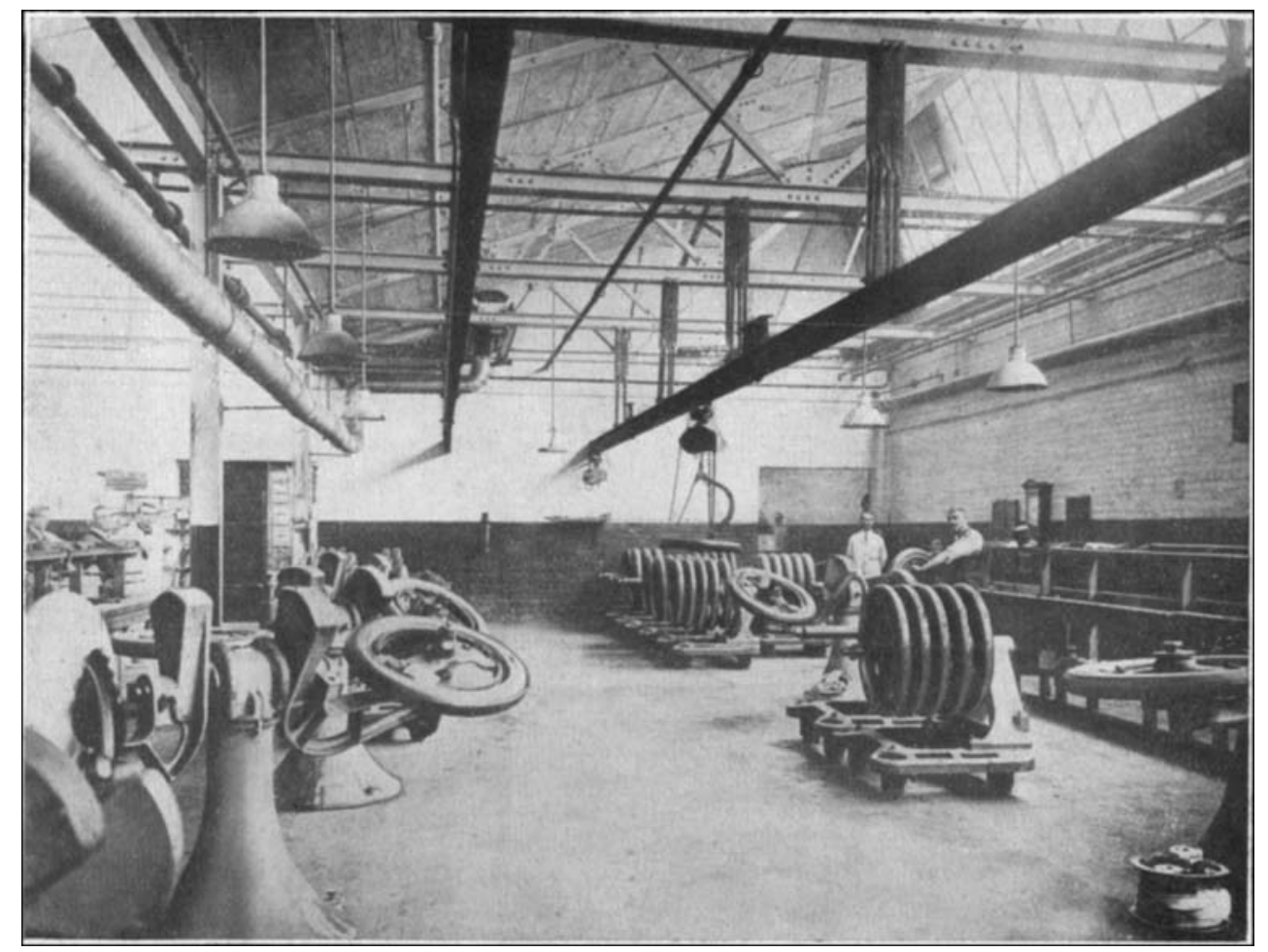

Fig. 48. 


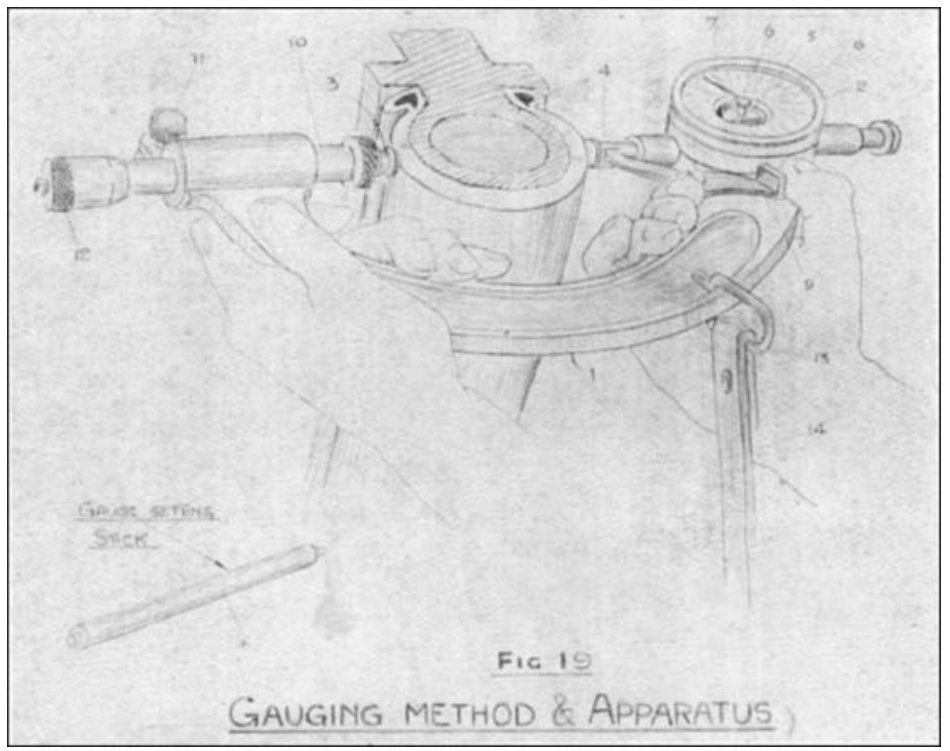

FIG. 49. 


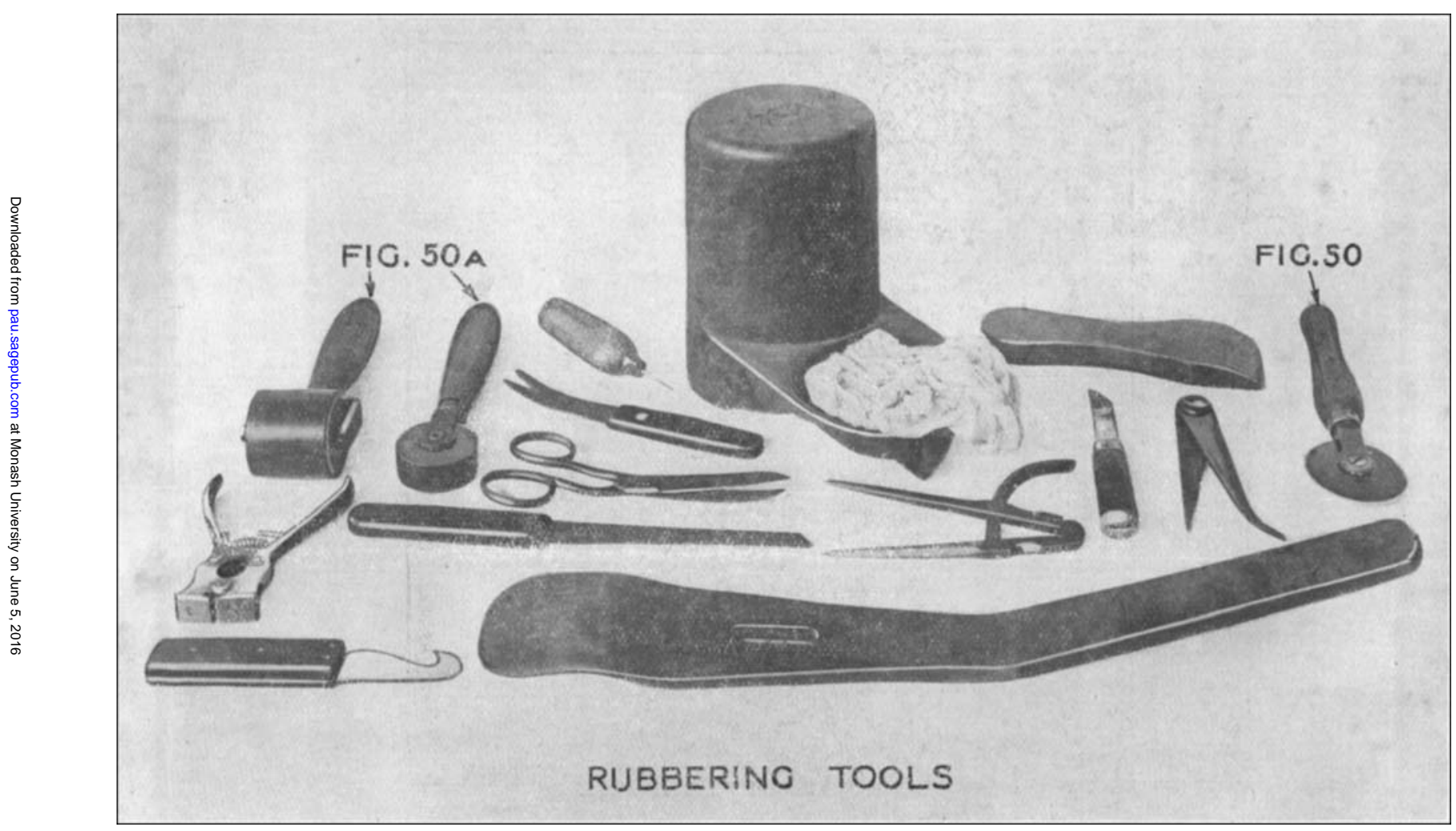




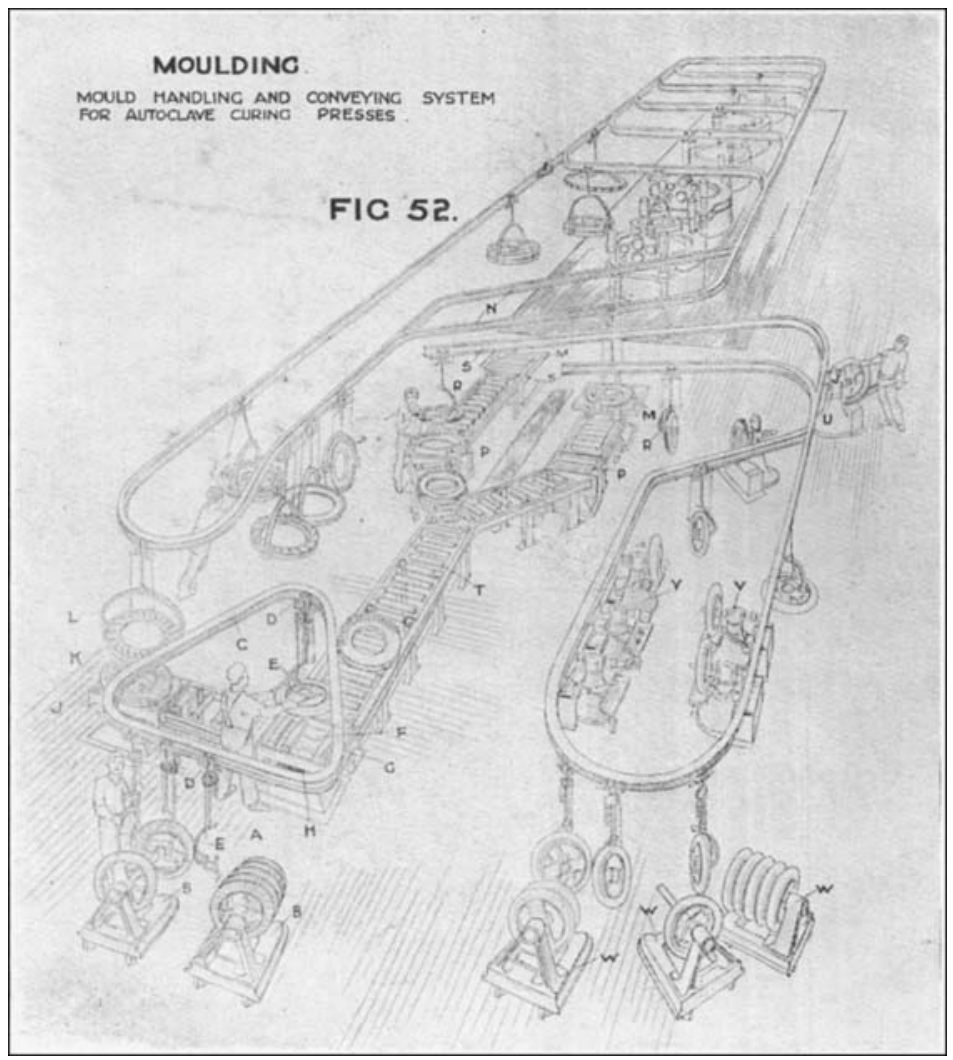

Fig. 52. 